\title{
Computed Tomography elucidates ontogeny within the basal therapsid clade Biarmosuchia
}

\author{
Aliénor Duhamel ${ }^{\text {Corresp., 1, 2, } 3}$, Julien Benoit ${ }^{2}$, Michael Day ${ }^{2,4}$, Bruce Rubidge ${ }^{2}$, Vincent Fernandez ${ }^{4,5}$ \\ 1 ENS de Lyon, CNRS, UMR 5276, LGL-TPE, Université Claude Bernard (Lyon I), Lyon, France \\ 2 Evolutionary Studies Institute, University of the Witwatersrand, Johannesburg, South Africa \\ 3 School of Geosciences, University of the Witwatersrand, Johannesburg, South Africa \\ 4 Department of Earth Sciences, Natural History Museum, London, United Kingdom \\ 5 European Synchrotron Radiation Facility, Grenoble, France \\ Corresponding Author: Aliénor Duhamel \\ Email address: alienor.duhamel@ens-lyon.org
}

Biarmosuchia is a clade of basal therapsids that includes forms possessing plesiomorphic 'pelycosaurian' cranial characters as well as the highly derived Burnetiamorpha which are characterised by cranial pachyostosis and a variety of cranial bosses. Potential ontogenetic variation in these structures has been suggested based on growth series of other therapsids with pachyostosed crania, which complicates burnetiamorph taxonomic distinction and thus it is essential to better understand cranial ontogeny of the Burnetiamorpha. Here, three new juvenile biarmosuchian skulls from the late Permian of South Africa are described using X-ray micro computed tomography (CT tomography). We found that juvenile biarmosuchians are distinguished from adults by their relatively large orbits, open cranial sutures, and incomplete ossification of the braincase and bony labyrinth. Also, they manifest multiple centres of ossification within the parietal and preparietal bones. CT examination reveals that the holotype of Lemurosaurus pricei (BP/1/816), previously alleged to be a juvenile, shows no evidence of juvenility and is thus probably an adult. This suggests that the larger skull NMQR 1702, previously considered to be an adult $L$. pricei, may represent a new taxon. This study provides, for the first time, a list of characters by which to recognise juvenile biarmosuchians. 


\section{Computed Tomography elucidates ontogeny within the basal}

\section{2 therapsid clade Biarmosuchia.}

3 Aliénor Duhamel ${ }^{1,2,3}$, Julien Benoit ${ }^{2}$, Michael Oliver Day ${ }^{2,4}$, Bruce Sidney Rubidge ${ }^{2}$, Vincent

$4 \quad$ Fernandez ${ }^{5,6}$

$5 \quad{ }^{1}$ Ecole Normale Supérieure de Lyon, Université Claude Bernard Lyon 1, CNRS, UMR 5276

6 LGL-TPE, F-69007 46 Allée d'Italie, Lyon, France.

$7{ }^{2}$ Evolutionary Studies Institute, University of the Witwatersrand, PO Wits, 2050, Johannesburg,

8 South Africa.

$9{ }^{3}$ School of Geosciences, University of the Witwatersrand, PO Wits, 2050, Johannesburg, South

10 Africa.

$11{ }^{4}$ Department of Earth Sciences, Natural History Museum, Cromwell Road, SW7 5BD London,

12 United Kingdom.

$13{ }^{5}$ Imaging and Analysis Centre, Natural History Museum, Cromwell Road, SW7

14 5BD London, United Kingdom.

15 European Synchrotron Radiation Facility, 71 Avenue des Martyrs, 38000, Grenoble, France.

17 Corresponding author:

18 Aliénor Duhamel

19 Evolutionary Studies Institute, University of the Witwatersrand, Johannesburg, Gauteng, 2001,

20 South Africa

21 Email address: alienor.duhamel@ens-lyon.org 


\section{Abstract}

24 Biarmosuchia is a clade of basal therapsids that includes forms possessing plesiomorphic 'pelycosaurian' cranial characters as well as the highly derived Burnetiamorpha which are 26 characterised by cranial pachyostosis and a variety of cranial bosses. Potential ontogenetic

27 variation in these structures has been suggested based on growth series of other therapsids with 28 pachyostosed crania, which complicates burnetiamorph taxonomic distinction and thus it is 29 essential to better understand cranial ontogeny of the Burnetiamorpha. Here, three new juvenile 30 biarmosuchian skulls from the late Permian of South Africa are described using X-ray micro 31 computed tomography (CT). We found that juvenile biarmosuchians are distinguished from 32 adults by their relatively large orbits, open cranial sutures, and incomplete ossification of the braincase and bony labyrinth. Also, they manifest multiple centres of ossification within the

34 parietal and preparietal bones. CT examination reveals that the holotype of Lemurosaurus pricei 35 (BP/1/816), previously alleged to be a juvenile, shows no evidence of juvenility and is thus 36 probably an adult. This suggests that the larger skull NMQR 1702, previously considered to be 37 an adult $L$. pricei, may represent a new taxon. This study provides, for the first time, a list of 38 characters by which to recognise juvenile biarmosuchians.

\section{Introduction}

42 poorly-understood group of mid-late Permian therapsids in terms of phylogeny, ontogeny, 43 locomotion (paucity of post-crania) and paleobiology (Hopson \& Barghusen, 1986; Rubidge \&

44 Sidor, 2001; Kemp, 2006). Broom (1913) was the first to describe a member of this clade, 
45

46

47

48

49

50

51

52

53

54

55

56

57

58

59

60

61

62

63

64

65

66

67

Ictidorhinus martinsi, from South Africa. Over the past two decades several new biarmosuchian specimens have been described and historical specimens have been re-assessed (Rubidge \& Kitching, 2003; Sidor, 2003; Rubidge, Sidor \& Modesto, 2006; Sidor \& Rubidge, 2006; Kruger et al., 2015; Day, Rubidge \& Abdala, 2016; Kammerer, 2016; Benoit et al., 2017b; Day et al., 2018; Kulik \& Sidor, 2019), but the systematics of the group remains uncertain as all described genera are monospecific and most species are represented by only one specimen (cranial material). Even though the Biarmosuchia is considered a monophyletic group (Rubidge \& Sidor, 2001; Liu, Rubidge \& Li, 2009; Day et al., 2018), taxonomic diversity and phylogenetic positions of genera are not yet well understood as some published phylogenetic analyses are still contradictory (Day, Rubidge \& Abdala, 2016; Kammerer, 2016; Day et al., 2018).

Thirty-one biarmosuchian genera have been described, mainly based on cranial material, from different regions of Pangea (Malawi, Zambia, Tanzania, Zimbabwe, and Russia). However, some of these are not considered valid or diagnosable. Twelve valid genera are from the main Karoo Basin of South Africa (Rubidge \& Kitching, 2003; Sidor, 2003; Sidor \& Welman, 2003; Sidor, Hopson \& Keyser, 2004; Rubidge, Sidor \& Modesto, 2006; Smith, Rubidge \& Sidor, 2006; Sidor \& Smith, 2007; Kruger et al., 2015; Kammerer, 2016; Day et al., 2018) where they have been recovered from all Permian tetrapod-defined biozones of the Beaufort Group except the Eodicynodon Assemblage Zone (AZ) (Day, Rubidge \& Abdala, 2016).

3 One of the best-represented biarmosuchian subclades, both in numbers of specimens and quality of preservation, is the Burnetiamorpha. This group includes Lemurosaurus pricei as the basal-most taxon (Sidor \& Welman, 2003; Sidor \& Smith, 2007; Kruger et al., 2015; Kammerer, 2016; Kammerer \& Sidor, 2021) and the Burnetiidae is the most derived subclade (Rubidge \& Kitching, 2003; Sidor, 2003; Sidor \& Welman, 2003; Sidor, Hopson \& Keyser, 2004; Rubidge, 
68 Sidor \& Modesto, 2006; Smith, Rubidge \& Sidor, 2006; Sidor \& Smith, 2007; Kruger et al.,

69 2015; Kammerer, 2016; Day et al., 2018; Kammerer \& Sidor, 2021). Most burnetiamorph genera

70 are represented by a single specimen, which limits understanding of ontogenetic development

71 and sexual dimorphism (Sigogneau, 1970; Sidor \& Welman, 2003; Kruger et al., 2015; Kulik \&

72 Sidor, 2019).

Previous research on ontogenetic series of some non-biarmosuchian therapsid taxa

74 provided insight on their palaeobiology. Allometric studies have been undertaken on various

75 therapsid groups to evaluate and study ontogenetic patterns (Huttenlocker \& Abdala, 2015;

76 Jasinoski, Abdala \& Fernandez, 2015; Jasinoski \& Abdala, 2017a; Krone, Kammerer \&

77 Angielczyk, 2019). Using allometric and multivariate analyses Jasinoski and Abdala (2017a)

78 identified ontogenetic modifications and sexual dimorphism in the cynodont Galesaurus

79 planiceps and found that a few craniomandibular features, including the shape of the sutures,

80 change during ontogeny. Moreover, the discovery of juvenile specimens of Thrinaxodon

81 liorhinus, Galesaurus planiceps, and Kayentatherium wellesi in association with adult

82 individuals enabled research on anatomical features linked to ontogeny and led to the conclusion

83 that both species provided parental care (Jasinoski \& Abdala, 2017b; Hoffman \& Rowe, 2018,

84 but see Benoit, 2019). Ontogenetic studies on South African and Russian dinocephalians also

85 revealed allometric growth in the length of the skull compared to the diameter of the orbit, and

86 some specimens like Stenocybus and Sinophoneus are likely to be part of the same ontogenetic

87 series (Ivakhnenko, 2003, 2008; Kammerer, 2011; Kruger, Rubidge \& Abdala, 2017). It has also

88 been demonstrated that cranial ornamentation developed during postnatal development in

89 Biarmosuchus and several dinocephalians such as Estemmenosuchus (Ivakhnenko, 2008).

90 Understanding burnetiamorph cranial ontogenesis would thus possibly provide a path to 
91 understand their elusive palaeobiology.

92 To investigate biarmosuchian ontogeny we studied two new, apparently juvenile,

93 biarmosuchian specimens (CGS MJF 22 and SAM-PK-K11126), and three already described

94 putative juvenile specimens: the holotype of Rubidgina angusticeps (RC 55), Lende chiweta

95 (MAL290), the holotype of Lemurosaurus pricei (BP/1/816), and a specimen (NMQR 1702)

96 previously considered to represent a more mature specimen of L. pricei (Sidor \& Welman,

97 2003). Micro CT was undertaken to determine histological and anatomical clues to characterise

98 ontogenetic stages in this clade. Our results support the non-juvenile status of BP/1/816 and the

99 taxonomic status of Lemurosaurus pricei is revised accordingly.

101 Materials and Methods

102 The specimens described in this paper were chosen either because they have been

103 described as juveniles, or because they have not yet been described and exhibit characters

104 suggesting that they are juveniles.

New material

106

CGS MJF 22 is an almost complete skull, collected in 1980 on the farm Amsterdam, in

107 the Victoria West district of the Northern Cape, in strata that appear on the geological map

108 (Geological Survey, 1989) as belonging to the Poortjie Member (presumably the Lycosuchus-

109 Eunotosaurus Subzone of the Endothiodon AZ) of the Teekloof Formation (Day \& Smith, 2020).

110 The biostratigraphic provenance of this specimen remains uncertain as associated material is

111 fragmentary and uninformative, and the lithostratigraphic units as mapped in the Victoria West 
112 area are not necessarily consistent with the biostratigraphic relationships established in their type

113 areas (Day \& Rubidge, 2019).

114 Specimen SAM-PK-K11126 includes a snout with an almost complete palate, a fragment

115 of the pineal region, a fragment of the occiput around the foramen magnum, and fragments of the

116 lower jaw. Eleven vertebrae (dorsal and sacral) and the pelvis are preserved in articulation. The

117 proximal epiphysis of a femur, one indeterminate long bone diaphysis, and three indeterminate

118 bony fragments are also preserved. Only the cranial material is described here for comparison;

119 the postcranium will be the subject of a future study. Specimen SAM-PK-K11126 was collected

120 in 2012 by Zaituna Skosan on the farm Reiersvlei, in the Beaufort West district of the Western

121 Cape. It was found in the upper part of the Poortjie Member (Endothiodon AZ) sensu (Day \&

122 Smith, 2020).

\section{Previously-described material}

124

Specimen RC 55 comprises an almost complete skull. It was collected in 1940 by a party

lead by Croonie Kitching on the farm Wellwood in the Graaff-Reinet district of the Eastern

Cape, from rocks of the Balfour Formation, likely Cistecephalus AZ, 256 Ma (Day et al.,

2015). It was described by Broom (1942) as the holotype of Rubidgina angusticeps, initially

considered a gorgonopsian, and later assigned to the "Ictidorhinidae" by Sigogneau (1970). Most

recently, RC 55 was identified as a potential juvenile of the non-burnetiamorph biarmosuchian

Herpetoskylax hopsoni (Sidor \& Rubidge, 2006).

$\mathrm{BP} / 1 / 816$ is a relatively complete skull and lower jaw, collected in 1948 by James

132 Kitching on the farm Dorsfontein in the Graaff-Reinet district in the lower Balfour Formation

133 (Cistecephalus AZ). It was described by Broom (1949), who designated it as the holotype of

134 Lemurosaurus pricei and was later part of Sigogneau's (1970) PhD dissertation. Lemurosaurus 
135 pricei was also placed among Ictidorhinidae by Sigogneau (1970) but was considered as a

136 possible juvenile burnetiamorph by Sidor \& Welman (2003).

137 Specimen NMQR 1702 is a well-preserved skull and lower jaw collected in 1974 by a

138 team from the National Museum, Bloemfontein, on the farm Petersburg in the Graaff-Reinet

139 district. Although the precise locality of the find is not known and the farm Petersburg straddles

140 the escarpment and a significant stratigraphic thickness, the specimen most likely comes from

141 the lower Balfour Formation (Cistecephalus AZ) (Sidor \& Welman, 2003). The specimen was

142 described and referred to L. pricei by Sidor \& Welman (2003).

143 Specimen MAL290 (holotype of Lende chiweta) is a well-preserved skull and lower jaw

144 collected in the Chiweta Beds of Malawi dated from the same period as the South African

145 Cistecephalus AZ. The specimen was described by Kruger et al. (2015) and classified as a

146 derived burnetiamorph.

147

148

Preparation

149 Specimen CGS MJF 22 was prepared mechanically at the Evolutionary Studies Institute by

150 Charlton Dube using a compressed air driven air-scribe equipped with specially adapted and

151 sharpened tungsten carbide tips. Paraloid diluted with acetone was used as an adhesive. For

152 SAM-PK-K11126, partial preparation was previously undertaken at Iziko Museum in Cape

153 Town. Specimen RC 55 had been previously prepared using a vibro-tool fitted with gramophone 154 needles.

$155 \quad$ Scanning 
156 To enhance understanding of internal cranial morphology and sutural patterns, CGS MJF22 and

$157 \mathrm{BP} / 1 / 816$ (holotype of L. pricei) were scanned at the ESI using X-ray microCT with a Nikon

158 Metrology XTH 225/320 LC (scanning parameters: $0.0445 \mathrm{~mm}, 185 \mathrm{kV}, 185 \mu \mathrm{A}$ and $0.050 \mathrm{~mm}$,

$159110 \mathrm{kV}, 150 \mu \mathrm{A}$ respectively). Specimen SAM-PK- K11126 was scanned during two sessions at

160 the same CT facility. The skull roof, occiput, and lower jaw were scanned during the first session

161 and the snout during the second one (scanning parameters: $0.034 \mathrm{~mm}, 155 \mathrm{kV}, 235 \mu \mathrm{A}$, and

$1620.03448 \mathrm{~mm}, 155 \mathrm{kV}, 235 \mu \mathrm{A}$ for each respective session). Specimens RC 55 and MAL 290

163 were also scanned at the ESI using the following scanning parameters: $0.0545 \mathrm{~mm}, 70 \mathrm{kV}$ and

$164160 \mu \mathrm{A}$; and $0.08 \mathrm{~mm}, 105 \mathrm{kV}$ and $160 \mu \mathrm{A}$ respectively. Specimen NMQR 1702 was scanned at

165 the ID17 beamline of the European Synchrotron Radiation Facility (ESRF, Grenoble, France),

166 using propagation phase contrast synchrotron X-ray micro computed tomography. The beamline

167 setup consisted of a monochromatic beam of $130 \mathrm{keV}$ (Si 111 double bent Lauë

168 monochromator); filtration with $4 \mathrm{~mm}$ of aluminium and $1 \mathrm{~mm}$ of copper; a sample-detector

169 distance of $10.9 \mathrm{~m}$; an indirect detector ( $2 \mathrm{~mm}$ thick LuAG scintillator, $0.26 \mathrm{x}$ optical

170 magnification and a FReLoN-2k camera), recording imaging with an isotropic pixel size of 0.054

$171 \mathrm{~mm}$. The data acquisition was done following the so-called attenuation protocol (Carlson et al.

172 2011), placing the specimen in a plastic tube filled with aluminium balls $5 \mathrm{~mm}$ in diameter, and

173 consisted of 4998 projections recorded over a rotation of $360^{\circ}$, an exposure time of $0.6 \mathrm{~s}$ each.

174 Additionally, the centre of rotation was shifted to increase the reconstructed horizontal field of

175 view. Given the limited vertical size of the X-ray beam $(\sim 8 \mathrm{~mm}), 71$ scans were necessary to

176 cover the full length of the skull, moving the specimen by $5 \mathrm{~mm}$ between each acquisition. The

177 CT reconstructions were done with the software PyHST2, using the single-distance phase

178 retrieval approach (Paganin et al., 2002; Mirone et al., 2014). The resulting 32-bit data were 
179 converted to a stack of 16 bits tiff using $0.02 \%$ saturation values from the 32-bit 3D histogram

180 generated by PyHST2. Raw CT-scan data are stored at the Evolutionary Studies Institute and are

181 available upon request to the authors by email: alienor.duhamel@ens-lyon.org.

182 Three-dimensional reconstructions and visualization of CT data of all specimens were

183 generated using AVIZO 9.0 (FEI VSG, Hillsboro OR, USA). Three-dimensional renderings were

184 obtained using manual segmentation with AVIZO 9.0 (FEI VSG, Hillsboro OR, USA). Surface

185 files from the 3D reconstruction are available in the Supplemental Information and on the

186 website MorphoBank under the project number P4003.

187

188

189

Institutional abbreviations-AMNH, American Museum of Natural History, New York, USA;

190

BP, Evolutionary Studies Institute (formerly the Bernard Price Institute for Paleontological

191 Research), University of the Witwatersrand, Johannesburg, South Africa; CGS, Council for

192 Geosciences, Pretoria, South Africa; MAL, Malawi Department of Antiquities Collection,

193 Lilongwe and Nguludi, Malawi; NHCC, National Heritage Conservation Commission, Lusaka,

194 Zambia; NMQR, National Museum, Bloemfontein, South Africa; PIN, Paleontological Institute,

195 Moscow, Russia; RC, Rubidge Collection, Graaff-Reinet, South Africa; SAM, Iziko South

196 African Museum, Cape Town, South Africa.

197

198

Anatomical Abbreviation-ang, angular; art, articular; aso, anterior extension of the

199 supraoccipital; bo, basioccipital; c, caniniform tooth; co, occipital condyle; cor, coronoid; d, 
200 dentary; ect, ectopterygoid; eo, exoccipital; f, frontal; fe, temporal fenestra; fm, foramen

201 magnum; i, incisiform tooth; $\mathbf{j}$, jugal; $\mathbf{l}$, lacrimal; m, maxilla; $\mathbf{n}$, nasal; o, orbit; op, opisthotic; $\mathbf{p}$,

202 parietal; pa, anterior portion of the parietal; pac, caudal portion of the parietal; pal, palatine; pal

203 t, palatal teeth; pao, paroccipital process; part, pre-articular; pbs, parabasisphenoid; pc,

204 postcanine; pf, postfrontal; pif, pineal foramen; pl, lateral portion of the parietal; pm,

205 premaxilla; po, postorbital; pp, postparietal; prf, prefrontal; pro, prootic; prp, preparietal; pt,

206 pterygoids; ptf, post-temporal fenestra; q, quadrate; qj, quadratojugal; rt, replacement tooth; sb,

207 supraorbital boss; scl, sclerotic ring; smx, septomaxilla; so, supraoccipital; spl, splenial; st,

208 stapes; sq, squamosal; sur surangular; $\mathbf{t}$, tabular; $\mathbf{v}$, vomer.

209

\section{Description}

211 This section presents a full updated anatomical description of three of the five above

212 mentioned skulls. Specimens NMQR 1702, BP/1/816 and MAL290 are not fully redescribed

213 here as i) sufficiently detailed descriptions of their external cranial anatomy are already available

214 in the published literature (Sigogneau, 1970; Sidor \& Welman, 2003; Kruger et al., 2015; Benoit

215 et al., 2017b) and ii) the $\mathrm{CT}$ images did not enable isolation all the bones using digital

216 segmentation and therefore do not significantly add to previous descriptions. Only new

217 observations enabled by CT scanning are discussed in this paper.

218

219 BIARMOSUCHIA Sigogneau-Russell, 1989

220 BIARMOSUCHIA gen. et sp. indet. 
222 Material - RC 55, the holotype of Rubidgina, comprises a nearly complete laterally compressed

223 skull. The specimen was considered a possible juvenile of Herpetoskylax hopsoni by Sidor and

224 Rubidge (2006). RC 55 can be identified as a biarmosuchian by the presence of a squamosal with

225 a long ventral ramus and an elongated zygomatic process under the orbit, but we consider it

226 indeterminate within this clade because of its juvenile condition and lack of diagnostic

227 characters.

228

229

230 Description - This specimen is an almost complete skull with lower jaws (Fig. 1). The orbit is

231 relatively large $(3 \mathrm{~cm}$ diameter) in comparison to the skull length $(7.5 \mathrm{~cm})$, and the skull roof is

232 flat and does not show any sign of bosses, ridges, or pachyostosis (Duhamel et al., 2016;

233 Duhamel, Benoit \& Rubidge, 2018; Kulik \& Sidor, 2019), consistent with a juvenile status or a

234 basal phylogenetic position (Sidor \& Rubidge, 2006). In lateral view, the skull has a triangular

235 outline (Fig. 1). The specimen is poorly preserved, being laterally compressed with the left side

236 eroded. The anterior snout has been eroded such that the premaxilla, septomaxilla, part of the

237 maxilla, incisors, and a large part of the nasals are damaged (Fig. 1). As a result of diagenesis,

238 most occipital bones are crushed, and the posterior margin of the right temporal fenestra is

239 missing while the left is distorted (Fig. 1). Because sutures are difficult to recognise and many

240 bones are concealed by matrix, the following description is mostly based on the $3 \mathrm{D}$ renderings.

241 As a result of the poor visibility of the sutures, the postparietal, supraoccipital, tabular,

242 opisthotic, prootic, parabasipshenoid and stapes could not be separated digitally but are definitely

243 preserved on the specimen as seen on the "unsegmented bones" section (Fig. 1-C). Both lower

244 jaw rami are present and articulated to the skull (Fig. 1). 


\section{Skull}

The anterior portion of the skull is damaged, including the premaxilla and septomaxilla.

247 The full extent of the maxilla is difficult to evaluate but despite its weathered surface it is clear

248 that it is the largest bone of the lateral surface of the snout (Figs. 1 and 2). Posterodorsally, the maxilla has a long and oblique sutural contact with the lacrimal on the anterior orbital rim.

Posteroventrally, the maxilla extends on the zygomatic arch as a long and thin process that reaches the anterior end of the jugal at the level of the dentary/surangular suture (Figs. 1-A and facial area of RC 55 is crushed, and it is thus difficult to position the prefrontal, lacrimal and jugal sutures with accuracy. The following description is based on an interpretation that we estimate to be the most probable, however a possible second interpretation is shown in Fig. 1-A and 2-A. The lacrimal, as preserved, is a thin strip-like bone limited to the anteroventral margin of the orbit (Figs. 1 and 2) but, because the facial process is damaged, it is difficult to estimate the anterolateral extension of the bone. Dorsally the lacrimal has a short contact with the prefrontal (Figs. 2-A and B). Posteroventrally, at the base of the zygomatic arch, the lacrimal meets the jugal and the maxilla in a tripartite suture (Fig. 2-A). Medially, the lacrimal has a sutural contact with the palatine within the orbit (Fig. 1-B). Two nasolacrimal foramina are present on the lacrimal: one medially positioned (Fig. 2-F) and the second is on the lateral surface (Fig. 2-A). B). Although the right prefrontal has a flat anterodorsal extension (Fig. 2-A and B), this unusual morphology could be the result of deformation or an artefact of segmentation. In dorsal view, the 
267 left prefrontal is triangular with posterolateral and posteromedial extensions (Fig. 2-D). The

268 anterior margin of the frontal is positioned between these two small extensions (Fig. 1-D).

269 The frontal is a long and thin bone forming the anterior half of the dorsal margin of the

270 orbit (Fig. 1). It sutures with the prefrontal anteriorly, the preparietal posteromedially, the

271 postfrontal posterolaterally, and the parietal posteriorly (Figs. 1 and 3-C). The suture with the

272 nasal is not preserved. In lateral view, a posterolateral process of the frontal extends lateral to the

273 postfrontal on the orbital rim (Fig. 3-B). Another thin process separates the postfrontal and the

274 preparietal and meets the parietal posteriorly with a short contact in line with the anterior margin

275 of the pineal foramen (Fig. 3-C). As in most biarmosuchians, a longitudinal depression on the

276 frontal separates the low orbital rim from a rounded midline ridge (Figs. 3-E and F). Given the

277 lateral compression of the specimen, the depth of this depression might have been exaggerated

278 by post-mortem damage. In ventral view (Fig. 3-D), the frontal bears a thick longitudinal ridge

279 that curves medially and (on the left frontal) continues posteriorly onto the parietal where it

280 disappears caudally (Fig. 3-D).

281 The preparietal is a small unpaired and almost rectangular bone located on the dorsal-

282 most point of the skull roof, above the posterior half of the orbit (Fig. 3-A). No midline suture is

283 visible (Figs. 1 and 3-C). It has sutural contact with the frontal rostrally and the parietal caudally

284 (Fig. 1 and 3). Its posterior margin is slightly elevated and contributes to the pineal boss and the 285 anterior margin of the pineal foramen (Figs. 3-A and C).

286 In lateral view the postfrontal is a prominent bone that has a vertical orientation (Figs. 1-

287 A, 1-B and 3). This vertical orientation might be exaggerated by lateral compression. The

288 postfrontal sutures with the frontal anteromedially, the parietal posteromedially, and the 289 postorbital posterolaterally (Fig. 3). 
The paired parietal bones are separated by a distinct midline suture (Fig. 3-C) and the

291 chimney-like pineal foramen is completely included within the parietals (Fig. 3-C). Because of

292 compression, the sutural contacts of the parietal are unclear on the left side. However, it is

293 evident that the parietal contacts the preparietal anterolateral to the pineal foramen through a

294 tripartite connection between the frontal, preparietal, and the parietal. Laterally, the parietal

295 contacts the postfrontal, and extends anteriorly to form another tripartite suture between the

296 postfrontal, the frontal, and parietal (Figs. 3-C and D). Finally, the lateral margin of the parietal

297 is overlapped by the postorbital (Figs. 3-D and F), with a small posterolateral cleavage above the 298 postorbital (Fig 3-F).

The right jugal of RC 55 forms the posterior half of the ventral and the posteroventral margins of the orbit (Fig. 1 and 2). It is an anteroposteriorly elongated bone that contacts the

301 lacrimal and the maxilla anteriorly (Figs. 2-A, B and F), and the postorbital posteriorly (Fig. 1-

302 A). The suture with the squamosal is unclear because of poor preservation (Fig. 1-A). The left

303 jugal has been displaced vertically and rotated counter clockwise such that the dorsal portion of

304 the displaced bone is actually the posterior portion of the jugal (Fig. 2-B). Its two extremities are

305 vertically flat and $\mathrm{V}$-shaped for articulation with the maxilla anteriorly and the squamosal

306 posteriorly. This gives it a double-wrench overall outline. Medially, the long shaft of the jugal is

307 slightly concave for insertion of the masseter muscle.

308 The postorbital is a T-shaped bone. Its ventral extension forms the postorbital bar and

309 marks the posterior margin of the orbit and the anterior border of the temporal fenestra (Figs. 1

310 and 3), but the nature of the contact with the squamosal and jugal is uncertain (Fig. 1-A). The

311 postorbital contacts the squamosal dorsomedially and forms the dorsal and posterior margin of

312 the temporal fenestra in lateral view (Figs. 1-B and C). Anterodorsally the postorbital contacts 
313 the postfrontal and frontal; and the parietal posterodorsally (Fig. 3). Medially, the ventral process

314 of the postorbital has a caudally curved ridge that extends from the postfrontal/postorbital suture

315 to the possible jugal/postorbital contact (Figs. 1-A, 1-B and 3-B).

316 The squamosal is a crescent-shaped bone forming the posterior and ventral margins of the

317 temporal fenestra (Fig. 4-A) and is best preserved on the left side. It possibly sutures with the

318 postorbital on the zygomatic arch below the anterior margin of the temporal fenestra (Fig. 1-A).

319 In occipital view, the squamosal overlies the quadrate dorsally (Figs. 4-A, B, E, and F). In medial

320 view (Fig. 4-B), the squamosal cradles the posterior side of the dorsal process of the quadrate.

321 Anteroventrally the squamosal has a triangular fossa at the base of the zygomatic process (Fig. 4-

322 B), which may represent the facet for the now displaced jugal.

323 Both quadrates of RC 55 are well preserved (Fig. 4). This bone is vertically flattened and

324 looks almost rectangular in occipital view. It is positioned on the anteromedial side of the

325 squamosal (Figs. 4-C and D). In occipital view (Fig. 4-E) the ventral articulatory margin of the

326 quadrate, comprising the lateral and the medial condyles, slopes ventrolaterally and has a smooth

327 surface that articulates with the articular (Figs. 1-C, 1-E and 4-E). Dorsal to the lateral condyle,

328 the quadrate has a small fossa (Fig. 4-F) where it contacts the small quadratojugal. On the right

329 side, the quadrate appears to share a contact with the angular (Figs. 1-A).

330 The quadratojugal is a small ovoid bone surfacing on the lateral side of the quadrate

331 (Figs. 4-A and E) and, like in other synapsids, participates in the jaw articulation with the

332 quadrate on the skull, and the articular and the angular on the lower jaw (Figs. 1-A, B, and E).

333 This tiny quadratojugal constitutes the dorsolateral part of the jaw articulation. Only the left

334 quadratojugal is preserved (Fig. 4), and it articulates solely with the quadrate on its dorsal,

335 medial, and ventral borders (Figs. 4-E and F). 


\section{Occiput and basicranium}

The occiput has a roughened surface and lateral compression has resulted in the occiput

340 having a square outline in posterior view. The occipital surface is poorly preserved, most of the

341 bones are crushed and could not be differentiated during segmentation (Figs. 1-C and E).

342 However, the jaw articulation is complete and well preserved in RC 55.

The small triangular exoccipital bone is preserved lateral to the foramen magnum (Figs.

4-B and E) and its medial margin meets the basioccipital (Figs. 4-B and E). is rounded in occipital view and extends ventrolaterally into a broken basioccipital tubera (Figs.

347 4-E and F). In dorsal view, the basioccipital is concave medially, probably for the pituitary fossa (Fig. 4-D) but, because of poor preservation this could not be confirmed from the CT data. In ventral view, a midline ridge extends from the middle of the basioccipital to the anterior border of the occipital condyle (Fig. 4-C). Although they cannot be identified with certainty, they may represent fragments of the prootic, opisthotic, basioccipital tubera, and/or stapes.

\section{Palate}

The palate has been damaged as a result of lateral compression. The vomers and the ectopterygoids are missing, and some sutures are unclear, especially the one between the 
359 not possible to digitally segment and isolate the posteriormost palatal bones and those of the

360 basicranium, such as the parabasisphenoid. The right side of the palate is best preserved and is

361 thus the basis of this description.

362 The anterior extension of the palatine extends posteriorly along the alveolar margin from

363 the last postcanine to the posterior margin of the palatine boss (Fig. 5-C), which in turn is in

364 contact with the pterygoid boss. Only the right palatine is preserved in RC 55 and contacts the

365 maxilla anteriorly and anterolaterally (Fig. 1-B), and the pterygoid posteriorly and

366 posterolaterally (Fig. 5). The dentigerous palatine boss bears eleven teeth arranged in a single U-

367 shaped row. In medial view (Fig. 5-B), the palatine has a dorsal process that projects vertically

368 from the anterior ramus of the palatine (Figs. 1-B and 5-B) and reaches the level of the dorsal

369 margin of the maxilla (Fig. 1-B) to form the posteroventral margin of the maxillary sinus. A

370 small vertical lamina present on the palatine also contributes to the lateral wall of the sinus. In

371 lateral view, the ascending process sutures with the maxilla and is excavated by an ovoid

372 concavity (Fig. 5-A). Medially and ventrally, the palatine shares a diagonal suture with the

373 pterygoid along the lateral margin of the palatine boss (Figs. 5-B and 5-C).

374 In all Biarmosuchia, the pterygoid is a tripartite, paired bone, comprising the

375 anteromedial process (or pterygoid corpus), the transverse process, and the quadrate ramus, the

376 last of which forms the posterolateral part of the pterygoid (Rubidge \& Sidor, 2002; Sidor \&

377 Welman, 2003; Rubidge \& Kitching, 2003; Sidor, Hopson \& Keyser, 2004; Kammerer, 2016;

378 Day et al., 2018). On RC 55, the palatine ramus expands anteriorly between the maxilla laterally

379 and the palatine medially (Fig. 5-C). A low longitudinal ridge is present on the lateral margin of

380 the palatine ramus (Fig. 5-C). A high vertical lamina extends anterodorsally from the dorsal

381 surface of the palatine ramus and reaches the level of the posteromedial border of the lacrimal 
382 dorsally (Figs. 1-B and 5-B). Posteromedial to the palatine ramus, the right pterygoid boss bears

383 six teeth which are circular in cross-section. The right transverse process forms a $90^{\circ}$ angle with

384 the rest of the pterygoid in ventral view (Fig. 5-C) and three palatal teeth are preserved on the

385 left transverse process but there are none on the right. A posteromedially oriented ridge marks

386 the transition between the transverse process and the quadrate ramus (Fig. 5-C). The latter is

387 divided into a thick posteromedial process and a thinner posterolateral process which is directed 388 toward the quadrate (Fig. 5-F).

389

\section{Lower jaw}

Both mandibular rami are damaged anterior to the level of the canine (Figs. 1 and 6) and

the right ramus is missing the canine and incisors, but the canine and two incisors are preserved on the left (Fig. 1).

Only the posterior part of the dentary is preserved in RC 55. It is a long and thin bone on the dorsolabial surface of the lower jaw and has ten tooth sockets on the left and five on the right ramus (Figs. 6-A and B). The dorsal margin of the dentary thickens posterodorsally to form a low coronoid process at the highest point of the lower jaw, where the dentary, the coronoid and the surangular meet (Fig. 6-B). Posteromedially, the dentary has a straight vertical contact with the prearticular and the splenial (Figs. 6-A, B and D). visible in lateral view (Fig. 6). Posterodorsally it has a sutural contact with the angular (Fig. 6-D) 402 and anteriorly it is broken at the level of the $9^{\text {th }}$ postcanine.

A small coronoid is positioned on the dorsal part of both lower jaw rami (Fig. 6) and is 
405 left lower jaw ramus, the coronoid cradles the anterior margin of the upper mandibular fenestra 406 (Fig. 6-B).

407 The angular is a large flat bone that forms a third of the posteroventral part of the lower 408 jaw on the medial side (Figs. 6-A and B) and is damaged along its ventral edge as a result of 409 post-mortem weathering (Figs. 6-A and B). The elongated and thin anterior portion is positioned 410 ventromedial to the dentary (Fig. 6-A). This portion of the angular contacts the splenial 411 anteriorly and the coronoid and the surangular dorsally (Figs. 6-A and B). The posterior portion 412 of the angular is broad with a damaged posteroventral margin (Figs. 6-A and B) and contacts the 413 prearticular posteriorly. Postmortem damage resulted in an opening between the angular and the 414 surangular on the left ramus (Fig. 6-B). Ventral to this opening the angular bears the reflected 415 lamina that is preserved on the left ramus (Fig. 6-B). The reflected lamina of RC 55 consists of a 416 thin ridge curving dorsally, that extends along the the ventral margin of the angular (Fig. 6-B).

417 As this ventral margin has been weathered away, it is possible that the ventral-most part of the 418 reflected lamina is not preserved on RC 55.

419 The poorly preserved surangular makes up the posterodorsal part of the lower jaw, 420 posterior to the coronoid, anterior to the angular, and dorsal to the prearticular (Fig. 6-B). The 421 surangular of RC 55 is badly preserved, however it is clear that the surangular forms most of the 422 dorsal margin of an opening, bordered anteriorly by the coronoid, and is due to possible post423 mortem damages (Fig. 6-B).

424 The prearticular is a small bone of the lower jaw located posteriorly, and exposed mainly 425 on the medial side of both rami (Fig. 6-A and D). It is better preserved on the left ramus and 426 surrounds the anterior margin of the articular posteriorly (Fig. 6-B), while sharing only a short 
427 contact with the articular on the right ramus (Fig. 6-A). The prearticular contacts the surangular 428 posterodorsally and the medial side of the angular anteriorly (Fig. 6-A and D).

In RC 55, the articulation surface of the articular is concave and positioned

431 posteromedially (Fig. 6-D). In posterior view (Figs. 6-D and E) the articular has two ventral 432 processes separated by a deep notch (Figs. 6-D and E).

\section{Dentition}

The anterior dentition of RC 55 is not preserved because of incomplete preservation of the anterior end of the lower jaws and snout (Figs. 1 and 7). Despite this, CT imagery has, for the first time, revealed the presence of three small upper and two lower incisors (Fig. 7). The last upper incisor seems to have a caniniform morphology but is too poorly preserved to ascertain.

One sharp caniniform is present on the lower jaw, and the upper canine has suffered post-mortem deformation. As in SAM-PK-K11126, a replacement upper canine is positioned posterior to the functional one. The upper postcanines are small and are poorly preserved such that it is not possible to determine their morphology. In contrast, the lower jaw has ten well-preserved conical postcanines (Fig. 7). arranged in a U-shaped single row (Figs. 1-E and 5-C). The six teeth on the pterygoid boss are smaller and randomly distributed. Three medially positioned teeth are present on the transverse 447 process (Figs. 1-E and 5-C). 
BIARMOSUCHIA Sigogneau-Russell, 1989

451

BURNETIAMORPHA Broom, 1923

452

BURNETIAMORPHA gen. et sp. indet.

453

454 Material - CGS MJF 22, an almost complete skull with the lower jaw. The anterior part of the

455 snout and dentary are missing. It can be recognized as a burnetiamorph on the basis of a median

456 ridge on the skull roof and a supraorbital boss; the palatal process of premaxilla is long and

457 laterally bounds the anterior portion of vomer; and the surangular bears a deep fossa laterally.

458 The genus cannot be determined because of its juvenile condition.

460 Description - Specimen CGS MJF 22 (Fig. 8) comprises an almost complete skull and occluded

461 lower jaw. On specimen CGS MJF 22, the roof of the snout and part of the left side are damaged.

462 Superficially the skull is broadly triangular in lateral view (Fig. 8-A). The right side of the skull

463 is relatively well preserved, allowing most bones to be digitally segmented (Fig. 8). Similarly,

464 the right ramus of the lower jaw is well-preserved except for the anterior tip of the dentary,

465 which is missing. The left lower jaw is badly weathered and preserves only the anterior portion

466 of the dentary. The large orbit makes up about $70 \%$ of the lateral surface of the skull (orbit

467 diameter is $30 \mathrm{~mm}$ and basal skull length is $77 \mathrm{~mm}$ ). It forms an almost perfect circle and at least

468 six sclerotic plates from the posterodorsal region of the sclerotic ring are preserved in the right

469 orbit. As the left side is poorly preserved, this description is based mostly on the right side. The

470 palate is well preserved and much of the anatomy is visible, including the palatal teeth. The

471 medial portion of the occiput is well preserved, but the left side is missing and the right side is

472 weathered, which prevents accurate description. 


\section{Skull}

474

The anterior tip of the skull is weathered away, and it is not possible to determine the

475

476

477

478

480

481

482

483

484

485

486

487

488

489

490

491

492

494
The lacrimal is a quadrangular bone, forming most of the anterior margin of the orbit (Fig. 8-A) and contacts the jugal ventrally, the maxilla anteriorly, and the prefrontal dorsally but the anterior part of the prefrontal is not preserved. A vertical ridge extends up the lacrimal along the anterior border of the orbit. The lacrimal is excavated by an ovoid depression anterior to the orbit, close to the suture between the maxilla and jugal.

The jugal comprises almost the entire ventral margin of the orbit and forms a small part of the anteroventral margin of the temporal fenestra (Fig. 8-A). Anterodorsally it shares a horizontal sutural contact with the lacrimal and meets the maxilla anteroventrally, the squamosal posteroventrally, and the postorbital posterodorsally. The suborbital portion of the zygomatic arch formed by the jugal is thin and not pachyostosed. The small triangular temporal fenestra is less than one third the size of the orbit and is positioned posteroventral to the orbit. It is bordered anteriorly by the postorbital and the jugal, and posteriorly by the squamosal.

Peer) reviewing PDF | (2019:07:39842:2:0:NEW 24 Jun 2021) 

and forms practically the entire postorbital bar (Fig. 8-A). Anterodorsally it meets the postfrontal

497 at the posterior margin of the orbit, has a long sutural contact with the postfrontal on the skull

498 roof, and meets the parietal posteromedially such that the postorbital has extensive exposure on 499 the skull roof (Fig. 8-C).

$500 \quad$ The squamosal is a comparatively large bone forming the ventral and posterior borders of 501 the temporal fenestra. It shares a suture with the tabular on the occiput, and ventrally it contacts 502 the quadrate and quadratojugal (Figs. 8-A and C). Anteriorly, the squamosal tapers into a long 503 process that sutures with the posterior process of the maxilla (Figs. 8-A and C). As many of the skull roof bones are slightly pachyostosed (Fig. 8-B), their sutural contacts are not readily visible and were identified using CT data. The orbital rim bears a conspicuous supraorbital boss that reaches its highest point halfway above the orbit and is

507 formed mainly by the frontal and the postfrontal. A large domed boss surrounds the circular 508 pineal foramen (Fig. 8-B) which is positioned posteromedial to the orbit. The pineal tube extends anteroventrally at an angle of about $70^{\circ}$ relative to the skull axis (Fig. 8-A). Only a small portion

510 of the posterior end of the right prefrontal is preserved. It constitutes the anterior-most part of the 511 supraorbital boss and forms the anterodorsal rim of the orbit (Fig. 8-B). Although the degree of

512 pachyostosis of the supraorbital boss is low in CGS MJF 22, the CT data revealed the presence 513 of radial structures in coronal cross-section (Fig. 8-B), which are considered to be radial vascular 514 structures linked to the possibly juvenile status of the specimen (see discussion).

515 The paired frontals have a smooth dorsal surface with no midline ridge (Fig. 8-B). Each

516 frontal contributes a large portion of the supraorbital part of the skull roof, participates in the 517 dorsal margin of the orbit, and tapers posterolaterally between the preparietal and postfrontal. 
518 The posterior tip of the frontal forms a pointed contact with the parietal at the level of the

519 anterior margin of the pineal foramen.

520 The preparietal is a relatively large, roughly triangular, paired bone positioned between

521 the two supraorbital bosses (Fig. 8-B) with the apex of the preparietal tapering anteriorly

522 between the frontals. Posteromedially, the preparietal contributes to the border of the pineal

523 foramen, and posterolaterally it shares an oblique sutural contact with the parietal. A midline

524 suture is present in the preparietal (Fig. 8).

525 The parietal contributes to the lateral margin of the pineal foramen and extends onto the

526 lateral and posterior sides of the pineal boss (Fig. 8-B). In dorsal view, it contacts the preparietal

527 anteromedially, shares a short contact with the frontal and postfrontal anterolaterally, with the

528 postorbital posterolaterally, and the postparietal posteriorly on the occiput (Fig. 8-C). In addition,

529 the postfrontal forms a posteriorly directed process between the frontal and the postorbital. Based

530 on the CT images it appears that the parietal is divided into two separate bones (Fig. 8-B), a

531 rostrolateral part and a posteromedial part radiating posteriorly from the pineal foramen (Fig. 8),

532 which may indicate two distinct centres of ossification (see Discussion). The midline suture

533 between the paired parietals, posterior to the pineal foramen, is not fused (Fig. 8).

534 Most of the left side of the occiput of CGS MJF 22 is missing and the right side is badly

535 weathered (Fig. 8-C). However, the central portion is preserved. The postparietal is a large

536 unpaired rectangular bone that forms the dorsal half of the occiput. Ventrally it shares a

537 horizontal suture with the supraoccipital and touches the parietal dorsally. Because of extensive

538 post-mortem damage, the lateral suture with the tabular is impossible to determine. However, a

539 short dorsolateral contact with the right squamosal is evident. A vertical midline ridge, the 
540 external occipital ridge, extends ventrally from the postparietal to the foramen magnum (Fig. 8-

541 C) and is more rounded on the supraoccipital than on the postparietal.

542 The unpaired supraoccipital is not well preserved, and the left side is the most complete

543 (Fig. 8-C). It forms the dorsal margin of the foramen magnum and extends laterally and ventrally

544 to contact the exoccipital ventrally, and the opisthotic ventrolaterally. Dorsally it shares a long

545 horizontal contact with the postparietal.

546 The opisthotic is mostly weathered, its exact shape cannot be determined, and it is only

547 partly preserved on the left side of the occiput (Fig. 8-C). It contacts the supraoccipital

548 dorsomedially, the exoccipital medially, and the basioccipital ventromedially. On the ventral side

549 (Fig. 8-D), the opisthotic is oriented posterolaterally and shares a sinusoidal medial contact with

550 the basioccipital. The opisthotic contacts the parabasisphenoid anteromedially, and bears the

551 fenestra ovalis anteriorly. This fenestra is partially crushed laterally and has a straight sutural

552 contact with the opisthotic medially (Fig. 8-D).

553 A small, oval exoccipital forms the lateral border of the foramen magnum (Fig. 8-C).

554 Ventrally, it contacts the basioccipital, dorsally the supraoccipital, and the opisthotic laterally.

555 The right exoccipital is not preserved.

556 The midline basioccipital forms the ventral and ventrolateral margin of the foramen

557 magnum and the occipital condyle (Fig. 8-C). It contacts the exoccipital dorsolaterally and the

558 opisthotic laterally. Only a small portion of the left basioccipital condyle is preserved ventrally.

559 In palatal view (Fig. 8-D), the basioccipital contacts the opisthotic laterally and the

560 parabasisphenoid anteriorly.

561

562

Palate 
Generally, the ventral side of the skull is well preserved except for the posterior part close

564 to the basicranium (Fig. 8-D). Anteriorly, the vomer is a thin midline bone which has not been

565 extensively prepared because it is too delicate. From the CT data, it appears that the vomer is an

566 unpaired structure with a medial trough flanked by two thin vertically oriented lateral flanges.

567 Posteriorly, the vomer forms a large expanded vomerine plate (Fig. 8-D). The lateral flanges of

568 the vomers converge posteriorly to form a midline ridge that extends posteriorly onto the

569 vomerine plate (Fig. 8-D) which has posterior contact with the palatines. The horizontal suture

570 between the vomerine plate and the palatine is more dorsally positioned than the rest of the

571 palate.

The palatine and pterygoid form most of the palate (Fig. 8-D). The palatine bears a long

573

574

575

576

577

578

579

580

581

582

583

584

585 anterior tongue-like process that forms the lateral margin of the internal naris and extends

anteriorly to the level of the caniniform tooth. A prominent palatine boss protrudes ventrally and

bears numerous nubbin-like teeth arranged in a U-shaped pattern (Figure. 8-D). Twenty small

teeth are present on the right palatine boss and are arranged in two rows (Fig. 8-D). The left

palatine boss is not well preserved. A midline trough separates the paired palatine and pterygoid bosses. Posteriorly, the palatine shares a reverse V-shaped suture with the pterygoid and meets the ectopterygoid posterolaterally (Fig. 8-D).

The ectopterygoid (Fig. 8-D) is preserved on the right side. It is an anteroposteriorly long and flat bone that constitutes the lateral aspect of the palate. Anteriorly and anteromedially it has a long sutural contact with the palatine and posteriorly contacts the pterygoid.

The tripartite paired pterygoid comprises the pterygoid boss anteriorly, the transverse process, and the quadrate ramus caudally (Fig. 8-D). The pterygoid boss is in continuity with the palatine boss and also bears small nubbin-like teeth (Fig. 8-D). On the right pterygoid boss,

Peer) reviewing PDF | (2019:07:39842:2:0:NEW 24 Jun 2021) 
586 about 25 teeth are clustered randomly, but because of the poor preservation of the left side, the

587 exact number of teeth is uncertain (both on the specimen and the CT data). The transverse

588 process is robust and positioned halfway along the pterygoid, at the level of the anterior margin

589 of the orbit. On the medial side of the right transverse process, are four teeth arranged in a single

590 row. As a result of post-mortem damage, it is not possible to determine whether teeth are present

591 on the left transverse process and metallic inclusions prevent clear identification on the CT data.

592 Posterior to the transverse process, the pterygoid corpus is excavated by a long slit-like

593 interpterygoid vacuity (Fig. 8-D). The raised margins of the interpterygoid vacuity are in

594 continuity with the transverse processes. A long quadrate ramus extends back from the lateral

595 side of the pterygoid corpus, posterior to the transverse process (Fig. 8-D).

596 Posteromedially, the pterygoid corpus meets the parabasisphenoid (fusion of the

597 parasphenoid and basisphenoid), which is slightly offset dorsally (Fig. 8-D). On its ventral

598 surface, this bone bears an elongated medial mound. Lateral to this mound, the parabasisphenoid

599 forms a small shelf (Fig. 8-D). Posterior to the mound, the suture with the basioccipital is

600 unclear, but a very slight depression is present between the two basal tubera. Posterolaterally, the

601 parabasisphenoid meets the opisthotic and forms the anteromedial border of the fenestra ovalis

602 (Fig. 8-D).

603 The quadrate forms the jaw articulation with the articular, and only the right quadrate is

604 preserved (Fig. 8-D). The ventral side of the quadrate is rectangular, mediolaterally elongated,

605 and presents a medial crest. This crest is probably a result of the fusion between the two quadrate

606 condyles as already observed in other biarmosuchian taxa (Sidor \& Rubidge, 2006). The

607 quadrate contacts the quadrate ramus of the pterygoid anteromedially and the quadratojugal

608 posterodorsally (Fig. 8-D). In lateral view, the quadrate has a small exposure at the 
609 posteroventral extremity of the skull (Fig. 8-A), but in occipital view the dorsal process is broad

610 and attaches to the anterior side of the squamosal ventral flange (Fig. 8-C). It is in close contact

611 with the articular such that its anterior aspect is not visible.

612 The quadratojugal is a small, thin, and vertically flat bone that is visible in lateral,

613 occipital, and ventral views (Figs. 8-A, C, D respectively) on the right side. On its lateral aspect,

614 the rectangular quadratojugal contacts the quadrate dorsal to its lateral articular condyle (Fig. 8-

615 A). In occipital view the quadratojugal contacts the quadrate below the small quadratojugal

616 foramen and the squamosal dorsally (Fig. 8-C). In palatal view, the quadratojugal contacts the

617 lateral quadrate condyle and has an articular contact with the angular anteriorly (Fig. 8-D).

618

Lower jaw

620

The right dentary is reasonably well preserved in comparison to the left, but the ventral

621 surface has been weathered away. In lateral view, the dentary forms the anterior half of the

622 mandible (Fig. 8-A). Posteroventrally, the dentary contacts the angular with a posterodorsally

623 oriented suture. The exact nature of the contact is unclear because of damage to the ventral part

624 of the mandible from this point forward. The dentary meets the surangular and continues

625 posterodorsally as a process that overlies the surangular and forms the dorsal margin of the

626 mandible. Below the orbit, the dentary is mediolaterally compressed into a low coronoid process

627 (Fig. 8-A). The lateral surface of the dentary is relatively flat and smooth, as is typical in

628 biarmosuchians (Rubidge \& Kitching, 2003; Sidor, 2003; Sidor \& Welman, 2003; Sidor, Hopson

629 \& Keyser, 2004; Rubidge, Sidor \& Modesto, 2006; Smith, Rubidge \& Sidor, 2006; Sidor \&

630 Smith, 2007; Kruger et al., 2015; Kammerer, 2016). The posterodorsal margin of the dentary

631 forms a laterally projecting ridge that extends posteriorly, dorsal to the surangular. This structure 
632 originates dorsal to the contact of the dentary and angular, initially swelling into a round ridge

633 but flaring caudally so that it is very thin as it projects over the surangular (Fig. 8-A). The

634 splenial is visible as a long, thin ribbon-like bone on the medial side of the jaw. It extends

635 anteriorly from the ectopterygoid to the tip of the mandible (Fig. 8-D).

636 In lateral view, the surangular has a small exposure on the posterodorsal side of the

637 mandible, where it forms the curved posterodorsal edge of the coronoid process. It bears a

638 prominent laterally projecting longitudinal ridge (Fig. 8-A). On its ventral side, the surangular

639 has a long horizontal sutural contact with the angular and contacts the dentary dorsally (Fig. 8-

640 D).

641 The angular forms the posterolateral portion of the lower jaw extending posteriorly from

642 below the anterior margin of the orbit (Fig. 8-A). The extensive reflected lamina bears a

643 prominent oblique ridge that curves posterodorsally. In lateral view, the angular contacts the

644 surangular dorsally and the dentary anteriorly (Fig. 8-A). On the medial side it contacts the

645 dentary anterolaterally and posteriorly reaches the two articular condyles (Fig. 8-D). The anterior

646 contact with the splenial cannot be determined because of poor preservation.

647 The poorly preserved articular is located posterior to the angular as is usual in

648 Biarmosuchia (Sidor, Hopson \& Keyser, 2004). Medially the articular bears two condyles, one

649 lateral and one medial (Fig. 8-D). The articular articulates with the quadrate posteriorly to form 650 the jaw joint.

651

652

653

654

\section{Dentition}

As the tip of the snout and mandible is eroded, no pre-canine teeth are preserved on the upper and lower jaw. On the maxilla, the weathered alveolus of the right caniniform tooth

Peer) reviewing PDF | (2019:07:39842:2:0:NEW 24 Jun 2021) 
655 extends dorsally almost as far as the dorsal margin of the maxillary bone (Fig. 8-A). CT data

656 reveal the presence of an unerupted tooth posterior to the erupted caniniform socket that might

657 be a replacement caniniform tooth (Fig. 8-A). The scan also reveals eight marginal postcanines

658 in the right maxilla, but no teeth are visible on the left side. The anterior-most three postcanines

659 have serrations on their posterior edge, whereas the four posterior-most ones bear serrations on

660 both the anterior and posterior edges (Fig. 8-A). It was not possible to determine the serration

661 pattern on the fourth postcanine.

662 No pre-canine or caniniform teeth are preserved on the lower jaw. Eight postcanines are

663 visible on the right lower jaw (Fig. 8-A). They all share a similar, conical morphology, and

664 decrease in size posteriorly. No serrations are visible on the anterior-most post-canine tooth, but

665 the second, third, and fourth teeth have serrations on the anterior side. The fifth post-canine tooth

666 has serrations on both sides, the sixth does not have visible serrations, and the seventh and eighth

667 post-canines have serrations on both sides. These seemingly random variations could be the

668 result of over-preparation or differential weathering due do rapid dental replacement in this

669 juvenile individual.

670

671 BIARMOSUCHIA Sigogneau-Russell, 1989

672 BURNETIAMORPHA Broom, 1923

673 cf. Lophorhinus willodenensis Sidor and Smith (2007)

674

675 Material -Specimen SAM-PK-K11126, a broken potential juvenile specimen which preserves a

676 partial snout and palate, the pineal region, the occiput, a partial lower jaw, posterior dorsal and

677 sacral vertebrae attached to a pelvis, a distal part of a femur and some indeterminate bones. 
678 SAM-PK-K11126 can be identified as a burnetiamorph because of the presence of a median

679 ridge-like structure on the skull roof and a long palatal process of the premaxilla laterally

680 bounding the anterior portion of the vomer. We think it to be likely referrable to Lophorhinus

681 willodenensis because of the presence of a long palatal process of the premaxilla that laterally

682 bounds the anterior part of the vomer (Sidor \& Smith, 2007) and similarities in the shape of the

683 vomer in SAM-PK-K11126 and SAM-PK-K6655 (holotype of Lophorhinus willodenensis).

684 Description - The description of the skull fragments of SAM-PK-K11126 is mostly based on CT

685 data, as the delicate nature of its bones prevents further preparation. Description of the

686 postcranial material will be the subject of a future paper. Bone sutures are readily visible making

687 segmentation of individual bones relatively easy to accomplish (Figs. 9-13).

688

689 Snout fragment

690 On the left side, most of the maxilla and the complete premaxilla are preserved as well as

691 part of the jugal (Fig. 9-A). The right side is severely damaged, and this description is thus based

692 mostly on the left lateral side of the specimen.

693 The premaxilla is a short and thin bone on the anterior aspect of the snout (Fig. 9-A) and

694 accommodates six incisiform teeth. It has sutural contacts with the maxilla posterior to the last

695 incisiform tooth, and with the vomer posteromedially through the vomerine process. In palatal

696 view, the vomerine process of the premaxilla extends posteriorly to the level of the first

697 caniniform tooth (Figs. 9-B and 10-B). Because of the presence of many crushed bones inside

698 the snout, the morphology of the anterior part of the vomerine process of the premaxilla is

699 uncertain (Figs. 9-B and 10-B). In lateral view, the premaxilla tapers posterodorsally into an 
700 elongated caudal process (Fig. 9). As the nasals are not preserved, it is not possible to evaluate

701 the sutural contact of the premaxilla with these bones.

702 In lateral view the maxilla is a large bone that makes up most of the face of the isolated

703 snout, but the bone is very thin and bears many fractures. At its anterior end, it overlaps the

704 posterior margin of the premaxilla (Fig. 9-A). Two caniniform teeth and eight postcanines are

705 preserved on the left side (Fig. 9-A). Posterodorsally the maxilla has an oblique sutural contact

706 with the jugal which begins dorsally below the anterior margin of the orbit and continues

707 posteroventrally to the broken zygomatic arch (Fig. 9-A). In ventral view, the thin elongated

708 maxilla has short sutural contacts with the palatine and a long contact with the ectopterygoid

709 posteromedially (Fig. 9-B).

710

$711 \quad$ Palate

712 The anterior part of the palate is relatively well preserved on the snout, up to the posterior

713 border of the ectopterygoid, and segmentation enabled description of the internal anatomy (Fig.

714 10). Because of deformation and the thin nature of some bones (particularly the dorsal lamina),

715 some sutures were not discernible in the CT data. We present here our interpretation of the palate

716 of SAM-PK-K11126 with some uncertainties.

717 The vomer is a long unpaired bone that extends almost half of the length of the palatal

718 surface of the snout fragment (Fig. 10-A). It has a longitudinal midline trough bordered by lateral

719 ridges that join anteromedially to form a midline ridge at the level of the last incisiform, just

720 posterior to the suture with the premaxilla (Figs. 10-A and B). The resulting medial ridge

721 continues anteriorly onto the premaxilla. The midline trough extends posteriorly as far as the

722 level of the third postcanine. Posteriorly the vomer contacts the palatine and separates the 
723 palatine bosses ventrally (Fig. 10-A). On its dorsal side, the vomer forms a long thin septum that

724 separates the nasal chamber into two bilateral cavities (Figs. 10-B and C). In lateral view, the

725 dorsal margin of this septum slopes at a $30^{\circ}$ angle (Fig. 10-C). Posteriorly, the suture between

726 the vomer and the palatine cannot be determined with certainty due to post-mortem damage, but

727 it appears that the vomer thins to form a wedged contact between the two palatine bones (Fig.

728 10-A).

729 The posterior half of the palatal surface comprises the paired palatine and pterygoid

730 bones (Fig. 10-A). As the right palatine bone is poorly preserved and incomplete, the description

731 is based on the left side. The maxillary process of the palatine is triangular. It extends anteriorly

732 along the tooth row (Fig. 10-B) and tapers against the maxilla at the level of the first postcanine

733 tooth (Fig. 9-B). The palatine bosses are separated by a midline suture and a medial trough. The

734 palatine contacts the pterygoid posteroventrally and medially (Fig. 10-A). Laterally the palatine

735 shares a long and oblique suture with the ectopterygoid. (Fig. 10-A). Dorsally, a thin and high

736 septum extends from the level of the ectopterygoid to the vomerine septum caudally (Fig. 10-B,

737 C and D). This septum may belong, at least in part, to the pterygoid, though the quality of

738 preservation does not allow the definitive identification of a suture in CT data. Posterodorsally,

739 the palatine overlies the pterygoid bosses (Fig. 10-C).

740 In ventral view the ectopterygoid is a rectangular and longitudinally elongated edentulous

741 bone located anterolateral to the lateral process of the pterygoid (Figs. 10-A and B). The left

742 ectopterygoid is best preserved and shows that it contacts the palatine boss medially and the

743 maxilla laterally. Its contribution to the medial septum dorsally is uncertain (Fig. 10-C).

744 Posteromedially, the ectopterygoid borders the pterygoid boss (Fig. 10-A and B). 
In SAM-PK-K11126 only the corpus and quadrate ramus of the pterygoid are preserved.

746

747

748

749

750

751

752

753

754

755

756

757

758

759

760

761

762

763

764

765

766

The quadrate ramus is visible on the occipital fragment as a thin process that contacts the quadrate posteriorly (Fig. 11-D) and curves anteromedially toward the anterior margin of the parabasisphenoid (Fig. 11-D). On the palatal side of the snout, the anterior part of the pterygoid corpus is damaged; however, it is clear that the pterygoid boss overlaps the palatine (Fig. 10-C). The anterior end of the pterygoid corpus is separated from its counterpart by the palatine. On the left side, the pterygoid contacts the ectopterygoid laterally (Fig. 10-B). The transverse process is not preserved in SAM-PK-K11126.

\section{Pineal region fragment}

This fragment comprises the supraorbital and pineal region of the skull roof (Fig. 12). The dorsal rim of the left orbit is preserved and has no pachyostosis or supraorbital boss. The left side preserves no sutures and most of the bones could not be identified. Accordingly, the segmentation and description are mostly based on the right side (Fig. 12).

The frontal is a paired bone with a smooth dorsal surface and forms a large part of the interorbital region (Fig. 12-A). A low ridge is present on the midline between the two frontals and extends posteriorly on the preparietal, and up to the pineal boss (Fig. 12-A). Because the anterior portion of the frontal is not preserved, the frontal appears as a triangular bone. It tapers caudally and extends laterally to the pineal foramen as a thin caudal process contacting the parietal and preparietal medially, the postfrontal laterally, and the postorbital posteriorly (Fig. 12-A). The suture between the frontal and the postfrontal appears ridged, but CT data reveal that this is due to post-mortem displacement of the frontal to artificially overlap the postfrontal (Fig. 
767 12-A). In ventral view, the frontal bears a longitudinal, medially curved ridge extending from the

768 level of the middle of the preparietal to the anterior part of the frontal (Fig. 12-B).

769 The postfrontal forms the posterodorsal margin of the orbit in dorsal view (Fig. 12-A) and

770 shares a sinuous suture with the postorbital posterolaterally (Fig. 12-C). In ventral view, the

771 posterior end of the postfrontal has a short posteromedial contact with the parietal (Fig. 12-B).

772 Only a small fragment of the postorbital is present in this skull roof fragment, posterior to the 773 postfrontal (Fig. 12) and makes up a very short part of the posterior margin of the orbit (Fig. 12-

774 C). Anteriorly, the postorbital mostly contacts the postfrontal and also shares a short suture with

775 the caudal process of the frontal. The postorbital has sutural contact with the parietal medially

776 (Fig. 12-B) and posterolaterally the rim of the postorbital is inset by the dorsal margin of the

777 temporal fenestra. The squamosal is not preserved.

778 The preparietal is an unpaired and relatively small diamond-shaped bone on the skull roof

779 that forms the anterior margin of the pineal foramen and tapers anteriorly between the two

780 frontals (Fig. 12). It has a long oblique anterior sutural contact with the frontal and a short,

781 slightly curved suture with the parietal posteriorly (Fig. 12-A).

782 The pineal foramen is relatively large and surrounded by a prominent pineal boss formed by

783 the preparietal anteriorly and the parietal laterally and caudally (Fig. 12-A and B). The parietal is

784 a paired bone that contacts the preparietal anteriorly and anterodorsally, extends onto the frontal

785 laterally, and is overlapped by the postorbital posterolaterally (Fig. 12-B). Based on CT images,

786 it appears that the parietal comprises three parts separated by distinct sutures radiating from the

787 pineal foramen: an anterior part, a lateral part, and a caudal part behind the pineal foramen (Fig.

788 12). The implications of these subdivisions are addressed in the discussion. 


\section{Occipital fragment}

791 The occipital part of the skull, and some of the basicranial elements are preserved on a single

792 fragment (Fig. 11). The supraoccipital is a relatively large and unpaired bone, contributing $40 \%$

793 of the surface on the occiput fragment, and forming the dorsal margin of the foramen magnum

794 (Fig. 11-A). Dorsolaterally, the supraoccipital has a short contact with the remains of the

795 postparietal (Fig. 11-A). The anterior extension of the supraoccipital forms a cavity on the

796 ventral surface to accommodate part of the brain (Fig. 11-C). Ventrolaterally, the supraoccipital

797 forms the dorsal margin of the post-temporal fenestra. Lateral and medial to the fenestra, it

798 shares sutures with the opisthotic (Fig. 11-A). Laterally the supraoccipital has a diagonal contact

799 with the medial margin of the tabular, ventrally with the dorsal process of the basioccipital (Fig.

800 11-A and B). The supraoccipital appears to surround the ovoid exoccipital (Fig. 11-A) and that

801 the supraoccipital is positioned anterior to the exoccipital. Their exact position in relation to the

802 supraoccipital and the basioccipital cannot be accurately determined (Fig. 11-A).

803 A broken piece of the tabular is present on the right side of the occiput in association with

804 part of the squamosal and the quadrate (Figs. 11-A and B). The tabular extends dorsoventrally

805 from the top of the supraoccipital to the ventral margin of the opisthotic. It shares an

806 anteromedial contact with the supraoccipital and contacts the opisthotic along its ventromedial

807 margin (Fig. 11-A). On its anterior side, the tabular has a slight depression to fit the anterior 808 depressed surface of the squamosal (Fig. 11-B).

809 Part of the dorsal process of the squamosal is positioned anterior to the tabular and the

810 opisthotic (Figs. 11-A, B, and C). The squamosal contacts the stapes posteromedially and the 811 quadrate anteromedially. 
812 The opisthotic is positioned on the ventrolateral side of the occiput and is shaped like a

813 horizontal hourglass (Fig. 11-A). Its dorsal concavity constitutes the ventral border of the post-

814 temporal fenestra while its ventral concavity forms the dorsal margin of the fenestra ovalis. The

815 opisthotic contacts the basioccipital medially, and the supraoccipital dorsomedially. Laterally,

816 the opisthotic has a flat contact with the squamosal and is overlapped by the tabular

817 dorsolaterally (Figs. 11-A and B).

818 The basioccipital is an unpaired midline bone forming the lateral and ventral edges of the

819 foramen magnum, and comprises the single occipital condyle (Fig. 11-A). The two dorsolateral

820 parts of the basioccipital are ovoid and in contact with the exoccipital dorsomedially, the

821 supraoccipital medially, and the opisthotic laterally. The ventral part of the basioccipital contacts

822 the parabasisphenoid anteriorly (Fig. 11-B).

823 The prootic is positioned between the basioccipital and the parabasisphenoid (Figs. 11-B and

824 D) and shares a contact with the stapes and the supraoccipital (Fig. 11). The prootic on SAM-

825 PK-K11126 is a tripartite bone, with a median posterior process at the level of the occipital

826 condyle, and two lateral processes. The right lateral process is oriented toward the supraoccipital

827 (Figs. 11-B and D).

828 Only the posterior part of the quadrate is preserved on the occipital fragment (Fig. 11).

829 Dorsally, it is in sutural contact with the opisthotic. A curved suture runs dorsolaterally along the

830 left quadrate and separates it from the stapes (Fig. 11-A). On the right quadrate, only the ventral

831 side reaches the stapes. In right lateral view (Fig. 11-B) it is evident that the quadrate underlies

832 the squamosal and extends anterodorsally along the anterior margin of the squamosal (Fig. 11-

833 B). Anteromedially, the left quadrate contacts the quadrate ramus of the pterygoid (Figs. 11-A

834 and D). 
835 The stapes is a small dumbbell-shaped bone that contacts the ventral margin of the fenestra

836 ovalis (Fig. 11-A). This description is based on the right stapes as it is the best preserved. The

837 stapes is positioned lateral to the ventral process of the basioccipital and the prootic (Figs. 11-A

838 and D) and shares a sutural contact with the basioccipital and the prootic medially and the

839 quadrate and the tabular laterally. No stapedial foramen is present.

840 The laterally displaced parabasisphenoid is visible on the ventral side of the fragment.

841 Anteriorly it divides into two processes (Figs. 11-B and D).

842

$843 \quad$ Lower jaw

844 A small posterior portion of the left lower jaw is preserved attached to the occiput fragment

845 (Fig. 11). No sutures could be identified but as it is articulated to the quadrate, this part of the

846 lower jaw is probably the angular with a piece of articular (Figs. 11-A and D). In addition to the

847 posterior piece of left lower jaw, a small portion of the right lower jaw ramus is also preserved

848 and bears the four distal-most postcanine teeth (Fig. 13). In dorsal view, the CT data clearly

849 show a vertical suture extending along the three teeth sockets and the suture between the dentary

850 and splenial (Fig 13-B).

851

$852 \quad$ Dentition

853 On the ventral side of the snout, it is evident that six incisiform teeth are present in the

854 premaxilla, two prominent caniniform teeth are rooted anteriorly in the maxilla, and eight

855 postcanines are positioned caudally on the maxilla (Figs. 9 and 14-A). A replacement tooth at the

856 third incisiform position is preserved on each side (Fig. 14-A). All the incisiform teeth are

857 elongated and slender. The caniniform teeth are well exposed (Figs. 9 and 14) and have, 
858 serrations on the posterior face. The canines are curved and laterally compressed, with the distal

859 side sharper than the mesial side. Two replacement teeth are visible medial to the caniniforms

860 (Fig. 14). Eight postcanines are arranged in a single row on the left maxilla, while the right side

861 shows only six poorly preserved postcanines (Figs. 9 and 14).

862 Posteromedially, on the body of the palatine, the prominent, anteriorly rounded, dentigerous

863 palatine boss (Fig. 10-A) bears twenty-four nubbin-like teeth arranged in a U-shaped manner

864 along the anterior edge of the boss (Fig. 14-A). On the lateral edge they are arranged in two

865 parallel rows, but there is only a single row on the medial edge (Fig. 14-A).

866 Nubbin-like teeth arranged in a V-shape are also present on the pterygoid boss with the apex

867 of the V-oriented posteriorly (Fig. 10-A). Fourteen teeth are visible on the CT data of the left

868 boss, and twenty-three on the right boss.

869

870 BURNETIAMORPHA Broom, 1923

871 Genus LEMUROSAURUS Broom, 1949

872 LEMUROSAURUS PRICEI Broom, 1949

873 Material - BP/1/816 (holotype of L. pricei), NMQR 1702 (Sidor \& Welman, 2003) and

874 BP/1/818 (cf. Lemurosaurus, referred as BPI 353 in Sigogneau (1970))

875

876 Holotype - BP/1/816, complete skull and lower jaw.

877

878 Description - Sigogneau (1970) provided a full description of BP/1/816 pointing out that the

879 skull is small (basal skull length of $71 \mathrm{~mm}$ ) and complete with a lower jaw. The relatively large

880 orbit $(21 \mathrm{~mm})$ is suggestive of a juvenile status. The specimen has been previously considered to 
881 be possibly a juvenile specimen when NMQR 1702 was described (Sidor \& Welman, 2003). The

882 ratio of the diameter of the orbit to skull length is 0.3 . This small specimen has pachyostotic and

883 relatively large supraorbital bosses (Fig. 15). CT data (Fig. 15-A) show thick and dense tissue

884 inside the supraorbital boss instead of a thin and porous skull cap. The pineal boss is a domed

885 structure and a round boss is present on the posterior part of the zygomatic arch. The braincase is

886 fully formed and its walls are thick and well ossified (Benoit et al., 2017a). The two

887 orbitosphenoids are long and fused in the midline to form a gutter that cradled the anteriormost

888 part of the tubular brain (Benoit et al., 2017a). The orbitosphenoid sutures with the prootic

889 caudally to close the lateral wall of the braincase. The bony labyrinth is completely separated

890 from the brain cavity (Benoit et al., 2017a). The same degree of ossification of the braincase and

891 bony labyrinth walls are also found in the alleged adult specimen NMQR 1702, whereas it is

892 absent in the above-described juveniles. In CGS MJF 22, SAM-PK-K11126, and RC 55, no bony

893 labyrinth could be segmented out because of the lack of fusion between the opisthotic and

894 prootic and the absence of a medial wall on the inner ear capsule, and no ossified orbitosphenoid

895 or epipterygoid are preserved. In addition, the supraorbital boss of NMQR 1702 is comparatively

896 thinner and less developed than that of the Lemurosaurus holotype, despite the former being the

897 larger specimen (Fig. 16). Sidor and Welman (2003) considered the differences between NMQR

8981702 and the holotype (BP/1/816) to be the result of either intraspecific or ontogenetic variation.

899 They gave preference to the ontogenetic explanation because of the great differences in cranial

900 length and the comparatively larger orbit of the smaller specimen (BP/1/816), implying that

$901 \mathrm{BP} / 1 / 816$ is a juvenile of the same species as NMQR 1702 (Sidor \& Welman, 2003). From our

902 observations and CT assisted re-assessment of these two specimens, it appears more likely that 
$903 \mathrm{BP} / 1 / 816$ and NMQR 1702 are at a similar stage of development and that BP/1/816 cannot be

904 referred to a juvenile of the taxon represented by NMQR 1702.

905

906

907 Discussion

908 What are the reliable indicators of juvenility in Biarmosuchia?

909 Here we discuss characters that can be or have been considered in the literature as indicators of

910 juvenile status, and their relevance in the context of biarmosuchian ontogeny at a suborder level.

\section{$911 \quad$ Orbit size}

912 Specimens CGS MJF 22 and BP/1/816 have large orbits relative to their skull lengths. This

913 character is commonly considered a juvenile characteristic in therapsids (Abdala, Flores \&

914 Giannini, 2001; Giannini et al., 2010; Jasinoski \& Chinsamy-Turan, 2012; Kruger et al., 2015;

915 Kruger, Rubidge \& Abdala, 2017). In Biarmosuchus, the orbit remains similar in absolute size

916 during growth from the juvenile to adult stage but reduces in size relative to skull length

917 (Ivakhnenko, 1999, 2008). Recently, specimen BP/1/816 (Lemurosaurus pricei) was re-

918 identified as a juvenile specimen because of its comparatively large orbit and overall small size

919 (Sidor \& Welman, 2003); however, as shown above, BP/1/816 displays many other traits that are

920 indicative of a maturity. This casts doubt on the reliability of relative orbit size as an indicator of

921 juvenility in biarmosuchians.

922 In extant species, a large eye diameter compared to skull length characterizes nocturnal

923 species, as it enhances sensitivity to light in low light conditions (Hall, 2008; Heesy \& Hall,

924 2010; Schmitz \& Wainwright, 2011). In extinct species, the dimensions of the eyeball can be

925 inferred from those of the sclerotic ring (optical ratio) (Hall, 2008; Schmitz \& Motani, 2011). 
926 The calculation of the optical ratio (a proxy to determine the light sensitivity of the eye) in

927 synapsids enabled Angielczyk and Schmitz (2014) to determine the diel activity pattern of many

928 species, including biarmosuchians. They concluded that most biarmosuchians had eyes adapted

929 to either a scotopic or mesopic environment, and were thus likely not diurnal. If nocturnality was

930 common in biarmosuchians, it is expected that many species may have developed larger orbits to

931 accommodate larger eyeballs, and it is reasonable to hypothesize that Lemurosaurus pricei may

932 be one of them. As such, a large orbit alone is not a reliable indicator of juvenility in

933 biarmosuchians as it could be related to specific diel activity, and should be backed with other

934 anatomical clues before concluding on a possible juvenile condition (see below).

935

936 Tooth replacement

937 Specimens SAM-PK-K11126 and RC 55 have erupting caniniforms positioned lingually and

938 posteriorly relative to the main row of teeth (Fig. 7 and 14). Until the present description

939 replacement canines had never been observed in biarmosuchians. In dinocephalians, Moschops,

940 Tapinocaninus and Agnosaurus show a pattern of tooth replacement (Boonstra, 1962; Whitney \&

941 Sidor, 2019; Neumann, 2020). In dicynodonts, the presence of a supernumerary tusk is

942 considered pathological (Fröbisch, 2005; Jinnah \& Rubidge, 2007; Fröbisch \& Reisz, 2008). In

943 theriodonts (Gorgonopsia, Therocephalia and Cynodontia), replacement canines are found late in

944 ontogeny but are not found in the largest specimens (Kermack, 1956; Hopson, 1964; Van den

945 Heever, 1980; Norton, 2020; Norton et al., 2020) except for Thrinaxodon (Abdala, Jasinoski \&

946 Fernandez, 2013). As such, double canines are expected to be found in, but are not exclusive to,

947 juveniles. Specimen CGS MJF 22, and the holotypes of Lende chiweta and Lemurosaurus pricei 
948 do not show a replacement caniniform and as such, are better interpreted as mature specimens

949 compared to SAM-PK-K11126 and RC 55 (see Norton, 2020; Norton et al., 2020).

950 Notably SAM-PK-K11126 has two functional upper caniniforms, which is unusual among

951 Biarmosuchia (Sidor \& Welman, 2003; Sidor \& Rubidge, 2006; Day et al., 2018). In SAM-PK-

952 K11126 (Fig. 14), it is likely that the two caniniform teeth might have been functional at the

953 same time to some degree given that the two labial teeth are totally or partially erupted. One row

954 of replacement teeth is positioned posterolingually to the corresponding functional caniniform

955 (Fig. 14). The presence of two erupted maxillary caniniforms is considered a plesiomorphic

956 condition in synapsids as sphenacodontians present continuous replacement with two functional

957 maxillary caniniforms (Romer \& Price, 1940; Van den Heever, 1980; Sigogneau-Russell, 1989;

958 Norton, 2020; Norton et al., 2020).

959

$960 \quad$ Cranial bosses and pachyostosis

961 Pachyostosis is a non-pathological augmentation of the volume of the bone by an increase of

962 deposit of periosteal cortices (de Buffrénil \& Rage, 1993). Among biarmosuchians, cranial

963 pachyostosis is present in burnetiamorphs, particularly on the cranial roof (Kulik and Sidor,

964 2019). In CGS MJF 22, SAM-PK-K11126, and RC 55, cranial ornamentation and pachyostosis

965 are weakly developed (Figs. 1, 8, and 12). Low development of cranial ornamentation and

966 pachyostosis have been linked to an early ontogenetic stage in various groups of therapsids,

967 including dinocephalians and burnetiamorphs (Estes, 1961; Van Heerden, 1972; Ivakhnenko,

968 2008; Horner \& Goodwin, 2009; Kammerer, 2011; Liu, 2013; Cassini, Flores \& Vizcaíno, 2015;

969 Kruger, Rubidge \& Abdala, 2017; Kulik \& Sidor, 2019). Ivakhnenko (2008) and Kruger,

970 Rubidge \& Abdala (2017) showed that in Titanophoneus potens and Anteosaurus magnificus the 
971 fronto-nasal ridge, supraorbital bosses, and pachyostosis developed between the juvenile and the

972 adult conditions. The formation of cranial bosses in the anteosaurian genus Sinophoneus was also

973 noted as a postnatal development (Liu, 2013). A similar ontogenetic development was observed

974 for the bosses of Estemmenosuchus uralensis (Ivakhnenko 2008). In tapinocephalids, cranial

975 pachyostosis develops while the relative size of the orbit and temporal fenestra shrinks during

976 growth (Gregory \& Broom, 1926; Boonstra \& Broom, 1936; Boos et al., 2015; Neumann, 2020).

977 Compared to the juvenile specimens studied here, adult burnetiamorphs show a higher degree of

978 pachyostosis and cranial ornamentation (Figs. 15, 16 and 17). A low degree of pachyostosis thus

979 appears to be linked to juvenility, whereas the higher degree of pachyostosis in MAL 290 and

$980 \mathrm{BP} / 1 / 816$ (Figs. 15 and 17), as well as the presence of well-formed cranial bosses (Fig. 16 and

981 17) suggest that these specimens are a lot more mature. However, pachyostosis and cranial

982 bosses are known to vary with phylogeny, as basal biarmosuchians display lower degree of

983 cranial pachyostosis and smaller cranial bosses than derived burnetiamorphs (Sidor \& Rubidge,

984 2006; Day et al., 2018). Sexual dimorphism may also result in differences in cranial boss and

985 pachyostosis development (Lande, 1980; Kraaijeveld, Kraaijeveld-Smit \& Komdeur, 2007;

986 Benoit et al., 2016; Gates, Organ \& Zanno, 2016), although this has not been documented in

987 biarmosuchians. As such, cranial pachyostosis should not be considered in isolation as a means

988 to determine whether a biarmosuchian specimen is a juvenile.

989

$990 \quad$ Radial vasculature pattern

991 In pachycephalosaur dinosaurs, the presence of radial vasculature in the bones of the

992 pachyostotic cranial dome is indicative of juvenile status at the time of death, and overall

993 vascularization decreases with ontogeny and the growing of pachyostosis (Schott et al., 2011). 
994 Radial vascular patterns in the cranial bones of dicynodonts have been interpreted similarly

995 (Jasinoski \& Chinsamy-Turan, 2012) and similar radially arranged vascular canals are also

996 visible on CT images in the supraorbital bosses of CGS MJF 22 (Fig. 8-B). Using thin sections

997 and CT data, Kulik and Sidor (2019) also observed radial vasculature in the skull caps of some

998 juvenile and sub-adult burnetiamorphs. The presence of these patterns could not be confirmed in

999 SAM-PK-K11126 and RC 55 because their supraorbital bosses are not well preserved.

1000 A radial vascular pattern has been interpreted as an adaptation to resist tensile constraints in

1001 (Lee, 2004) but we find this an unlikely explanation in the case of CGS MJF 22 because the

1002 supraorbital boss is not an attachment point for any muscle that could have generated such

1003 tensile constraints (Benoit et al., 2016). Instead, because it occurs in combination with other

1004 characters (e.g., orbit size, a low degree of pachyostosis and other juvenile features), we interpret

1005 the radial vasculature patterns observed in CGS MJF 22 to be linked to the immature status of

1006 specimen. In MAL 290, NMQR 1702, and BP/1/816 (Figs. 15, 17 and 18), the supraorbital

1007 bosses are thick and dense, with no sign of a radial vasculature pattern, which suggests that their

1008 bosses were fully grown at the time of death.

1009

1010 Braincase and bony labyrinth ossification

1011 In CGS MJF 22, SAM-PK-K11126, and RC 55 individual cranial bones are disarticulated as

1012 most sutures are wide open, which is commonly interpreted as a juvenile trait (Estes, 1961;

1013 Kermack, 1984; Rieppel, 1992; Schaefer et al., 2009; Giere et al., 2010; Sekiya \& Dong, 2010).

1014 CT images through the braincase and bony labyrinth of CGS MJF 22 (not preserved in SAM-

1015 PK-K11126 and RC 55) reveal that these anatomical structures are not well ossified as the

1016 orbitosphenoid is absent (and was likely still cartilaginous), and the prootic and opisthotic are not 
1017 fused (Fig. 19). An epipterygoid was not found in any of the juvenile specimens either. This

1018 contrasts with adult burnetiamorphs in which these structures are well co-ossified and solidly

1019 sutured to each other (Fig. 15; Benoit et al, 2017). In mammals the capsule of the bony labyrinth

1020 and the orbitosphenoid ossify early in ontogenetic development (Jeffery \& Spoor, 2004; Ekdale,

1021 2010; Koyabu et al., 2014; Spiekman \& Werneburg, 2017; Sánchez-Villagra \& Forasiepi, 2017),

1022 but in sauropsids this happens later and more slowly, if at all (Ngwenya et al., 2013; Neenan et

1023 al., 2019). The lack of ossification of these structures in CGS MJF 22 suggests that the

1024 development of the braincase and bony labyrinth had not yet reached maturity. The braincases of

1025 BP/1/816, MAL 290 and NMQR 1702 are fully ossified (Figs. 15, 17 and 18; Benoit et al, 2017),

1026 which is suggestive of cranial maturity.

1027

1028

\section{Fusion of the preparietals and internal parietal sutures}

1029 Adult biarmosuchians have an unpaired preparietal (Rubidge \& Kitching, 2003; Rubidge,

1030 Sidor \& Modesto, 2006; Sidor, 2003; Sidor, Hopson \& Keyser, 2004; Smith, Rubidge \& Sidor,

1031 2006; Sidor \& Smith, 2007; Sidor \& Welman, 2003; Marilao, Kulik \& Sidor, 2020). This

1032 character is present in RC 55 and SAM-PK-K11126 (Figs. 3 and 12), but not in CGS MJF 22

1033 where the bone is paired (Figs. 8-B and 20). In addition, all juvenile specimens studied here

1034 share the presence of intraparietal sutures (except, maybe RC 55, in which this condition is

1035 unclear Fig. 3-A). The parietal of CGS MJF 22 is not only paired but comprises four parts (Figs.

1036 8-B and 20), while the parietal of SAM-PK-K1126 is made of six parts (Figs. 12 and 21). Based

1037 on their spatial configuration, none of these additional parts are homologous to the bones usually

1038 encountered in therapsids. As these sutures are symmetrical, they are unlikely cracks resulting

1039 from post-mortem damage (Figs. 20 and 21). From histological studies, Kulik \& Sidor (2019) 
1040 also observed this in the skull cap of a subadult burnetiamorph from Zambia (NHCC LB373)

1041 where the right parietal comprises two distinct bones.

1042 Supernumerary cranial bones (called wormian bones) have been reported in adult human

1043 skulls (Bellary et al., 2013) and are formed by the addition of extra ossification centres (da Mata,

1044 da Mata \& Aversi-Ferreira, 2010; Bellary et al., 2013). Veterinary studies have also reported

1045 wormian bones in dogs (Linton, 1906). However, recent studies on adult and juvenile human

1046 skulls suggest that wormian bones are more likely due to congenital pathological conditions

1047 rather than ontogenetic variation (Marti et al., 2013; Nikolova et al., 2014a). In addition,

1048 anomalous parietal sutures have been recognised in some modern human individuals (Hrdlička,

1049 1903; Shapiro, 1972). These sutures, found on adult individuals, are perpendicular to the

1050 interparietal suture, and appear to be an anomalous rather than a juvenile feature (Shapiro, 1972).

1051 Unlike what would be expected in the case of wormian bones or post-mortem breakage, the

1052 condition in CGS MJF 22 and SAM-PK-K11126 is perfectly bilaterally symmetrical and radiates

1053 from the pineal foramen (instead of being perpendicular to the interparietal suture, or randomly

1054 distributed). As such, they are unlikely to be pathological or post-mortem damage.

1055 Extra cranial bones have been observed in the skull of various juvenile dicynodonts and

1056 lycosuchid therocephalians (Estes, 1961; Van den Heever, 1980; Jasinoski et al., 2014; Kulik \&

1057 Sidor, 2019; Marilao, Kulik \& Sidor, 2020). For example, some supernumerary bones found in

1058 the nasal of a small-sized Lystrosaurus specimen have been tentatively homologized to the

1059 anterior process of the frontal and been hypothetically linked to their juvenile condition

1060 (Jasinoski et al., 2014). Amongst the Cynodontia, two small specimens of Thrinaxodon liorhinus

1061 (UCMP 42878 and UCMP 42877) possess a divided interparietal (Estes, 1961; Van Heerden,

1062 1972). The extra intraparietal bones of CGS MJF 22 and SAM-PK-K11126 resemble the Os 
1063 Incae (or Inca bones) that are present in a small fraction of modern human populations (Shapiro

1064 \& Robinson, 1976; Hanihara \& Ishida, 2001; Wu et al., 2011; Thanapaisal et al., 2013; Nikolova

1065 et al., 2014b). This condition usually results in a non-symmetrical division of the supraoccipital

1066 in humans; however, in some rare cases, this division can be symmetrical and results in radiating

1067 sutures, just like in CGS MJF 22 and SAM-PK-K11126 (Hanihara \& Ishida, 2001: Figs. 2b and

1068 5). In humans the presence of an interparietal is the result of the persistence of the Mendosal

1069 fontanel in adults (Wu et al., 2011) which supports the contention that the condition observed in

1070 CGS MJF 22 and SAM-PK-K11126 is a juvenile feature. The Inca bones, which in mammals

1071 normally fuse to form the interparietal bone (e.g. artiodactyls, hyracoids) or fuse to either the

1072 supraoccipital (e.g. humans) or parietal (e.g. possum, sirenians), comprises two to four pairs of

1073 ossification (Wu et al., 2011; Koyabu, Maier \& Sánchez-Villagra, 2012; Nikolova et al.,

$10742014 \mathrm{~b}, \mathrm{a})$; which is reminiscent of the condition in the parietal of CGS MJF 22.

1075 Accordingly, we interpret the presence of intraparietal sutures and the absence of interparietal

1076 fusion as a manifestation of the juvenile status of our specimens, each resulting bone probably

1077 being an independent centre of ossification of the parietal bone normally observed in adult

1078 specimens (Figs. 20, 21). That this phenomenon is a real anatomical feature, and not the result of

1079 some taphonomic processes or CT scanning artefact, is demonstrated by the study of the

1080 histological sections made by Kulik \& Sidor (2019:Fig. 1-I), who found the same results as the

1081 present work. The variable number of centres of ossifications is not abnormal given the diversity

1082 of Inca bone patterns observed in modern humans (Hanihara \& Ishida, 2001; Wu et al., 2011). It

1083 appears that this condition is relatively common in juvenile burnetiamorphs (and perhaps

1084 biarmosuchians in general), but has not previously been observed in other therapsids with the the 
1085 exception of the few specimens recently studied by Kulik \& Sidor (2019) and Marilao, Kulik \&

1086 Sidor (2020).

1087

1088

\section{Conclusion on ontogenetic characters}

1089 It is important to point out that the characters presented in this discussion cannot be

1090 considered on their own, but rather that a combination of morphological features should be

1091 considered in a specimen to assess its ontogenetic status. The general size of the specimen and its

1092 orbit diameter in comparison to the basal skull length is often a good sign of juvenility, but can

1093 also reflect the lifestyle of the animal (eg. nocturnality). In modern mammals, the presence of

1094 replacement teeth is usually an indication of immaturity. By contrast, non-mammalian therapsids

1095 were likely replacing their teeth throughout their life, although it is possible that some taxa, such

1096 as Galesaurus, might have experienced replacement of the canine only up to the subadult stage.

1097 This variability of tooth replacement pattern between genera and species might have occurred in

1098 Biarmosuchia. The degree of development of cranial bosses and pachyostosis is traditionally

1099 interpreted as ontogenetic, but can vary between lineages and within species (eg. sexual

1100 dimorphism). The degree of ossification of the braincase region is rather a strong argument to

1101 assess the ontogenetic stage of the specimen, but like in extant species, the timing of ossification

1102 of the different internal bones is taxon dependant. The presence of intra-bone sutures is rarely

1103 observed in extinct and extant species, especially on the parietal, but, when not pathological, this

1104 has been observed in immature specimens only.

1105

1106 A hypothetical biarmosuchian ontogenetic series 
1107 As demonstrated above there are a number of clues from cranial morphology that, when

1108 considered together, enable recognition of a juvenile burnetiamorph: the presence of two

1109 caniniform teeth on the upper jaw; incomplete cranial fusion; low degree of pachyostosis and

1110 cranial ornamentation (bosses and ridges small or absent); and the presence of a paired

1111 preparietal and subdivisions of the parietal. A sizable orbit relative to skull length and a

1112 relatively short snout are not reliable juvenile characters on their own as they can be the result of

1113 interspecific allometry.

1114

1115 Here we propose a hypothetical ontogenetic sequence of the Biarmosuchia based on the

1116 anatomical data from the actual specimens studied and literature presented above (Fig. 22). It is

1117 challenging to build a complete ontogenetic series of an extinct higher ranked taxon as the order

1118 of closure of the sutures is likely to be variable among the lower ranked taxa. As such, our

1119 hypothetical model focuses on the occurrence of different centres of ossification, the presence

1120 and relative size of cranial bosses and ridges, and the overall proportions of the different parts of

1121 the skull. Two ontogenetic directions are reconstructed depending on whether the species

1122 considered is a burnetiamorph or a non-burnetiamorph biarmosuchian (Fig. 22). In green are

1123 reconstructed stages that we postulate for all biarmosuchians and in red are ontogenetic stages

1124 that would pertain only to burnetiamorphs.

1125 Beginning with a hypothetical juvenile stage (stage 0 on Fig. 22; sutures visible within the

1126 parietal, preparietal paired, no cranial ornamentation visible, replacement caniniforms present as

1127 in CGS MJF 22), we identified two different juvenile stages before the adult stage. In stage 1

1128 (Fig. 22), the preparietal fuses, and the supraorbital bosses and naso-frontal ridge then begins to

1129 grow (only in burnetiamorphs). This stage is exemplified by SAM-PK-K11126. In stage 2 (Fig. 
1130 22), the intraparietal sutures may fuse, and cranial ornamentation becomes larger (in

1131 burnetiamorphs only). According to the model, this stage corresponds to the status of RC 55.

1132 Finally, the possible adult stage (stage 3 in Fig. 22) is be marked by the absence of replacement

1133 caniniforms, significant elongation of the snout and enlargement of the temporal fenestra. In

1134 burnetiamorphs cranial ornaments lose their radial vasculature, the skull roof is fully

1135 pachyostotic, and the braincase and bony labyrinth become completely ossified. According to

1136 this model, the development of cranial pachyostosis occurs after complete ossification of the

1137 preparietal and parietal, which concurs with the conclusions made by Kulik \& Sidor (2019).

1138 This hypothetical series could be tested in the future by the discovery of a single species

1139 ontogenetic series.

1140

1141 Reconsideration of Lemurosaurus Broom, 1949?

1142 In contrast to the situation in the juvenile specimens described above, both the braincase and

1143 the bony labyrinth of BP/1/816 (holotype of Lemurosaurus pricei) are well ossified (Fig. 15;

1144 Benoit et al., 2017) and they are even more extensively ossified than in the largest specimen

1145 (NMQR 1702) attributed to Lemurosaurus pricei (Fig. 19; Benoit et al., 2017b). Most cranial

1146 sutures of the holotype are completely fused and cannot be determined, even on the CT images

1147 (Fig. 15). In contrast to the juvenile biarmosuchian specimens described above, the supraorbital

1148 bosses are well developed, show no radial vasculature (Figs. 15 and 16-A). More importantly, no

1149 replacement canine is present, which is only found otherwise in the most mature (such as the

1150 holotype of Lende chiweta), and largest specimens in other therapsid taxa (Norton, 2020). This

1151 supports the idea that the holotype of Lemurosaurus pricei (BP/1/816), despite having very large

1152 orbits and a relatively short snout, is an adult (contra Sidor and Welman 2003). As stated above, 
1153 the large size of the orbit is not a reliable indicator of juvenility in biarmosuchians. The only

1154 characters left supporting that BP/1/816 may be a juvenile are thus its small cranial length and

1155 short snout, two characters that are also expected to occur in dwarf species of a given taxon

1156 (Reynoso \& Clark, 1998). As such, given the comparatively large amount of evidence suggesting

1157 that BP/1/816 is an adult, the juvenile hypothesis is untenable. Specimen NMQR 1702, one of

1158 the best preserved biarmosuchian specimens, comprises a large skull with lower jaw that were

1159 described as an adult specimen of Lemurosaurus pricei by Sidor \& Welman (2003). Compared

1160 to the holotype of Lemurosaurus (BP/1/816), NMQR 1702 has a much longer snout (115 mm)

1161 and the size of the orbit is smaller $(35 \mathrm{~mm})$ relative to skull length, with an orbit to basal skull

1162 length ratio of 0.3 (Fig. 16). In contrast to $\mathrm{BP} / 1 / 816$, which has six postcanines, the maxilla of

1163 NMQR 1702 bears only three or four teeth (Sidor \& Welman, 2003). If BP/1/816 is a juvenile

1164 representative of the same taxon as NMQR 1702, this would imply that the number of post-

1165 canine teeth decreasd during ontogeny, whereas jaw length increased. Though counterintuitive,

1166 such a reduction has been anecdotally hypothesized in gorgonopsians (Sigogneau (1970), who, in

1167 contrast, found that the dental formula remains constant) but dedicated studies are lacking. Two

1168 zygomatic bosses are present in NMQR1702, whereas there is only one in BP/1/816 (Fig. 16).

1169 The supraorbital boss of NMQR 1702 is comparatively thinner and less developed than that of

1170 the Lemurosaurus holotype (Fig. 16). In the holotype the highest point on the skull roof is above

1171 the centre of the orbit, whereas the highest point in NMQR 1702 is behind the orbit (Fig. 16).

1172 The skull roof of NMQR 1702 has a long midline crest extending from the nasal to the parietal

1173 foramen, whereas the holotype of Lemurosaurus pricei has only a little boss at the level of the

1174 orbit (Fig. 16). The pineal boss of NMQR 1702 is a well-defined chimney, whereas that of the

1175 Lemurosaurus holotype is a smooth dome-like structure (Fig. 16). 
1176 In occipital view, the external occipital ridge of NMQR 1702 extends ventrally across the

1177 postparietal and supraoccipital from the skull roof to the foramen magnum. In the holotype, this

1178 ridge is confined to the postparietal. In addition, NMQR 1702 possesses a nubbin-like boss on

1179 the dorsal apex of the lateral temporal fenestra; a low-developed boss on the anteroventral

1180 margin of the temporal fenestra, and two bosses on the zygomatic bar; characters that are absent

1181 on the holotype.

1182 Considering the number and nature of the anatomical differences between $\mathrm{BP} / 1 / 816$ and

1183 NMQR 1702, and given that BP/1/816 might be an adult individual, it is unlikely that these

1184 differences represent intraspecific variation and it is more likely that NMQR 1702 represents a

1185 different taxon, distinct from Lemurosaurus pricei. The creation of a new nomenclatorial

1186 combination for NMQR 1702 might be taken into consideration in the future.

1187 Similarly, MAL 290, the holotype of Lende Chiweta, which has relatively large orbits in

1188 comparison to the skull length, was previously identified as a possible juvenile (Kruger et al.,

1189 2015). However, it displays well-developed cranial ornamentation and no visible replacement

1190 caniniforms, which are probably indicative of an adult, very mature age (Fig. 17). Along with

1191 BP1/816, MAL 290 suggests that a paedomorphic cranial morphology (large orbit, short snout)

1192 might have been common among adult burnetiamorphs. As discussed above, large orbits may

1193 have been an adaptation to a nocturnal lifestyle in biarmosuchians (Angielczyk \& Schmitz,

1194 2014), but further study will be necessary to better understand the cause of such dramatic

1195 interspecific allometry.

1196

\section{Conclusion}


1198 The discovery of new immature biarmosuchian cranial material and its study has lead to a

1199 better understanding of ontogenetic variation within the clade. We found that the presence of

1200 multiple centres of ossification in the bones of the skull roof is unique to juvenile

1201 biarmosuchians and a reliable indicator of an immature individual in addition to the presence of a

1202 replacement canine, poorly developed cranial ornamentation and pachyostosis, and poorly

1203 ossified braincase and bony labyrinth. In contrast, the reliability of other previously recognised

1204 possible juvenile characters, such as the presence of relatively large orbits, is questioned. Some

1205 of these juvenile features are currently used in character matrices for phylogenetic analysis and

1206 need to be reconsidered in light of the ontogenetic and intraspecific variations highlighted in this

1207 contribution.

1208

1209 Acknowledgements

1210 We acknowledge the assistance of Charlton Dube and Sifelani Jirah with preparation,

1211 Kudakwashe Jakata for performing the scans, and the Council for Geosciences in Pretoria, the

1212 National Museum in Bloemfontein, the Rubidge Collection and the Iziko South African Museum

1213 for the loan of specimens. We express our gratitude for financial assistance to the National

1214 Research Foundation (NRF), South Africa; the Paleontological Scientific Trust (PAST) and its

1215 Scatterlings of Africa program; the African Origins Program (AOP) of the National Research

1216 Foundation (NRF), South Africa, and the University of the Witwatersrand, Johannesburg, South

1217 Africa. We are grateful to Paul Tafforeau at the European Synchrotron Radiation Facility

1218 (ESRF), Grenoble, France, for providing assistance in using beamline ID17. We acknowledge

1219 Gilles Cuny, Jérémy Martin, Nour-Eddine Jalil and Christian Sidor for their constructive 
1220 comments on the study and the manuscript. We thank Christian Kammerer, Luisa Pusch, Claudia

1221 Marsicano, Jörg Fröbisch and an anonymous reviewer for editing and reviewing the manuscript.

\section{References}

1223 Abdala F, Flores DA, Giannini NP. 2001. Postweaning ontogeny of the skull of Didelphis

1224 albiventris. Journal of Mammalogy 82:190-200.

1225 Abdala F, Jasinoski SC, Fernandez V. 2013. Ontogeny of the Early Triassic cynodont

1226 Thrinaxodon liorhinus (Therapsida): dental morphology and replacement. Journal of Vertebrate

1227 Paleontology 33:1408-1431.

1228 Angielczyk KD, Schmitz L. 2014. Nocturnality in synapsids predates the origin of mammals by

1229 over 100 million years. Proceedings of the Royal Society of London B: Biological Sciences

$1230 \quad 281: 20141642$.

1231 Bellary SS, Steinberg A, Mirzayan N, Shirak M, Tubbs RS, Cohen-Gadol AA, Loukas M. 2013.

1232 Wormian bones: a review. Clinical Anatomy 26:922-927.

1233 Benoit J. 2019. Parental care or opportunism in South African Triassic cynodonts? South African

1234 Journal of Science 115:1-2.

1235 Benoit J, Fernandez V, Manger PR, Rubidge BS. 2017a. Endocranial casts of pre-mammalian

1236 therapsids reveal an unexpected neurological diversity at the deep evolutionary root of mammals.

1237 Brain, behavior and evolution 90:311-333.

1238 Benoit J, Manger PR, Fernandez V, Rubidge BS. 2016. Cranial Bosses of Choerosaurus dejageri

1239 (Therapsida, Therocephalia): Earliest Evidence of Cranial Display Structures in Eutheriodonts.

$1240 \quad$ PLoS One 11:e161457.

1241 Benoit J, Manger PR, Fernandez V, Rubidge BS. 2017b. The bony labyrinth of late Permian

1242 Biarmosuchia: palaeobiology and diversity in non-mammalian Therapsida.

1243 Boonstra LD. 1962. The dentition of the titanosuchian dinocephalians. Annals of the South

1244 African Museum 46:57-112.

1245 Boonstra LD, Broom R. 1936. The cranial morphology of some titanosuchid deinocephalians.

1246 American Museum of Natural History.

1247 Boos ADS, Kammerer CF, Schultz CL, Neto VP. 2015. A tapinocephalid dinocephalian

1248 (Synapsida, Therapsida) from the Rio do Rasto Formation (Paraná Basin, Brazil): taxonomic,

1249 ontogenetic and biostratigraphic considerations. Journal of South American Earth Sciences

$1250 \quad 63: 375-384$.

1251 Broom R. 1913. On some new carnivorous therapsids. Bulletin of the American Museum of

1252 Natural History 32.

1253 Broom R. 1942. Evidence of a new sub-order of mammal-like reptiles. South African Museums

1254 Association Bulletin 2:386.

1255 Broom R. 1949. New fossil reptile genera from the Bernard Price collection. Annals of the

1256 Transvaal Museum 21:187-194.

1257 de Buffrénil V, Rage J-C. 1993. La «pachyostose» vertébrale de Simoliophis (Reptilia,

1258 Squamata): données comparatives et considérations fonctionnelles [Pachyostosis of the vertebral

1259 column of Simoliophis (Reptilia: Squamata): comparative data and functional morphology].

1260 Annales de paléontologie 79:315-335.

1261 Cassini GH, Flores DA, Vizcaíno SF. 2015. Postnatal ontogenetic scaling of pampas deer

1262 (Ozotoceros bezoarticus celer: Cervidae) cranial morphology. Mammalia 79:69-79.

Peer) reviewing PDF | (2019:07:39842:2:0:NEW 24 Jun 2021) 
1263 Day MO, Ramezani J, Bowring SA, Sadler PM, Erwin DH, Abdala F, Rubidge BS. 2015. When

1264 and how did the terrestrial mid-Permian mass extinction occur? Evidence from the tetrapod

1265 record of the Karoo Basin, South Africa. In: Proc. R. Soc. B. The Royal Society, 20150834.

1266 Day MO, Rubidge BS. 2019. Biesiespoort revisited: a case study on the relationship between

1267 tetrapod assemblage zones and Beaufort lithostratigraphy south of Victoria West. Palaeontologia

1268 Africana 53:55-65.

1269 Day MO, Rubidge BS, Abdala F. 2016. A new mid-Permian burnetiamorph therapsid from the

1270 Main Karoo Basin of South Africa and a phylogenetic review of Burnetiamorpha. Acta

1271 Palaeontologica Polonica 61:701-719.

1272 Day MO, Smith RMH. 2020. Biostratigraphy of the Endothiodon Assemblage Zone (Beaufort

1273 Group, Karoo Supergroup), South Africa. South African Journal of Geology 123:165-180.

1274 Day MO, Smith RMH, Benoit J, Fernandez V, Rubidge BS. 2018. A new species of Burnetiid

1275 (Therapsida, Burnetiamorpha) from the early Wuchiapingian of South Africa and implications

1276 for the evolutionary ecology of the family Burnetiidae. Papers in Palaeontology:1-23.

1277 Duhamel A, Benoit J, Day MO, Rubidge BS. 2016. A new juvenile burnetiamorph (Therapsida:

1278 Biarmosuchia) skull from the Beaufort Group, South Africa and its role in a revision of

1279 Lemurosaurus pricei Broom, 1949. The Palaetolongical Association Annual Meeting with

1280 Program 54

1281 Duhamel A, Benoit J, Rubidge BS. 2018. Juvenile Biarmosuchians from the Karoo Beaufort

1282 Group Shed New Light on Basal Therapsid Ontogeny. Palaontological Society of Southern

1283 Africa Annual Meeting

1284 Ekdale EG. 2010. Ontogenetic variation in the bony labyrinth of Monodelphis domestica

1285 (Mammalia: Marsupialia) following ossification of the inner ear cavities. The Anatomical Record

1286 293:1896-1912.

1287 Estes R. 1961. Cranial anatomy of the cynodont reptile Thrinaxodon liorhinus. Bulletin of the

1288 Museum of Comparative Zoology at Harvard College.

1289 Fröbisch J. 2005. A double-tusked dicynodont therapsid-pathology, variability, or a new species?

1290 In: Journal of Vertebrate Paleontology. 61A-61A.

1291 Fröbisch J, Reisz RR. 2008. A new species of Emydops (Synapsida, Anomodontia) and a

1292 discussion of dental variability and pathology in dicynodonts. Journal of Vertebrate

1293 Paleontology 28:770-787.

1294 Gates TA, Organ C, Zanno LE. 2016. Bony cranial ornamentation linked to rapid evolution of

1295 gigantic theropod dinosaurs. Nature communications 7:1-10.

1296 Giannini NP, Segura V, Giannini MI, Flores D. 2010. A quantitative approach to the cranial

1297 ontogeny of the puma. Mammalian Biology-Zeitschrift für Säugetierkunde 75:547-554.

1298 Giere P, Möller L, Hilger A, Paulke A, Riesemeier H, Kuehbacher M. 2010. Modern and classic

1299 approaches towards revealing the orbital mosaic in the common shrew Sorex araneus Linnaeus,

13001758 (Soricidae, Lipotyphla, Mammalia). Zoosystematics and Evolution 86:343-350.

1301 Gregory WK, Broom R. 1926. The skeleton of Moschops capensis broom: A Dinocephalian

1302 reptile from the Permian of South Africa. The American Museum of Natural History.

1303 Hall MI. 2008. The anatomical relationships between the avian eye, orbit and sclerotic ring:

1304 implications for inferring activity patterns in extinct birds. Journal of Anatomy 212:781-794.

1305 Hanihara T, Ishida H. 2001. Os incae: variation in frequency in major human population groups.

1306 Journal of Anatomy 198:137-152.

1307 Heesy CP, Hall MI. 2010. The nocturnal bottleneck and the evolution of mammalian vision.

1308 Brain, behavior and evolution 75:195-203.

Peer) reviewing PDF | (2019:07:39842:2:0:NEW 24 Jun 2021) 
1309 Hoffman EA, Rowe TB. 2018. Jurassic stem-mammal perinates and the origin of mammalian

1310 reproduction and growth. Nature 561:104-108.

1311 Hopson JA. 1964. Tooth replacement in cynodont, dicynodont and therocephalian reptiles. In:

1312 Proceedings of the Zoological Society of London. 625-654.

1313 Hopson J, Barghusen H. 1986. An analysis of therapsid relationships. The ecology and biology of

1314 mammal-like reptiles:83-106.

1315 Horner JR, Goodwin MB. 2009. Extreme cranial ontogeny in the Upper Cretaceous dinosaur

1316 Pachycephalosaurus. PLoS One 4:e7626.

1317 Hrdlička A. 1903. Divisions of the Parietal Bone in Man \& Other Mammals. order of the

1318 Trustees, American Museum of Natural History.

1319 Huttenlocker AK, Abdala F. 2015. Revision of the first therocephalian, Theriognathus Owen

1320 (Therapsida: Whaitsiidae), and implications for cranial ontogeny and allometry in

1321 nonmammaliaform eutheriodonts. Journal of Paleontology 89:645-664.

1322 Ivakhnenko MF. 1999. Biarmosuches from the Ocher faunal assemblage of eastern Europe.

1323 Paleontological Journal 33:289-296.

1324 Ivakhnenko MF. 2003. Eotherapsids from the east European placket (Late Permian).

1325 Paleontological Journal 37.

1326 Ivakhnenko MF. 2008. Cranial morphology and evolution of Permian Dinomorpha

1327 (Eotherapsida) of eastern Europe. Paleontological Journal 42:859-995.

1328 Iwaniuk AN, Heesy CP, Hall MI. 2010. Morphometrics of the eyes and orbits of the nocturnal

1329 swallow-tailed gull (Creagrus furcatus). Canadian journal of zoology 88:855-865.

1330 Jasinoski SC, Abdala F. 2017a. Cranial ontogeny of the Early Triassic basal cynodont

1331 Galesaurus planiceps. The Anatomical Record 300:353-381.

1332 Jasinoski SC, Abdala F. 2017b. Aggregations and parental care in the Early Triassic basal

1333 cynodonts Galesaurus planiceps and Thrinaxodon liorhinus. PeerJ 5:e2875.

1334 Jasinoski SC, Abdala F, Fernandez V. 2015. Ontogeny of the Early Triassic cynodont

1335 Thrinaxodon liorhinus (Therapsida): cranial morphology. The Anatomical Record 298:1440-

13361464.

1337 Jasinoski SC, Chinsamy-Turan A. 2012. Biological inferences of the cranial microstructure of

1338 the dicynodonts Oudenodon and Lystrosaurus. Forerunners of Mammals-Radiation, Histology,

1339 Biology. Indiana University Press, Bloomington:149-176.

1340 Jasinoski SC, Cluver MA, Chinsamy A, Reddy BD. 2014. Anatomical plasticity in the snout of

1341 Lystrosaurus. In: Early evolutionary history of the Synapsida. Springer, 139-149.

1342 Jeffery N, Spoor F. 2004. Prenatal growth and development of the modern human labyrinth.

1343 Journal of Anatomy 204:71-92.

1344 Jinnah ZA, Rubidge B. 2007. A double-tusked dicynodont and its biostratigraphic significance.

1345 South African Journal of Science 103:51-53.

1346 Kammerer CF. 2011. Systematics of the Anteosauria (Therapsida: Dinocephalia). Journal of

1347 Systematic Palaeontology 9:261-304.

1348 Kammerer CF. 2016. Two unrecognised burnetiamorph specimens from historic Karoo

1349 collections. Palaeontologia Africana 50:64-75.

1350 Kammerer CF, Sidor CA. 2021. A new burnetiid from the middle Permian of Zambia and a

1351 reanalysis of burnetiamorph relationships. Papers in Palaeontology.

1352 Kemp TS. 2006. The origin and early radiation of the therapsid mammal-like reptiles: a

1353 palaeobiological hypothesis. Journal of evolutionary biology 19:1231-1247.

1354 Kermack KA. 1956. Tooth replacement in mammal-like reptiles of the suborders Gorgonopsia

Peer] reviewing PDF | (2019:07:39842:2:0:NEW 24 Jun 2021) 
1355 and Therocephalia. Philosophical Transactions of the Royal Society of London. Series B,

1356 Biological Sciences 240:95-133.

1357 Kermack D. 1984. New prosauropod material from South Wales. Zoological Journal of the

1358 Linnean Society 82:101-117.

1359 Koyabu D, Maier W, Sánchez-Villagra MR. 2012. Paleontological and developmental evidence

1360 resolve the homology and dual embryonic origin of a mammalian skull bone, the interparietal.

1361 Proceedings of the National Academy of Sciences 109:14075-14080.

1362 Koyabu D, Werneburg I, Morimoto N, Zollikofer CP, Forasiepi AM, Endo H, Kimura J,

1363 Ohdachi SD, Son NT, Sánchez-Villagra MR. 2014. Mammalian skull heterochrony reveals

1364 modular evolution and a link between cranial development and brain size. Nature

1365 communications 5:1-9.

1366 Kraaijeveld K, Kraaijeveld-Smit FJ, Komdeur J. 2007. The evolution of mutual ornamentation.

1367 Animal Behaviour 74:657-677.

1368 Krone IW, Kammerer CF, Angielczyk KD. 2019. The many faces of synapsid cranial allometry.

1369 Paleobiology 45:531-545.

1370 Kruger A, Rubidge BS, Abdala F. 2017. A juvenile specimen of Anteosaurus magnificus

1371 Watson, 1921 (Therapsida: Dinocephalia) from the South African Karoo, and its implications for

1372 understanding dinocephalian ontogeny. Journal of Systematic Palaeontology 16:139-158.

1373 Kruger A, Rubidge BS, Abdala F, Chindebvu EG, Jacobs LL. 2015. Lende chiweta, a new

1374 therapsid from Malawi, and its influence on burnetiamorph phylogeny and biogeography.

1375 Journal of Vertebrate Paleontology 35.

1376 Kulik ZT, Sidor CA. 2019. The original boneheads: histologic analysis of the pachyostotic skull

1377 roof in Permian burnetiamorphs (Therapsida: Biarmosuchia). Journal of Anatomy.

1378 Lande R. 1980. Sexual dimorphism, sexual selection, and adaptation in polygenic characters.

1379 Evolution:292-305.

1380 Lee AH. 2004. Histological organization and its relationship to function in the femur of Alligator

1381 mississippiensis. Journal of Anatomy 204:197-207.

1382 Linton RG. 1906. On some anomalies in the skull of the dog. The Veterinary Journal 62:228-

1383232.

1384 Liu J. 2013. Osteology, ontogeny, and phylogenetic position of Sinophoneus yumenensis

1385 (Therapsida, Dinocephalia) from the Middle Permian Dashankou Fauna of China. Journal of

1386 Vertebrate Paleontology 33:1394-1407.

1387 Liu J, Rubidge B, Li J. 2009. New basal synapsid supports Laurasian origin for therapsids. Acta

1388 Palaeontologica Polonica 54:393-400.

1389 Marilao LM, Kulik ZT, Sidor CA. 2020. Histology of the preparietal: a neomorphic cranial

1390 element in dicynodont therapsids. Journal of Vertebrate Paleontology:e1770775.

1391 Marti B, Sirinelli D, Maurin L, Carpentier E. 2013. Wormian bones in a general paediatric

1392 population. Diagnostic and interventional imaging 94:428-432.

1393 da Mata JR, da Mata FR, Aversi-Ferreira TA. 2010. Analysis of bone variations of the occipital

1394 bone in man. International Journal of Morphology 28:243-248.

1395 Mirone A, Brun E, Gouillart E, Tafforeau P, Kieffer J. 2014. The PyHST2 hybrid distributed

1396 code for high speed tomographic reconstruction with iterative reconstruction and a priori

1397 knowledge capabilities. Nuclear Instruments and Methods in Physics Research Section B: Beam

1398 Interactions with Materials and Atoms 324:41-48.

1399 Neenan JM, Chapelle KE, Fernandez V, Choiniere JN. 2019. Ontogeny of the Massospondylus

1400 labyrinth: implications for locomotory shifts in a basal sauropodomorph dinosaur. Palaeontology

PeerJ reviewing PDF | (2019:07:39842:2:0:NEW 24 Jun 2021) 
$1401 \quad 62: 255-265$.

1402 Neumann S. 2020. Taxonomic revision of the short-snouted tapinocephalid dinocephalia

1403 (Amniota- Therapsida)- The key to understanding Middle Permian tetrapod biodiversity.

1404 University of the Witwatersrand.

1405 Ngwenya A, Patzke N, Spocter MA, Kruger J-L, Dell L-A, Chawana R, Mazengenya P, Billings

1406 BK, Olaleye O, Herculano-Houzel S. 2013. The continuously growing central nervous system of

1407 the Nile crocodile (Crocodylus niloticus). The Anatomical Record 296:1489-1500.

1408 Nikolova SY, Toneva DH, Yordanov YA, Lazarov NE. 2014a. Multiple Wormian bones and

1409 their relation with definite pathological conditions in a case of an adult cranium.

1410 Anthropologischer Anzeiger 71:169-190.

1411 Nikolova S, Toneva D, Yordanov Y, Lazarov N. 2014b. Variations in the squamous part of the

1412 occipital bone in medieval and contemporary cranial series from Bulgaria. Folia Morphologica

1413 73:429-438.

1414 Norton L. 2020. Tooth replacement patterns in Eutheriodontia (Synapsida, Therapsida) from the

1415 South African Karoo Supergroup. University of the Witwatersrand.

1416 Norton LA, Abdala F, Rubidge BS, Botha J. 2020. Tooth replacement patterns in the Early

1417 Triassic epicynodont Galesaurus planiceps (Therapsida, Cynodontia). Plos one 15:e0243985.

1418 Paganin D, Mayo SC, Gureyev TE, Miller PR, Wilkins SW. 2002. Simultaneous phase and

1419 amplitude extraction from a single defocused image of a homogeneous object. Journal of

1420 Microscopy 206:33-40.

1421 Reynoso V-H, Clark JM. 1998. A dwarf sphenodontian from the Jurassic La Boca formation of

1422 Tamaulipas, México. Journal of Vertebrate Paleontology 18:333-339.

1423 Rieppel O. 1992. The skeleton of a juvenile Lanthanotus (Varanoidea). Amphibia-Reptilia

1424 13:27-34.

1425 Romer AS, Price LW. 1940. Review of the Pelycosauria. Geological Society of America Special

1426 Papers 28:1-534.

1427 Rubidge BS, Kitching JW. 2003. A new burnetiamorph (Therapsida: Biarmosuchia) from the

1428 lower Beaufort Group of South Africa. Palaeontology 46:199-210.

1429 Rubidge BS, Sidor CA. 2001. Evolutionary patterns among Permo-Triassic therapsids. Annual

1430 Review of Ecology and Systematics 32:449-480.

1431 Rubidge BS, Sidor CA. 2002. On the cranial morphology of the basal therapsids Burnetia and

1432 Proburnetia (Therapsida: Burnetiidae). Journal of Vertebrate Paleontology 22:257-267.

1433 Rubidge BS, Sidor CA, Modesto SP. 2006. A new burnetiamorph (Therapsida: Biarmosuchia)

1434 from the middle Permian of South Africa. Journal of Paleontology 80:740-749.

1435 Sánchez-Villagra MR, Forasiepi AM. 2017. On the development of the chondrocranium and the

1436 histological anatomy of the head in perinatal stages of marsupial mammals. Zoological letters

$1437 \quad 3: 1$.

1438 Schaefer M, Black SM, Schaefer MC, Scheuer L. 2009. Juvenile osteology. Elsevier.

1439 Schmitz L, Motani R. 2011. Nocturnality in dinosaurs inferred from scleral ring and orbit

1440 morphology. Science 332:705-708.

1441 Schmitz L, Wainwright PC. 2011. Nocturnality constrains morphological and functional

1442 diversity in the eyes of reef fishes. BMC Evolutionary Biology 11:338.

1443 Schott RK, Evans DC, Goodwin MB, Horner JR, Brown CM, Longrich NR. 2011. Cranial

1444 ontogeny in Stegoceras validum (Dinosauria: Pachycephalosauria): a quantitative model of

1445 pachycephalosaur dome growth and variation. PLoS One 6:e21092.

1446 Sekiya T, Dong Z. 2010. A New Juvenile Specimen of Lufengosaurus Huenei Young, 1941

Peer] reviewing PDF | (2019:07:39842:2:0:NEW 24 Jun 2021) 
1447 (Dinosauria: Prosauropoda) from the Lower Jurassic Lower Lufeng Formation of Yunnan, 1448 Southwest China. Acta Geologica Sinica-English Edition 84:11-21.

1449 Shapiro R. 1972. Anomalous parietal sutures and the bipartite parietal bone. American Journal of 1450 Roentgenology 115:569-577.

1451 Shapiro R, Robinson F. 1976. The os incae. American Journal of Roentgenology 127:469-471.

1452 Sidor CA. 2003. The naris and palate of Lycaenodon longiceps (Therapsida: Biarmosuchia), with 1453 comments on their early evolution in the therapsida. Journal of Paleontology 77:977-984.

1454 Sidor CA, Hopson JA, Keyser AW. 2004. A new burnetiamorph therapsid from the Teekloof

1455 Formation, Permian, of South Africa. Journal of Vertebrate Paleontology 24:938-950.

1456 Sidor CA, Rubidge BS. 2006. Herpetoskylax hopsoni, a new biarmosuchian (Therapsida:

1457 Biarmosuchia) from the Beaufort Group of South Africa. Amniote paleobiology: Perspectives on 1458 the evolution of mammals, birds, and reptiles:76-113.

1459 Sidor CA, Smith RM. 2007. A second burnetiamorph therapsid from the Permian Teekloof

1460 Formation of South Africa and its associated fauna. Journal of Vertebrate Paleontology 27:4201461430.

1462 Sidor CA, Welman J. 2003. A second specimen of Lemurosaurus pricei (Therapsida:

1463 Burnetiamorpha). Journal of Vertebrate Paleontology 23:631-642.

1464 Sigogneau D. 1970. Révision systématique des Gorgonopsiens Sud-Africains [Systematic

1465 revision of the south african gorgonopsians]. Éditions du Centre national de la recherche 1466 scientifique, Paris (in French).

1467 Sigogneau-Russell D. 1989. Theriodontia 1: Phthinosuchia, Eotitanosuchia, Gorgonopsia.

1468 Gustav Fischer Verlag, Stuttgart.

1469 Smith RM, Rubidge BS, Sidor CA. 2006. A new burnetiid (Therapsida: Biarmosuchia) from the

1470 Upper Permian of South Africa and its biogeographic implications. Journal of Vertebrate

1471 Paleontology 26:331-343.

1472 Spiekman SN, Werneburg I. 2017. Patterns in the bony skull development of marsupials: high

1473 variation in onset of ossification and conserved regions of bone contact. Scientific Reports

$1474 \quad 7: 43197$.

1475 Thanapaisal C, Duangthongpon P, Kitkuandee A, Chaiciwamongkol K, Morthong V. 2013.

1476 Incidence and variation of interpretably bone (os incae) in northeastern Thailand. Journal of the

1477 Medical Association of Thailand 96:S117-S123.

1478 Van den Heever JA. 1980. On the validity of the therocephalian Family Lycosuchidae (Reptilia, 1479 Therapsida). South African Museum.

1480 Van Heerden J. 1972. Interspecific variation and growth changes in the cynodont reptile

1481 Thrinaxodon liorhinus. Navorsinge van die Nasionale Museum Bloemfontein 2:307-347.

1482 Whitney MR, Sidor CA. 2019. Histological and developmental insights into the herbivorous

1483 dentition of tapinocephalid therapsids. PloS One 14:e0223860.

1484 Wu JK, Goodrich JT, Amadi CC, Miller T, Mulliken JB, Shanske AL. 2011. Interparietal bone

1485 (Os Incae) in craniosynostosis. American Journal of Medical Genetics Part A 155:287-294. 


\section{Figure 1}

Holotype of Rubidgina angusticeps, here considered Biarmosuchia indet., RC 55.

Photograph (left) and 3D rendering (right). (A) Right lateral view. (B) Left lateral view. (C) Occipital view. (D) Dorsal view. (E) Ventral view. Anatomical Abbreviations -ang, angular; art, articular; aso, anterior extension of the supraoccipital; bo, basioccipital; c, caniniform tooth; co, occipital condyle; cor, coronoid; d, dentary; ect, ectopterygoid; eo, exoccipital; f, frontal; fe, temporal fenestra; fm, foramen magnum; i, incisiform tooth; j, jugal; I, lacrimal; m, maxilla; $\mathbf{n}$, nasal; o, orbit; op, opisthotic; $\mathbf{p}$, parietal; pa, anterior portion of the parietal; pac, caudal portion of the parietal; pal, palatine; pal t $\mathbf{t}$ palate teeth; pao, paroccipital process; part, pre-articular; pbs, parabasisphenoid; pc, postcanine; pf, postfrontal; pif, pineal foramen; pl, lateral portion of the parietal; pm, premaxilla; po, postorbital; pp, postparietal; prf, prefrontal; pro, prootic; prp, preparietal; pt, pterygoids; ptf, post-temporal fenestra; q, quadrate; qj, quadratojugal; rt, replacement tooth; sb, supraorbital boss; scl, sclerotic ring; smx, septomaxilla; so, supraoccipital; spl, splenial; st, stapes; sq, squamosal; sur surangular; $\mathbf{t}$, tabular; $\mathbf{v}$, vomer. Pictures by A. Duhamel. 3D reconstructions were made by A. Duhamel and belong to the University of the Witwatersrand. Scale bar $=1 \mathrm{~cm}$. 


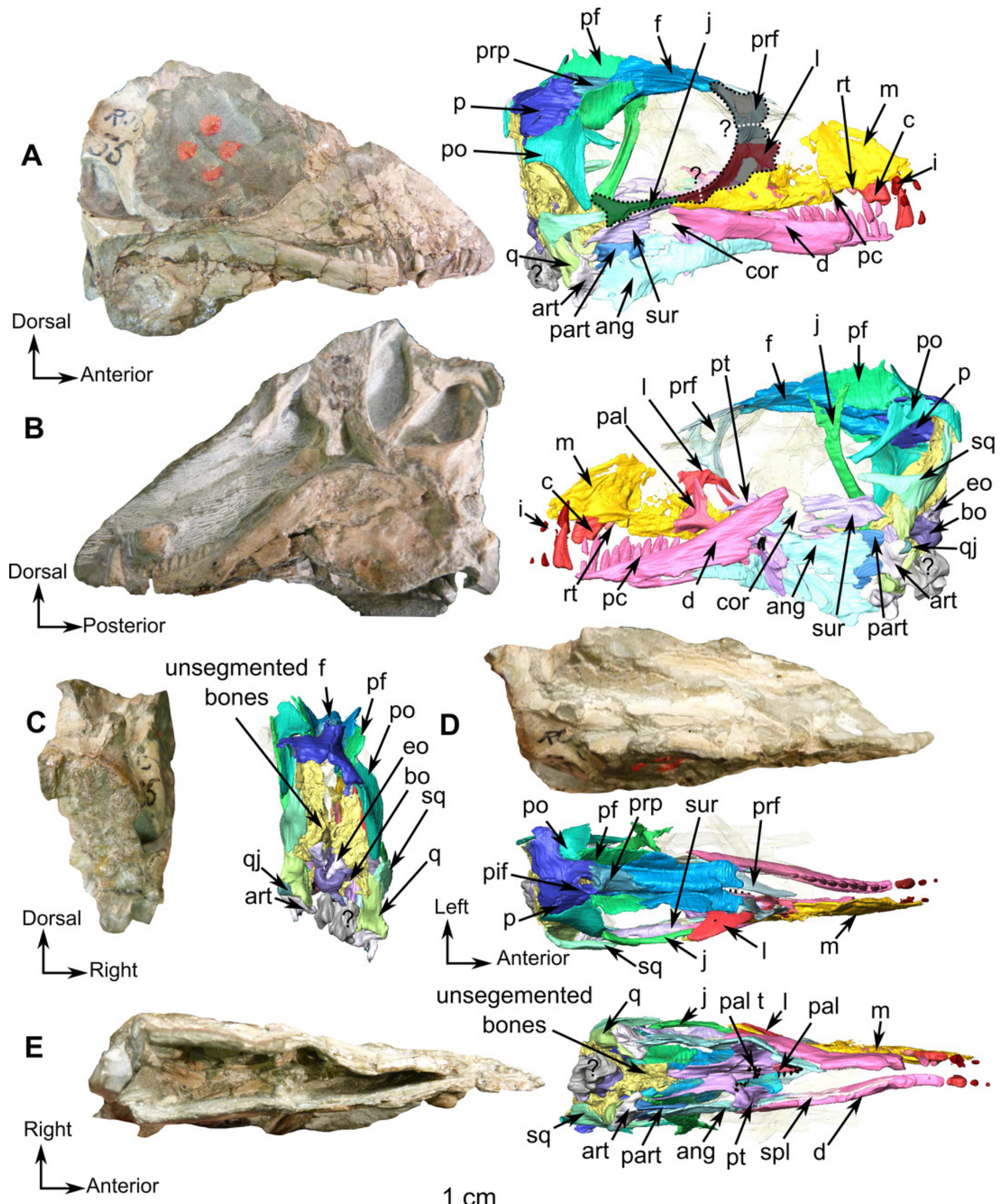




\section{Figure 2}

Holotype of Rubidgina angusticeps, here considered Biarmosuchia indet., RC 55.

3D rendering of the lateral portion of the skull. (A) Right lateral view. (B) Medial view. (C) Ventral view. (D) Dorsal view. (E) Anterior view. (F) Occipital view. Anatomical Abbreviations -ang, angular; art, articular; aso, anterior extension of the supraoccipital; bo, basioccipital; c, caniniform tooth; co, occipital condyle; cor, coronoid; d, dentary; ect, ectopterygoid; eo, exoccipital; f, frontal; fe, temporal fenestra; fm, foramen magnum; i, incisiform tooth; j, jugal; I, lacrimal; m, maxilla; $\mathbf{n}$, nasal; o, orbit; op, opisthotic; $\mathbf{p}$, parietal; pa, anterior portion of the parietal; pac, caudal portion of the parietal; pal, palatine; pal $\mathbf{t}$, palate teeth; pao, paroccipital process; part, pre-articular; pbs, parabasisphenoid; pc, postcanine; pf, postfrontal; pif, pineal foramen; pl, lateral portion of the parietal; pm, premaxilla; po, postorbital; pp, postparietal; prf, prefrontal; pro, prootic; prp, preparietal; pt, pterygoids; ptf, post-temporal fenestra; q, quadrate; qj, quadratojugal; rt, replacement tooth; sb, supraorbital boss; scl, sclerotic ring; smx, septomaxilla; so, supraoccipital; spl, splenial; st, stapes; sq, squamosal; sur surangular; t, tabular; $\mathbf{v}$, vomer. 3D reconstructions were made by A. Duhamel and belong to the University of the Witwatersrand. Scale bar $=1 \mathrm{~cm}$. 

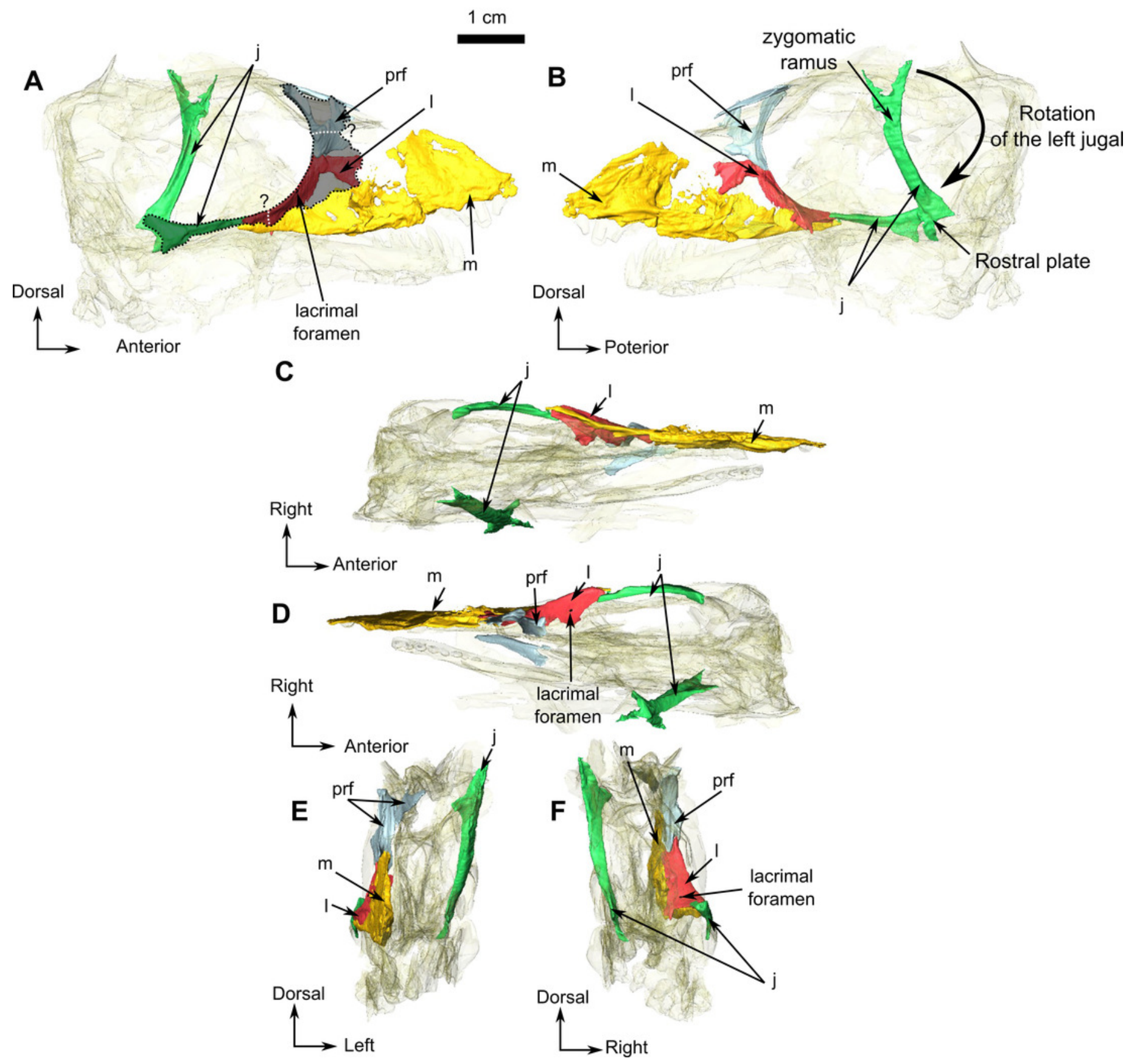


\section{Figure 3}

Holotype of Rubidgina angusticeps, here considered Biarmosuchia indet., RC 55.

3D rendering of the dorsal portion of the skull roof of RC 55. (A) Right lateral view. (B) Left lateral view. (C) Dorsal view. (D) Ventral view. (E) Anterior view. (F) Occipital view. Anatomical Abbreviations -ang, angular; art, articular; aso, anterior extension of the supraoccipital; bo, basioccipital; c, caniniform tooth; co, occipital condyle; cor, coronoid; d, dentary; ect, ectopterygoid; eo, exoccipital; f, frontal; fe, temporal fenestra; fm, foramen magnum; i, incisiform tooth; j, jugal; I, lacrimal; $\mathbf{m}$, maxilla; $\mathbf{n}$, nasal; o, orbit; op, opisthotic; p. parietal; pa, anterior portion of the parietal; pac, caudal portion of the parietal; pal, palatine; pal t t, palate teeth; pao, paroccipital process; part, pre-articular; pbs, parabasisphenoid; pc, postcanine; pf, postfrontal; pif, pineal foramen; pl, lateral portion of the parietal; pm, premaxilla; po, postorbital; pp, postparietal; prf, prefrontal; pro, prootic; prp, preparietal; pt, pterygoids; ptf, post-temporal fenestra; q, quadrate; qj, quadratojugal; rt, replacement tooth; sb, supraorbital boss; scl, sclerotic ring; smx, septomaxilla; so, supraoccipital; spl, splenial; st, stapes; sq, squamosal; sur surangular; t, tabular; v, vomer. $3 \mathrm{D}$ reconstructions were made by $\mathrm{A}$. Duhamel and belong to the University of the Witwatersrand. Scale bar $=1 \mathrm{~cm}$. 


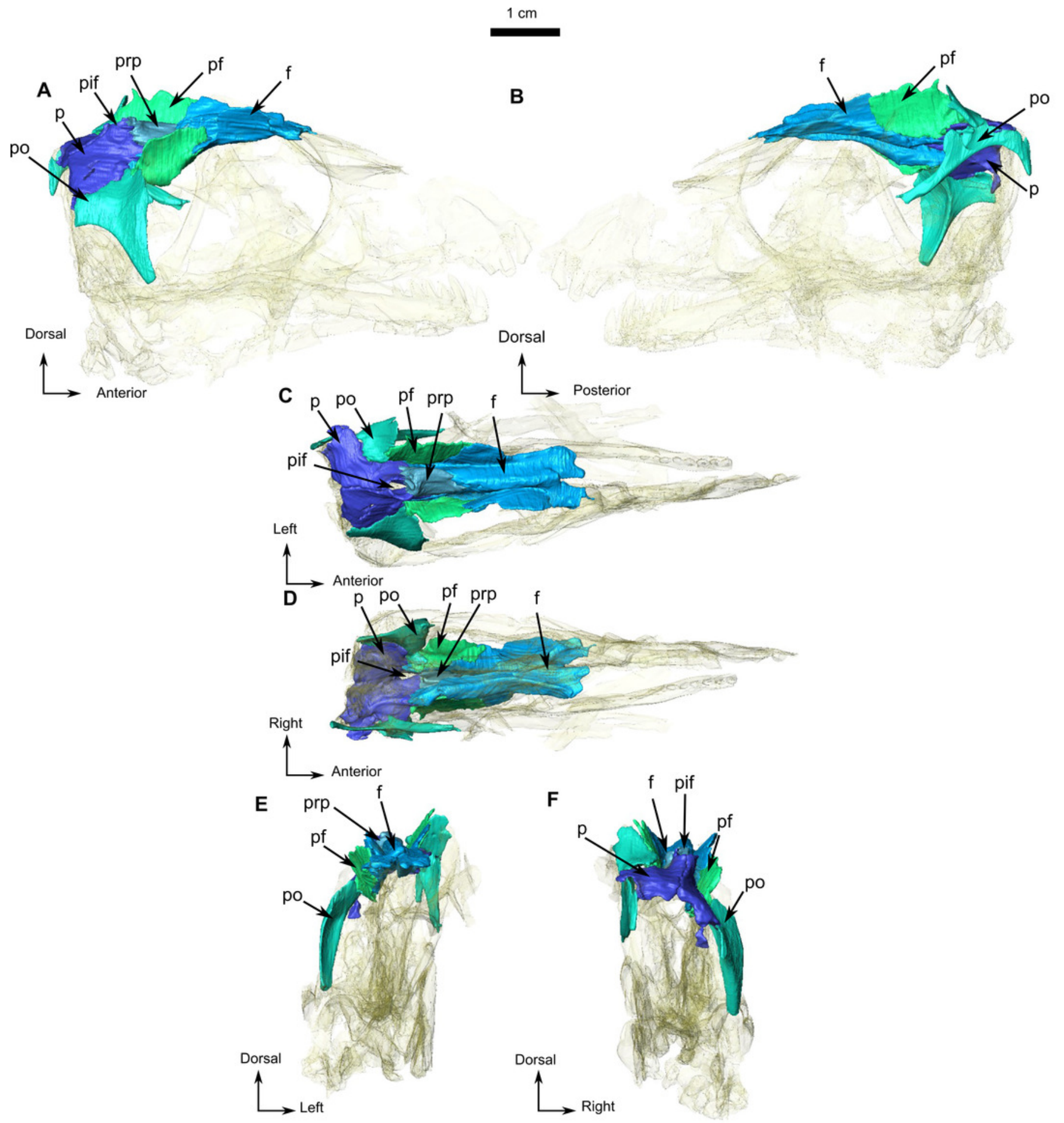




\section{Figure 4}

Holotype of Rubidgina angusticeps, here considered Biarmosuchia indet., RC 55.

3D rendering of the occipital portion of the skull of RC 55. (A) Left lateral view. (B) Right lateral view. (C) Ventral view. (D) Dorsal view. (E) Occipital view. (F) Anterior view. Anatomical Abbreviations -ang, angular; art, articular; aso, anterior extension of the supraoccipital; bo, basioccipital; c, caniniform tooth; co, occipital condyle; cor, coronoid; d, dentary; ect, ectopterygoid; eo, exoccipital; f, frontal; fe, temporal fenestra; fm, foramen magnum; i, incisiform tooth; j, jugal; I, lacrimal; $\mathbf{m}$, maxilla; $\mathbf{n}$, nasal; o, orbit; op, opisthotic; p. parietal; pa, anterior portion of the parietal; pac, caudal portion of the parietal; pal, palatine; pal t t, palate teeth; pao, paroccipital process; part, pre-articular; pbs, parabasisphenoid; pc, postcanine; pf, postfrontal; pif, pineal foramen; pl, lateral portion of the parietal; pm, premaxilla; po, postorbital; pp, postparietal; prf, prefrontal; pro, prootic; prp, preparietal; pt, pterygoids; ptf, post-temporal fenestra; q, quadrate; qj, quadratojugal; rt, replacement tooth; sb, supraorbital boss; scl, sclerotic ring; smx, septomaxilla; so, supraoccipital; spl, splenial; st, stapes; sq, squamosal; sur surangular; t, tabular; v, vomer. $3 \mathrm{D}$ reconstructions were made by $\mathrm{A}$. Duhamel and belong to the University of the Witwatersrand. Scale bar $=1 \mathrm{~cm}$. 


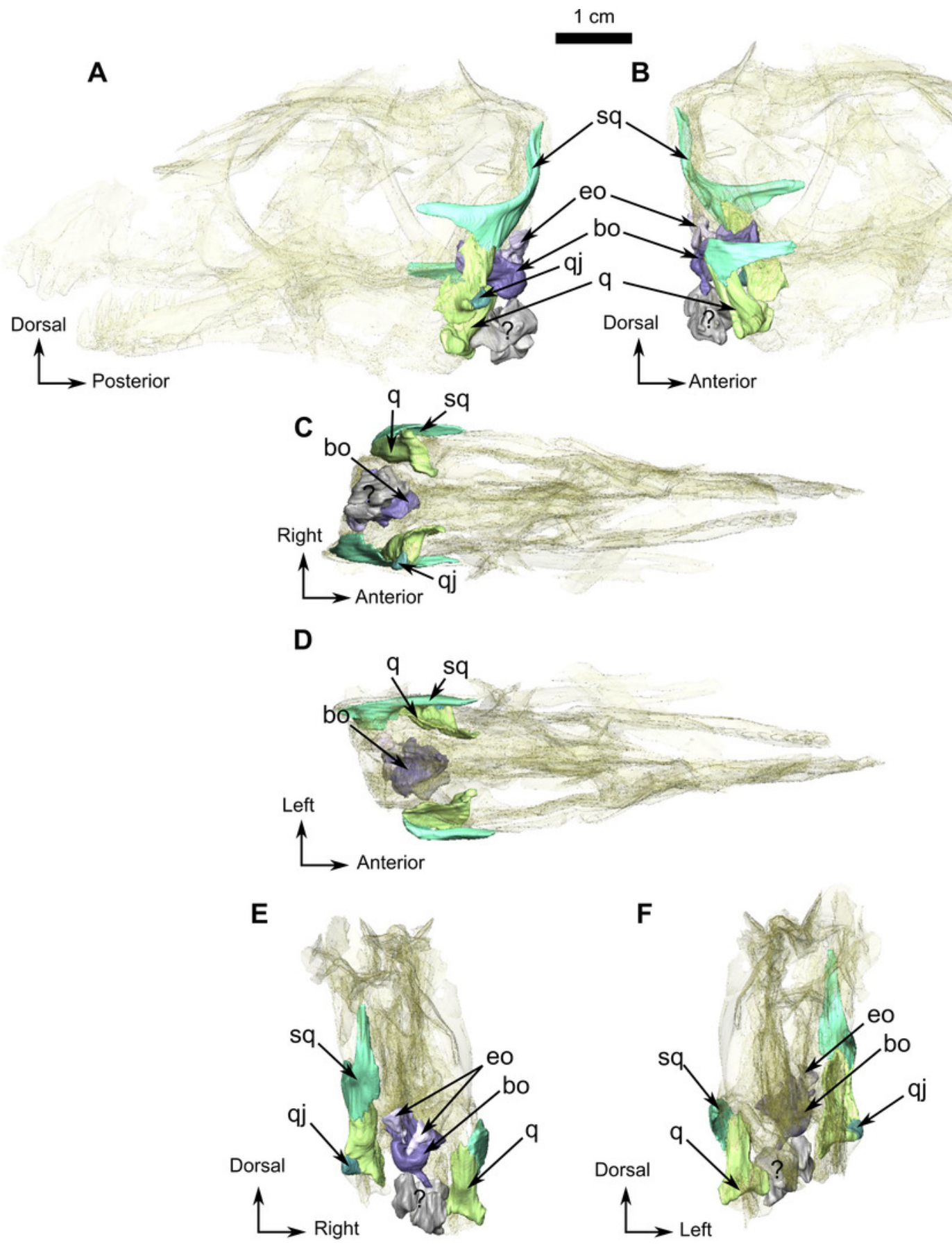




\section{Figure 5}

Holotype of Rubidgina angusticeps, here considered Biarmosuchia indet., RC 55.

3D rendering of the palatine portion of the skull of RC 55. (A) Right lateral view. (B) Left lateral view. (C) Ventral view. (D) Dorsal view. (E) Anterior view. (F) Occipital view. (G) Ventral view with lower jaw. (H) Dorsal view with lower jaw. Anatomical Abbreviations -ang, angular; art, articular; aso, anterior extension of the supraoccipital; bo, basioccipital;

c, caniniform tooth; co, occipital condyle; cor, coronoid; d, dentary; ect, ectopterygoid; eo, exoccipital; $\mathbf{f}$, frontal; fe, temporal fenestra; $\mathbf{f m}$, foramen magnum; $\mathbf{i}$, incisiform tooth; $\mathbf{j}$, jugal; I, lacrimal; m, maxilla; $\mathbf{n}$, nasal; o, orbit; op, opisthotic; p, parietal; pa, anterior portion of the parietal; pac, caudal portion of the parietal; pal, palatine; pal $\mathbf{t}$, palate teeth; pao, paroccipital process; part, pre-articular; pbs, parabasisphenoid; pc, postcanine; pf, postfrontal; pif, pineal foramen; pl, lateral portion of the parietal; pm, premaxilla; po, postorbital; pp, postparietal; prf, prefrontal; pro, prootic; prp, preparietal; pt, pterygoids; ptf, post-temporal fenestra; q, quadrate; qj, quadratojugal; rt, replacement tooth; sb, supraorbital boss; scl, sclerotic ring; smx, septomaxilla; so, supraoccipital; spl, splenial; st, stapes; sq, squamosal; sur surangular; $\mathbf{t}$, tabular; $\mathbf{v}$, vomer. 3D reconstructions were made by A. Duhamel and belong to the University of the Witwatersrand. Scale bar $=1 \mathrm{~cm}$. 


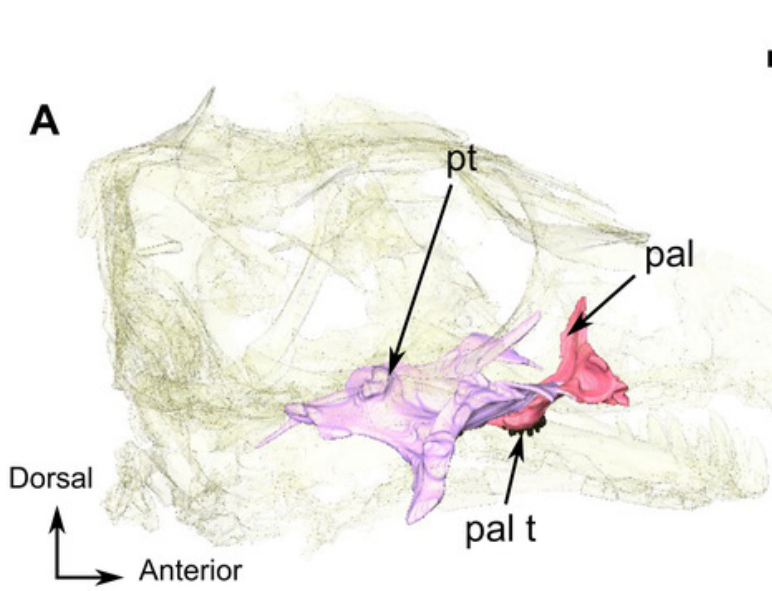

C

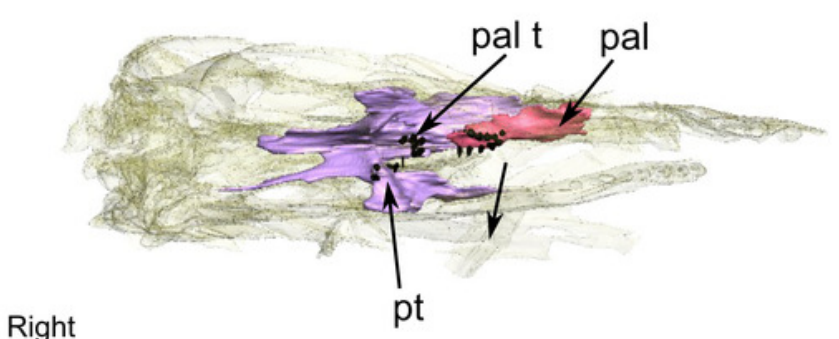

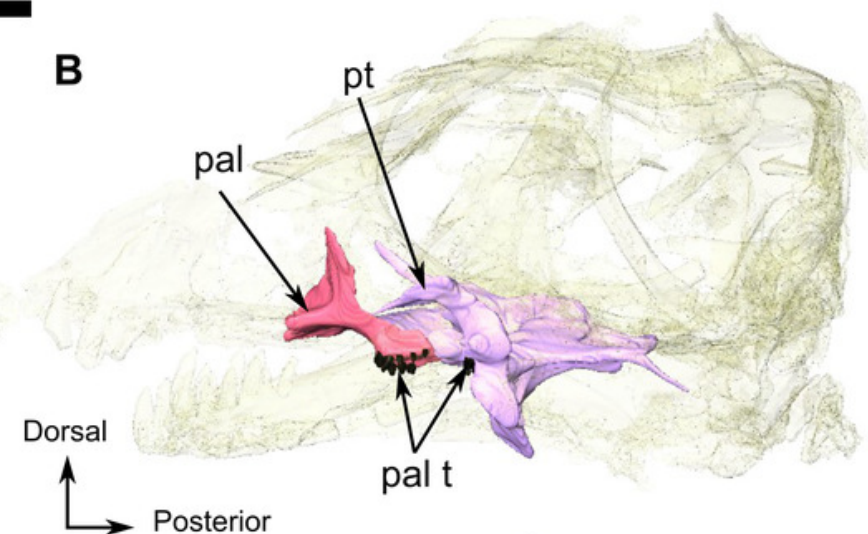

osterior
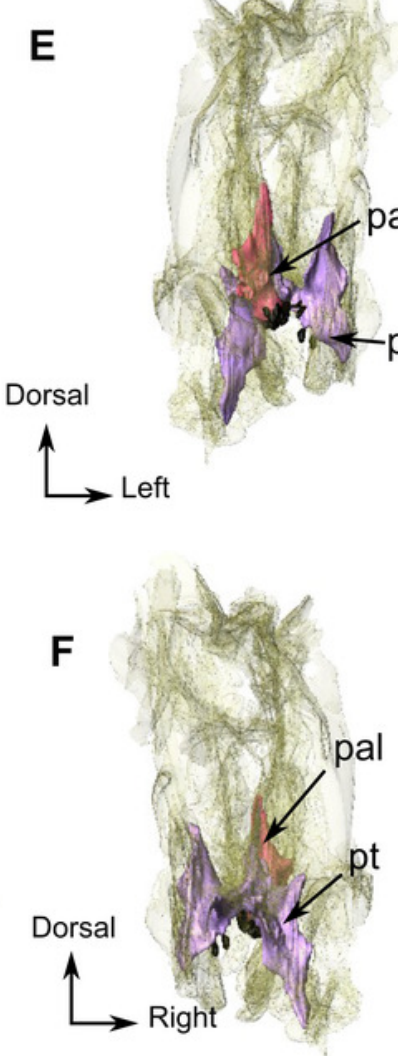


\section{Figure 6}

Holotype of Rubidgina angusticeps, here considered Biarmosuchia indet., RC 55.

3D rendering of the lower jaw of RC 55. (A) Right lateral view. (B) Left lateral view. (C) Dorsal view. (D) Ventral view. (E) Occipital view. Black outlines denote bones situated in the first plan of the figure. Anatomical Abbreviations -ang, angular; art, articular; aso, anterior extension of the supraoccipital; bo, basioccipital; c, caniniform tooth; co, occipital condyle; cor, coronoid; d, dentary; ect, ectopterygoid; eo, exoccipital; f, frontal; fe, temporal fenestra; fm, foramen magnum; i, incisiform tooth; $\mathbf{j}$, jugal; I, lacrimal; $\mathbf{m}$, maxilla; $\mathbf{n}$, nasal; $\mathbf{0}$, orbit; op, opisthotic; p, parietal; pa, anterior portion of the parietal; pac, caudal portion of the parietal; pal, palatine; pal t, palate teeth; pao, paroccipital process; part, pre-articular; pbs, parabasisphenoid; pc, postcanine; pf, postfrontal; pif, pineal foramen; pl, lateral portion of the parietal; pm, premaxilla; po, postorbital; pp, postparietal; prf, prefrontal; pro, prootic; prp, preparietal; pt, pterygoids; ptf, post-temporal fenestra; q, quadrate; qj, quadratojugal; rt, replacement tooth; sb, supraorbital boss; scl, sclerotic ring; smx, septomaxilla; so, supraoccipital; spl, splenial; st, stapes; sq, squamosal; sur surangular; $\mathbf{t}$, tabular; $\mathbf{v}$, vomer. 3D reconstructions were made by A. Duhamel and belong to the University of the Witwatersrand. Scale bar $=1 \mathrm{~cm}$. 


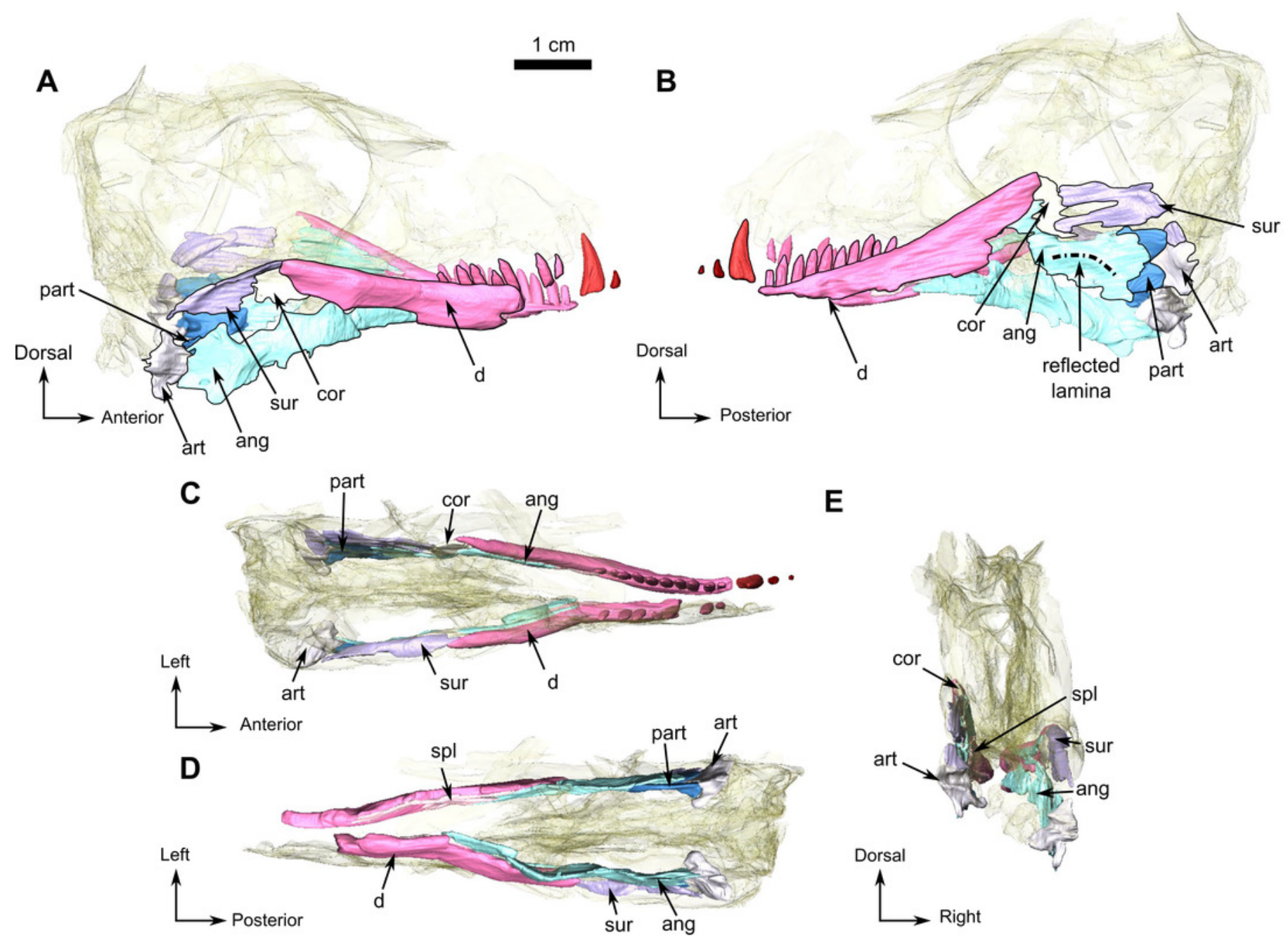




\section{Figure 7}

Holotype of Rubidgina angusticeps, here considered Biarmosuchia indet., RC 55.

3D rendering of the dentition of RC 55. (A) Right lateral view. (B) Left lateral view.

Anatomical Abbreviations-ang, angular; art, articular; aso, anterior extension of the supraoccipital; bo, basioccipital; c, caniniform tooth; co, occipital condyle; cor, coronoid; d, dentary; ect, ectopterygoid; eo, exoccipital; f, frontal; fe, temporal fenestra; fm, foramen magnum; i, incisiform tooth; j, jugal; I, lacrimal; $\mathbf{m}$, maxilla; $\mathbf{n}$, nasal; $\mathbf{0}$, orbit; op, opisthotic; p. parietal; pa, anterior portion of the parietal; pac, caudal portion of the parietal; pal, palatine; pal t t, palate teeth; pao, paroccipital process; part, pre-articular; pbs, parabasisphenoid; pc, postcanine; pf, postfrontal; pif, pineal foramen; pl, lateral portion of the parietal; pm, premaxilla; po, postorbital; pp, postparietal; prf, prefrontal; pro, prootic; prp, preparietal; pt, pterygoids; ptf, post-temporal fenestra; q, quadrate; qj, quadratojugal; rt, replacement tooth; sb, supraorbital boss; scl, sclerotic ring; smx, septomaxilla; so, supraoccipital; spl, splenial; st, stapes; sq, squamosal; sur surangular; t, tabular; v, vomer. $3 \mathrm{D}$ reconstructions were made by $\mathrm{A}$. Duhamel and belong to the University of the Witwatersrand. Scale bar $=1 \mathrm{~cm}$. 


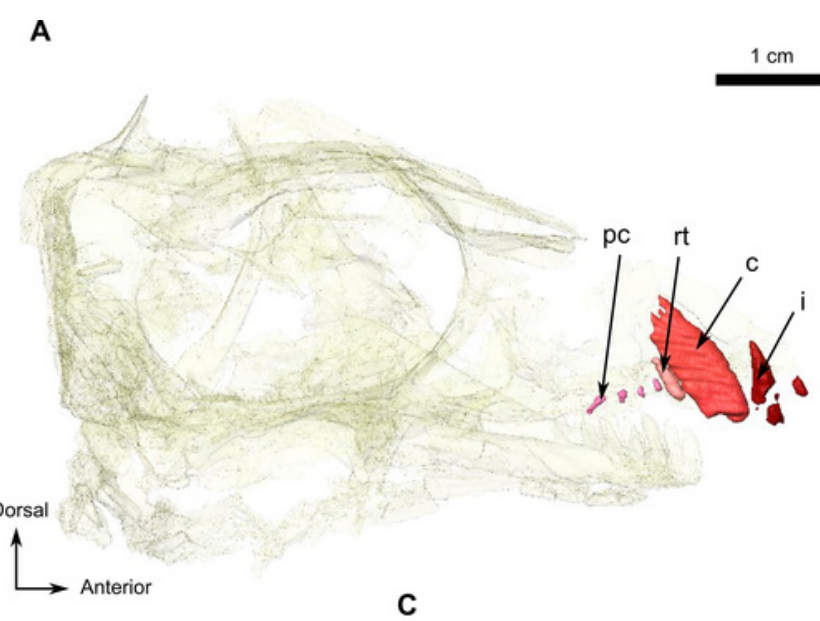

B

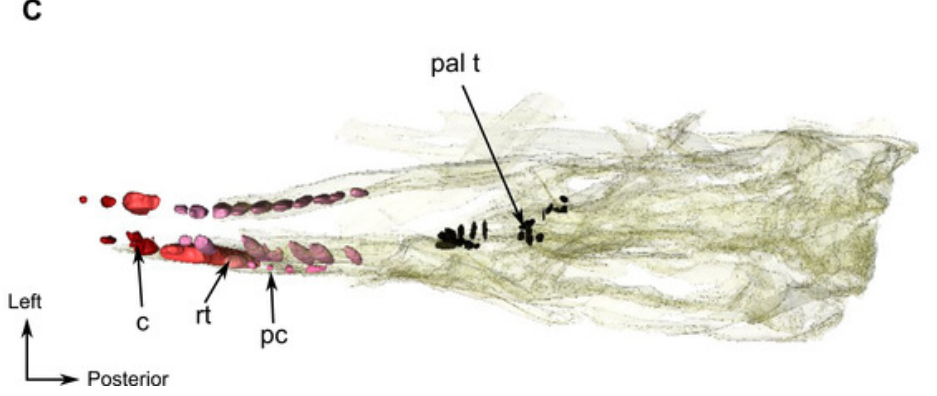




\section{Figure 8}

Burnetiamorpha indet., skull, CGS MJF 22.

(A) Lateral view, with a 3D rendering of the teeth (right). (B) Dorsal view with the bones of the pineal region segmented on the left; and the CT-image at the level of the supraorbital bosses and a diagram of the vasculature pattern found in the bosses (right). (C) Occipital view. (D) Ventral view. Questions mark denote unidentified bones. Short dotted line accentuates anatomical character; long dotted line indicates uncertainly about sutural pathway on bone. Anatomical Abbreviations -ang, angular; art, articular; aso, anterior extension of the supraoccipital; bo, basioccipital; c, caniniform tooth; co, occipital condyle; cor, coronoid; d, dentary; ect, ectopterygoid; eo, exoccipital; f, frontal; fe, temporal fenestra; fm, foramen magnum; i, incisiform tooth; j, jugal; I, lacrimal; $\mathbf{m}$, maxilla; $\mathbf{n}$, nasal; o, orbit; op, opisthotic; p, parietal; pa, anterior portion of the parietal; pac, caudal portion of the parietal; pal, palatine; pal t, palate teeth; pao, paroccipital process; part, pre-articular; pbs, parabasisphenoid; pc, postcanine; pf, postfrontal; pif, pineal foramen; pl, lateral portion of the parietal; pm, premaxilla; po, postorbital; pp, postparietal; prf, prefrontal; pro, prootic; prp, preparietal; pt, pterygoids; ptf, post-temporal fenestra; q, quadrate; qj, quadratojugal; rt, replacement tooth; sb, supraorbital boss; scl, sclerotic ring; smx, septomaxilla; so, supraoccipital; spl, splenial; st, stapes; sq, squamosal; sur surangular; $\mathbf{t}$, tabular; v, vomer. Pictures by A. Duhamel. Scan of the specimen was performed by Kudakwashe Jakata and belongs to the University of the Witwatersrand. 3D reconstructions were made by A. Duhamel and belong to the University of the Witwatersrand. Scale bar $=1 \mathrm{~cm}$. 

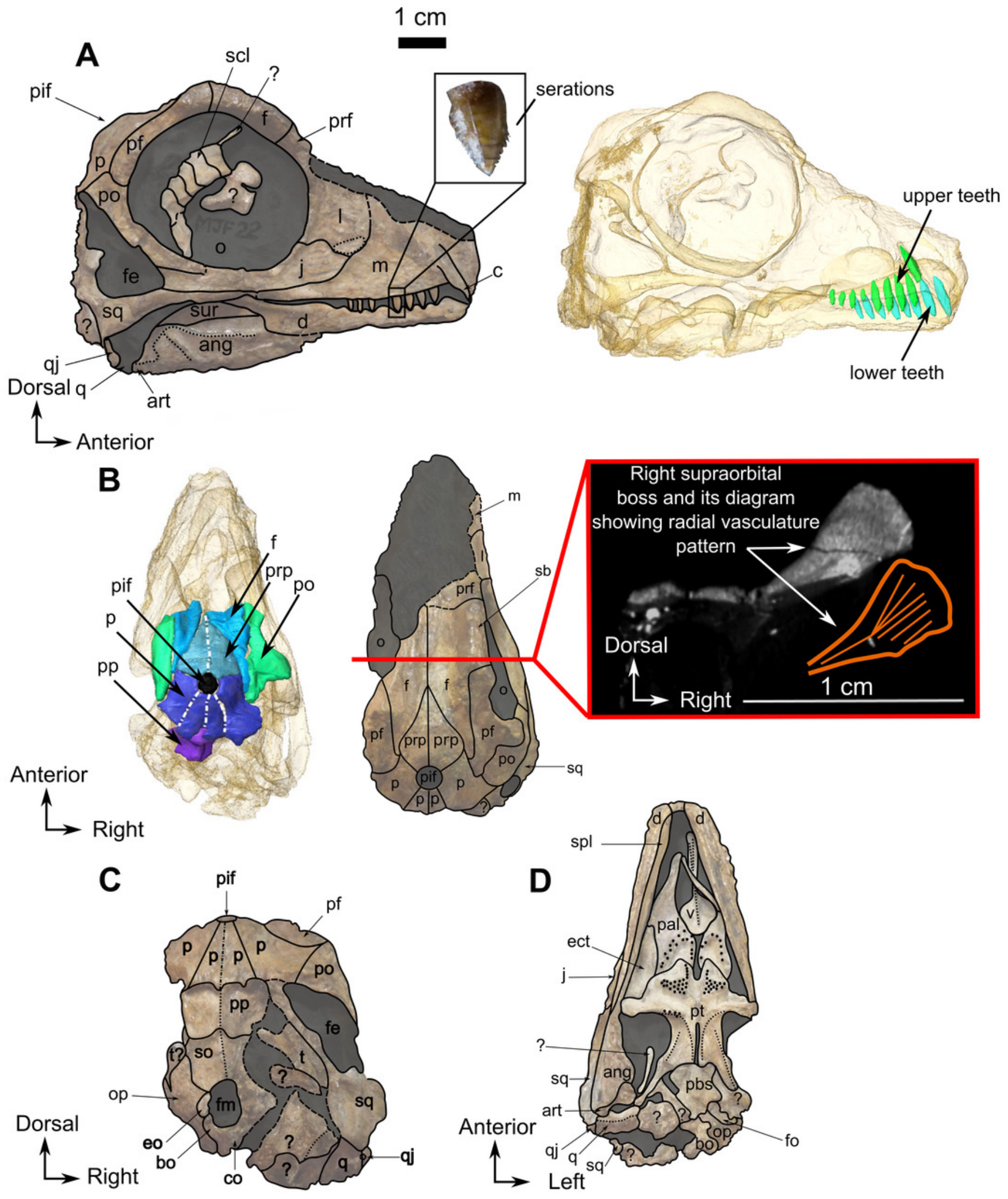


\section{Figure 9}

Burnetiamorph indet., snout, SAM-PK-K11126.

Photograph (left) and 3D rendering of SAM-PK-K11126 (right). (A) Left lateral view. (B) Ventral view. Anatomical Abbreviations -ang, angular; art, articular; aso, anterior extension of the supraoccipital; bo, basioccipital; c, caniniform tooth; co, occipital condyle; cor, coronoid; d, dentary; ect, ectopterygoid; eo, exoccipital; f, frontal; fe, temporal fenestra; fm, foramen magnum; i, incisiform tooth; j, jugal; I, lacrimal; $\mathbf{m}$, maxilla; $\mathbf{n}$, nasal; $\mathbf{0}$, orbit; op, opisthotic; p, parietal; pa, anterior portion of the parietal; pac, caudal portion of the parietal; pal, palatine; pal t, palate teeth; pao, paroccipital process; part, pre-articular; pbs, parabasisphenoid; pc, postcanine; pf, postfrontal; pif, pineal foramen; pl, lateral portion of the parietal; pm, premaxilla; po, postorbital; pp, postparietal; prf, prefrontal; pro, prootic; prp, preparietal; pt, pterygoids; ptf, post-temporal fenestra; q, quadrate; qj, quadratojugal; rt, replacement tooth; sb, supraorbital boss; scl, sclerotic ring; smx, septomaxilla; so, supraoccipital; spl, splenial; st, stapes; sq, squamosal; sur surangular; t, tabular; $\mathbf{v}$, vomer. Vertical jagging on the 3D rendering is an artefact of segmentation. Pictures by A. Duhamel. 3D reconstructions were made by A. Duhamel and belong to the University of the Witwatersrand. Scale bar $=1 \mathrm{~cm}$. 


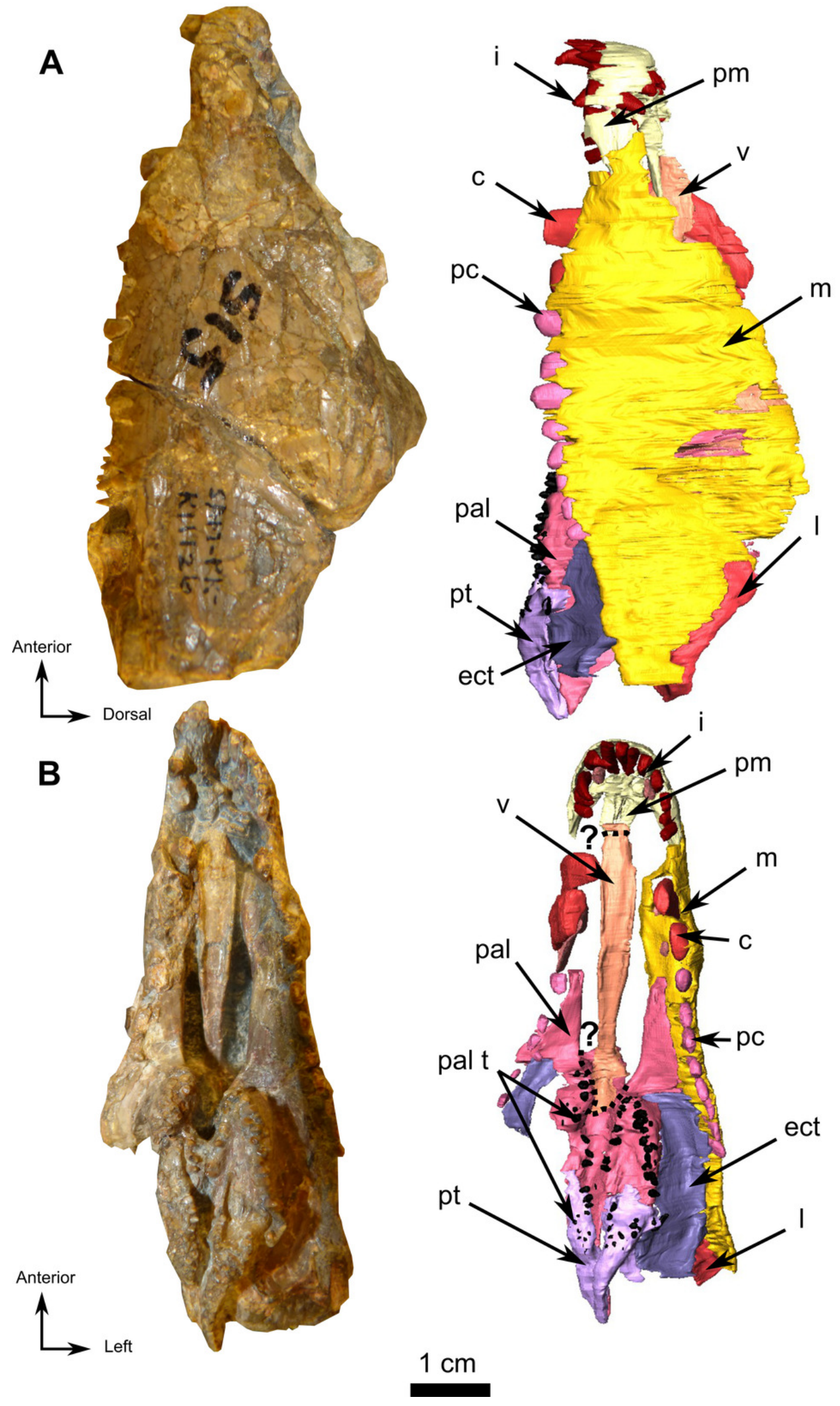




\section{Figure 10}

Burnetiamorph indet., palate, SAM-PK-K11126.

3D rendering of SAM-PK-K11126's palatine bones and teeth (right). (A) Ventral view. (B)

Dorsal view. (C) Left lateral view. Anatomical Abbreviations -ang, angular; art, articular; aso, anterior extension of the supraoccipital; bo, basioccipital; c, caniniform tooth; co, occipital condyle; cor, coronoid; d, dentary; ect, ectopterygoid; eo, exoccipital; f, frontal; fe, temporal fenestra; $\mathbf{f m}$, foramen magnum; $\mathbf{i}$, incisiform tooth; j, jugal; I, lacrimal; $\mathbf{m}$, maxilla; $\mathbf{n}$, nasal; o, orbit; op, opisthotic; p, parietal; pa, anterior portion of the parietal; pac, caudal portion of the parietal; pal, palatine; pal $\mathbf{t}$, palate teeth; pao, paroccipital process; part, prearticular; pbs, parabasisphenoid; pc, postcanine; pf, postfrontal; pif, pineal foramen; pl, lateral portion of the parietal; pm, premaxilla; po, postorbital; pp, postparietal; prf, prefrontal; pro, prootic; prp, preparietal; pt, pterygoids; ptf, post-temporal fenestra; q, quadrate; qj, quadratojugal; rt, replacement tooth; sb, supraorbital boss; scl, sclerotic ring; smx, septomaxilla; so, supraoccipital; spl, splenial; st, stapes; sq, squamosal; sur surangular; $\mathbf{t}$, tabular; $\mathbf{v}$, vomer. 3D reconstructions were made by A. Duhamel and belong to the University of the Witwatersrand. Scale bar $=1 \mathrm{~cm}$. 

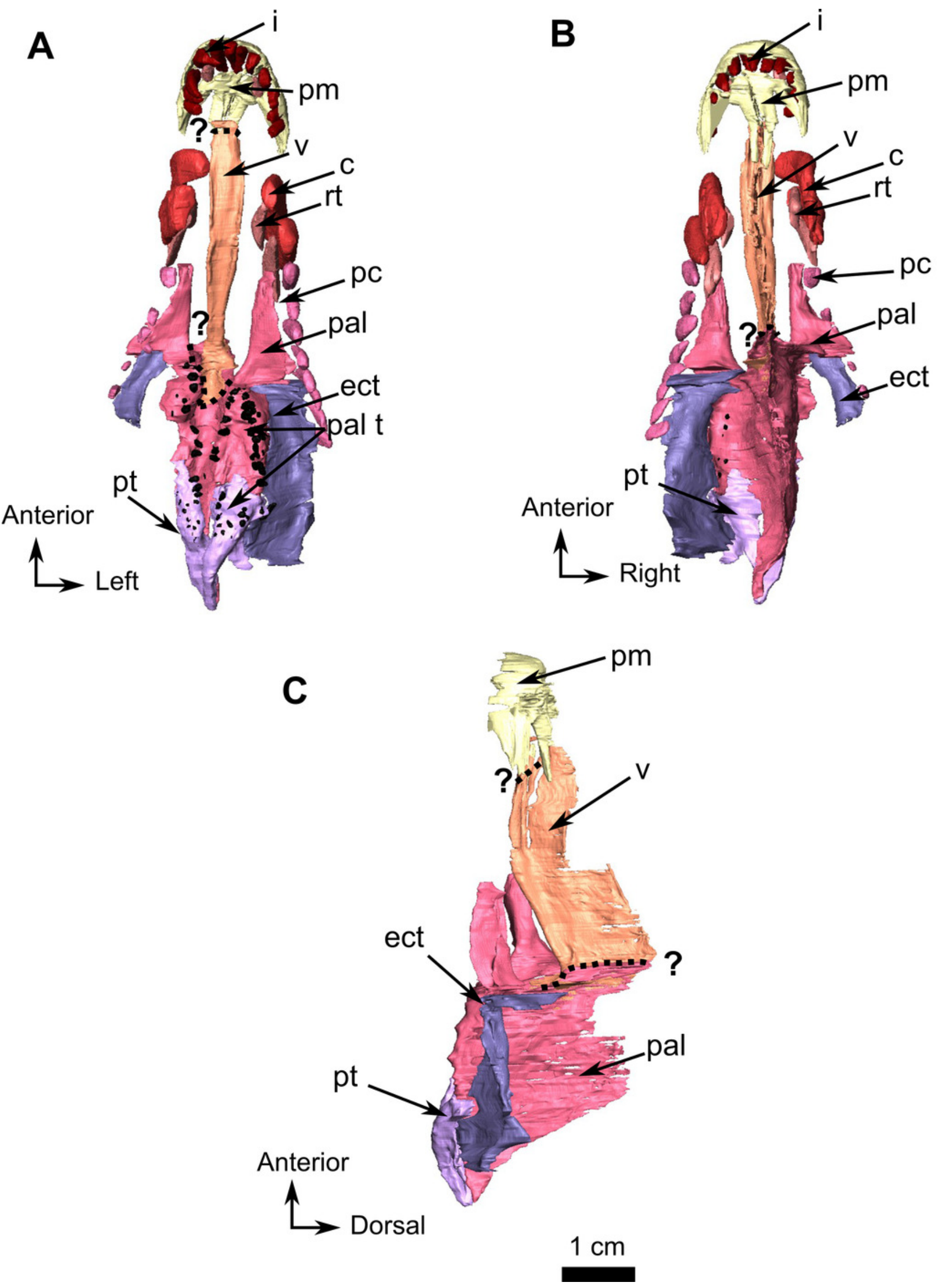


\section{Figure 11}

Burnetiamorph indet., occipital portion, SAM-PK-K11126.

Photograph (left) and 3D rendering of SAM-PK-K11126 (right). (A) Occipital view. (B) Right lateral view. (C) Dorsal view. (D) Ventral view. Anatomical Abbreviations -ang, angular; art, articular; aso, anterior extension of the supraoccipital; bo, basioccipital; c, caniniform tooth; co, occipital condyle; cor, coronoid; d, dentary; ect, ectopterygoid; eo, exoccipital; f, frontal; fe, temporal fenestra; fm, foramen magnum; i, incisiform tooth; j, jugal; I, lacrimal; m, maxilla; $\mathbf{n}$, nasal; o, orbit; op, opisthotic; $\mathbf{p}$, parietal; pa, anterior portion of the parietal; pac, caudal portion of the parietal; pal, palatine; pal t $\mathbf{t}$ palate teeth; pao, paroccipital process; part, pre-articular; pbs, parabasisphenoid; pc, postcanine; pf, postfrontal; pif, pineal foramen; pl, lateral portion of the parietal; pm, premaxilla; po, postorbital; pp, postparietal; prf, prefrontal; pro, prootic; prp, preparietal; pt, pterygoids; ptf, post-temporal fenestra; q, quadrate; qj, quadratojugal; rt, replacement tooth; sb, supraorbital boss; scl, sclerotic ring; smx, septomaxilla; so, supraoccipital; spl, splenial; st, stapes; sq, squamosal; sur surangular; $\mathbf{t}$, tabular; $\mathbf{v}$, vomer. Pictures by A. Duhamel. 3D reconstructions were made by A. Duhamel and belong to the University of the Witwatersrand. Scale bar $=1 \mathrm{~cm}$. 


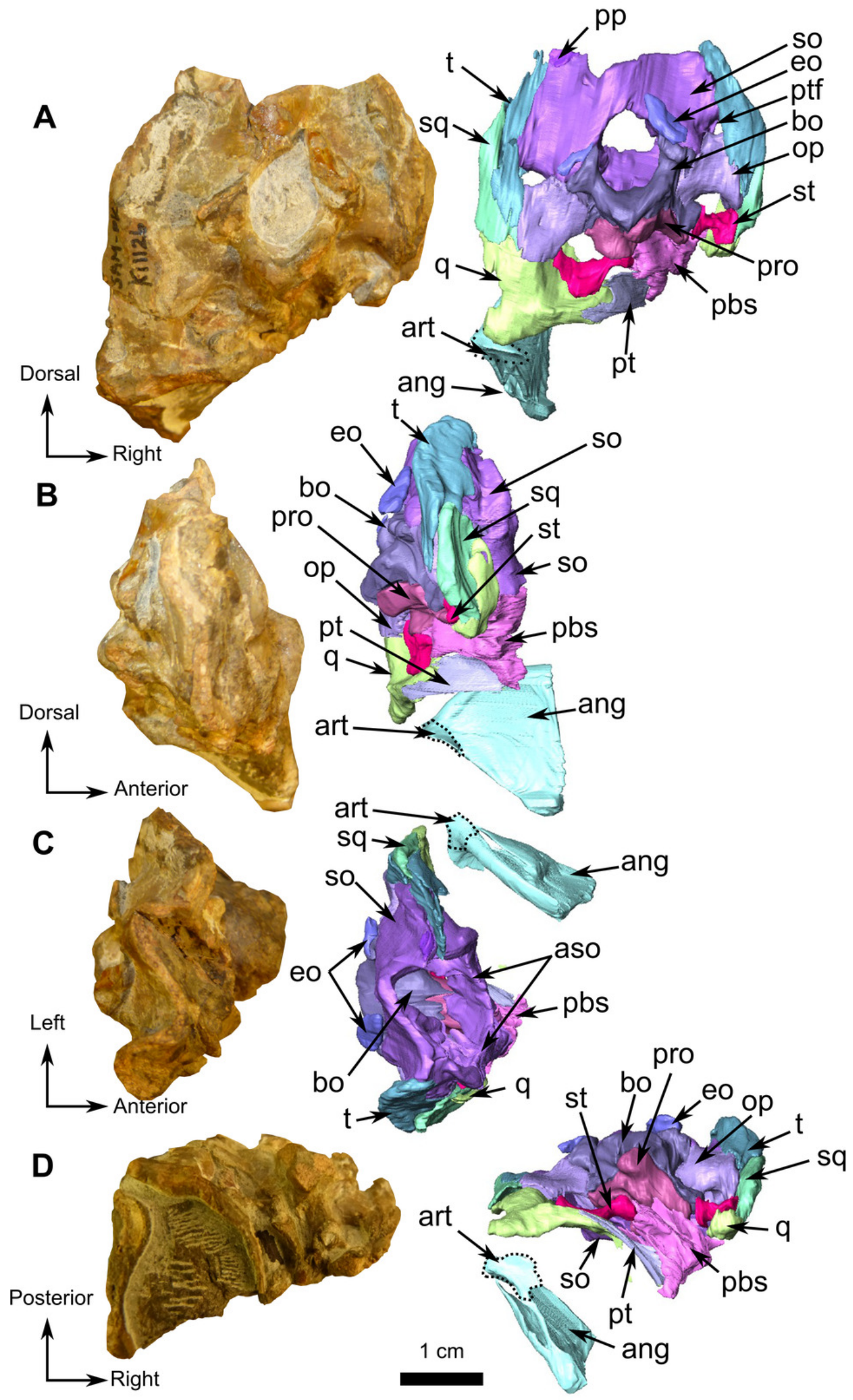




\section{Figure 12}

Burnetiamorph indet., skull cap, SAM-PK-K11126.

Photograph (left) and 3D rendering of SAM-PK-K11126. (A) Dorsal view. (B) Ventral view. (C) Right lateral view. White dotted lines point out inner-bone sutures. Anatomical

Abbreviations -ang, angular; art, articular; aso, anterior extension of the supraoccipital; bo, basioccipital; c, caniniform tooth; co, occipital condyle; cor, coronoid; d, dentary; ect, ectopterygoid; eo, exoccipital; f, frontal; fe, temporal fenestra; fm, foramen magnum; i, incisiform tooth; j, jugal; I, lacrimal; m, maxilla; $\mathbf{n}$, nasal; o, orbit; op, opisthotic; p, parietal; pa, anterior portion of the parietal; pac, caudal portion of the parietal; pal, palatine; pal t palate teeth; pao, paroccipital process; part, pre-articular; pbs, parabasisphenoid; pc, postcanine; pf, postfrontal; pif, pineal foramen; pl, lateral portion of the parietal; pm, premaxilla; po, postorbital; pp, postparietal; prf, prefrontal; pro, prootic; prp, preparietal; pt, pterygoids; ptf, post-temporal fenestra; q, quadrate; qj, quadratojugal; rt, replacement tooth; sb, supraorbital boss; scl, sclerotic ring; smx, septomaxilla; so, supraoccipital; spl, splenial; st, stapes; sq, squamosal; sur surangular; t, tabular; v, vomer. Pictures by A. Duhamel. 3D reconstructions were made by A. Duhamel and belong to the University of the Witwatersrand. Scale bar $=1 \mathrm{~cm}$. 

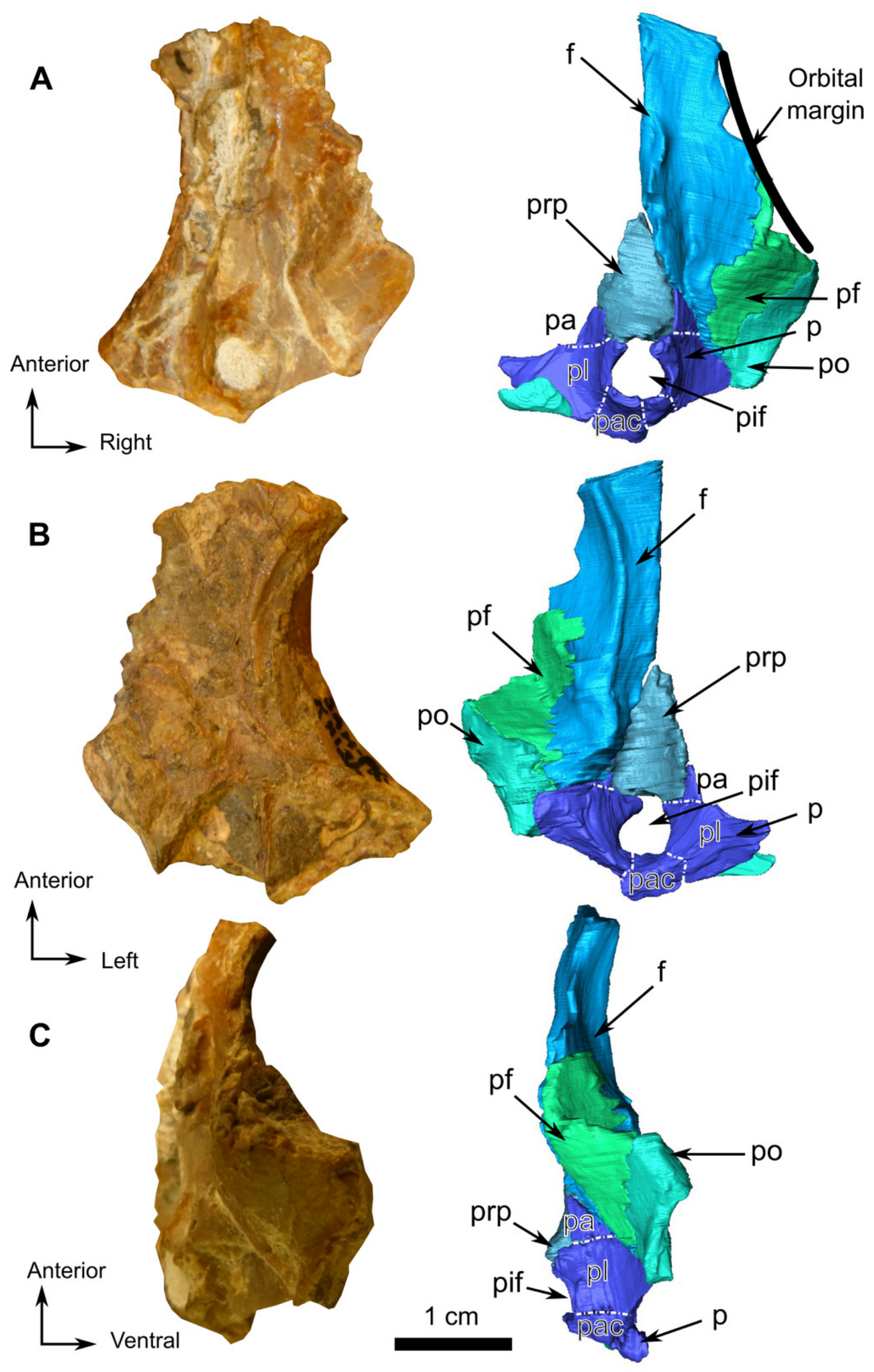


\section{Figure 13}

Burnetiamorph indet., right lower jaw, SAM-PK-K11126.

Photograph (left) and 3D rendering of SAM-PK-K11126 (right). (A) Right lingual view. (B)

Distal view. Anatomical Abbreviations -ang, angular; art, articular; aso, anterior extension of the supraoccipital; bo, basioccipital; c, caniniform tooth; co, occipital condyle; cor, coronoid; d, dentary; ect, ectopterygoid; eo, exoccipital; f, frontal; fe, temporal fenestra; fm, foramen magnum; i, incisiform tooth; j, jugal; I, lacrimal; $\mathbf{m}$, maxilla; $\mathbf{n}$, nasal; o, orbit; op, opisthotic; p, parietal; pa, anterior portion of the parietal; pac, caudal portion of the parietal; pal, palatine; pal t, palate teeth; pao, paroccipital process; part, pre-articular; pbs, parabasisphenoid; pc, postcanine; pf, postfrontal; pif, pineal foramen; pl, lateral portion of the parietal; pm, premaxilla; po, postorbital; pp, postparietal; prf, prefrontal; pro, prootic; prp, preparietal; pt, pterygoids; ptf, post-temporal fenestra; q, quadrate; qj, quadratojugal; rt, replacement tooth; sb, supraorbital boss; scl, sclerotic ring; smx, septomaxilla; so, supraoccipital; spl, splenial; st, stapes; sq, squamosal; sur surangular; t, tabular; v, vomer. Pictures by A. Duhamel. 3D reconstructions were made by A. Duhamel and belong to the University of the Witwatersrand. Scale bar $=1 \mathrm{~cm}$. 
A

Mesial

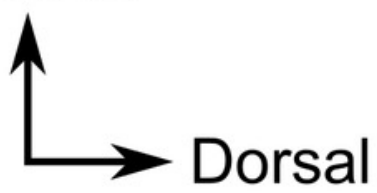

B

Dorsal

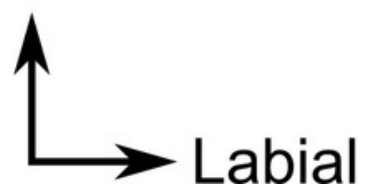

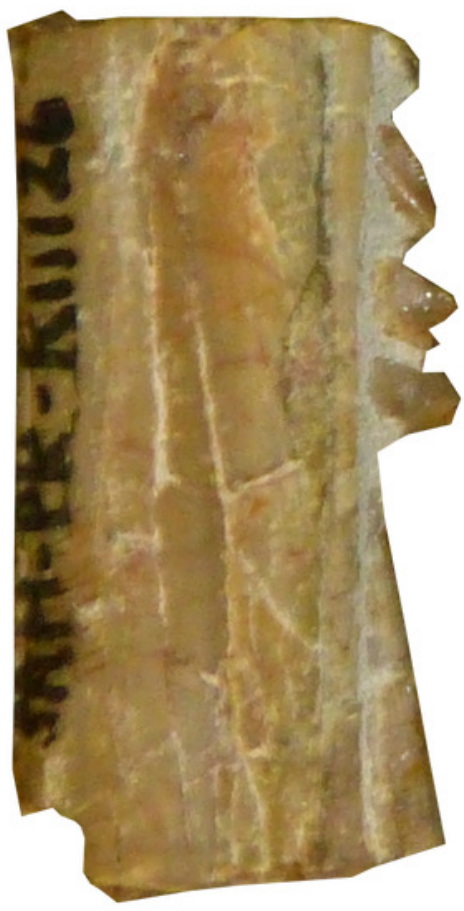
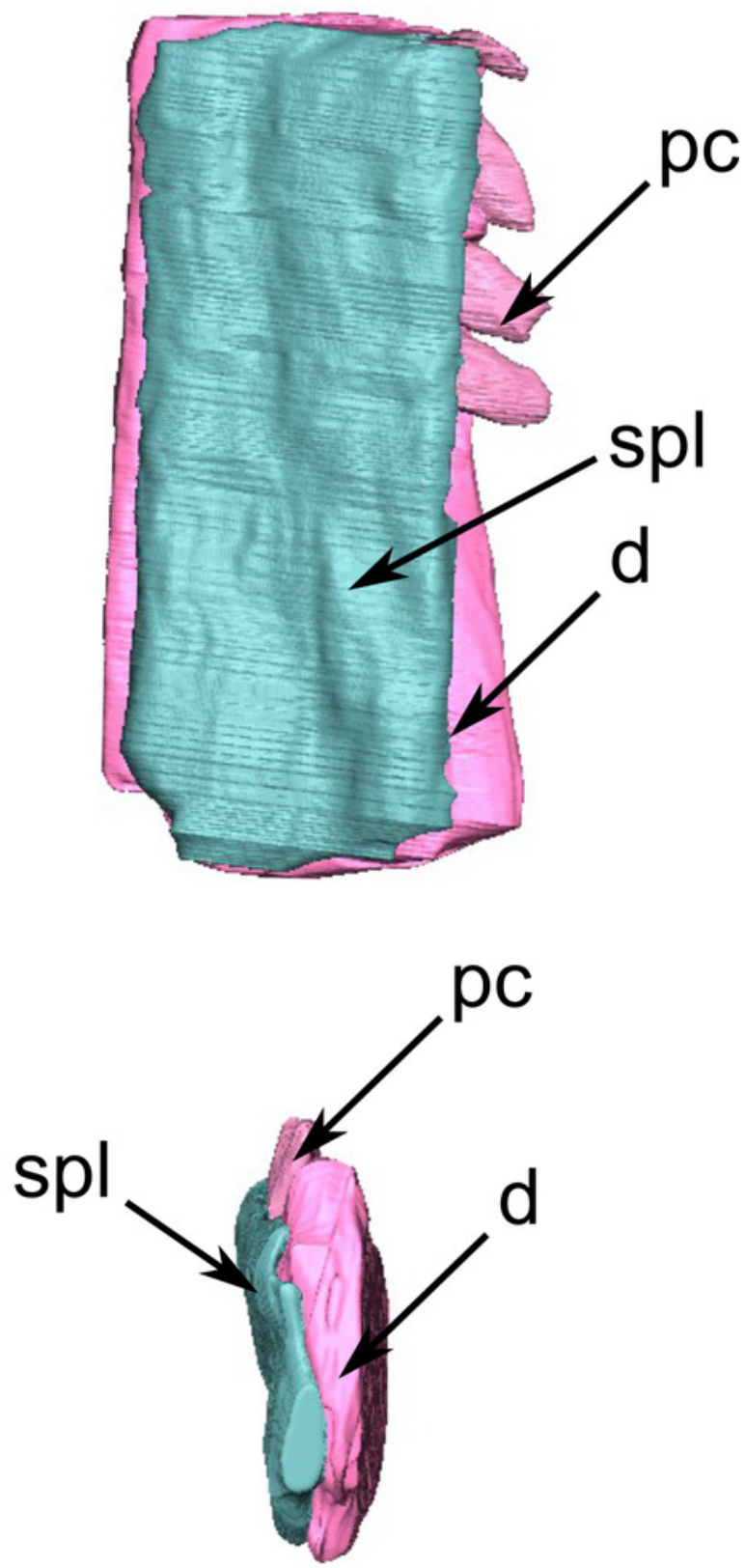

$1 \mathrm{~cm}$ 


\section{Figure 14}

Burnetiamorph indet., upper dentition, SAM-PK-K11126.

3D rendering of the upper dentition of SAM-PK-K11126, with a photograph background of the snout. (A) Ventral view. (B) Left labial view. Anatomical Abbreviation-ang, angular; art, articular; aso, anterior extension of the supraoccipital; bo, basioccipital; c, caniniform tooth; co, occipital condyle; cor, coronoid; d, dentary; ect, ectopterygoid; eo, exoccipital; f, frontal; $\mathbf{f e}$, temporal fenestra; $\mathbf{f m}$, foramen magnum; i, incisiform tooth; j, jugal; I, lacrimal; $\mathbf{m}$, maxilla; $\mathbf{n}$, nasal; o, orbit; op, opisthotic; p, parietal; pa, anterior portion of the parietal; pac, caudal portion of the parietal; pal, palatine; pal $\mathbf{t}$, palate teeth; pao, paroccipital process; part, pre-articular; pbs, parabasisphenoid; pc, postcanine; pf, postfrontal; pif, pineal foramen; pl, lateral portion of the parietal; pm, premaxilla; po, postorbital; pp, postparietal; prf, prefrontal; pro, prootic; prp, preparietal; pt, pterygoids; ptf, post-temporal fenestra; q, quadrate; qj, quadratojugal; rt, replacement tooth; sb, supraorbital boss; scl, sclerotic ring; smx, septomaxilla; so, supraoccipital; spl, splenial; st, stapes; sq, squamosal; sur surangular; $\mathbf{t}$, tabular; $\mathbf{v}$, vomer. Pictures by A. Duhamel. 3D reconstructions were made by A. Duhamel and belong to the University of the Witwatersrand. Scale bar $=1 \mathrm{~cm}$. 
A

Left
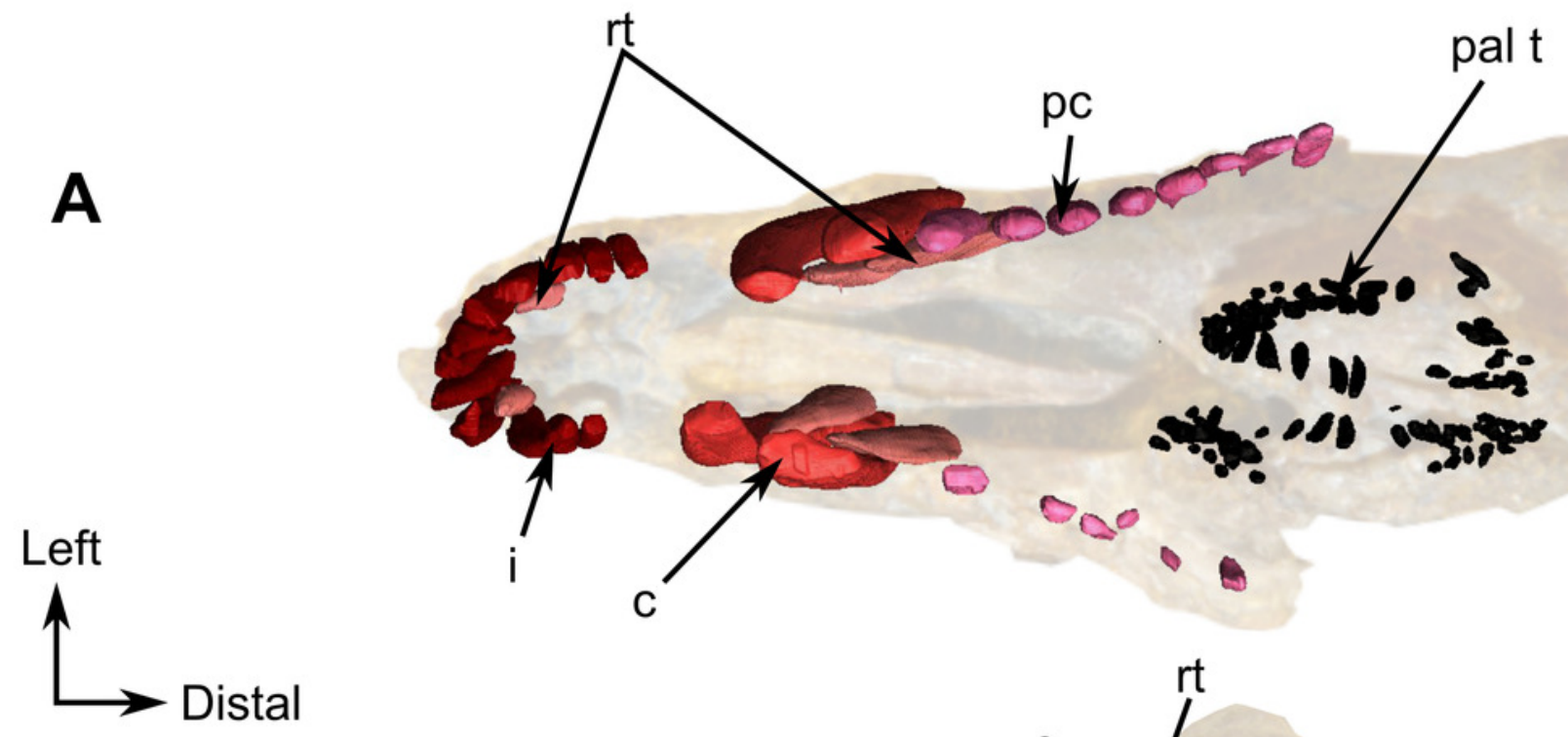

B

Dorsal
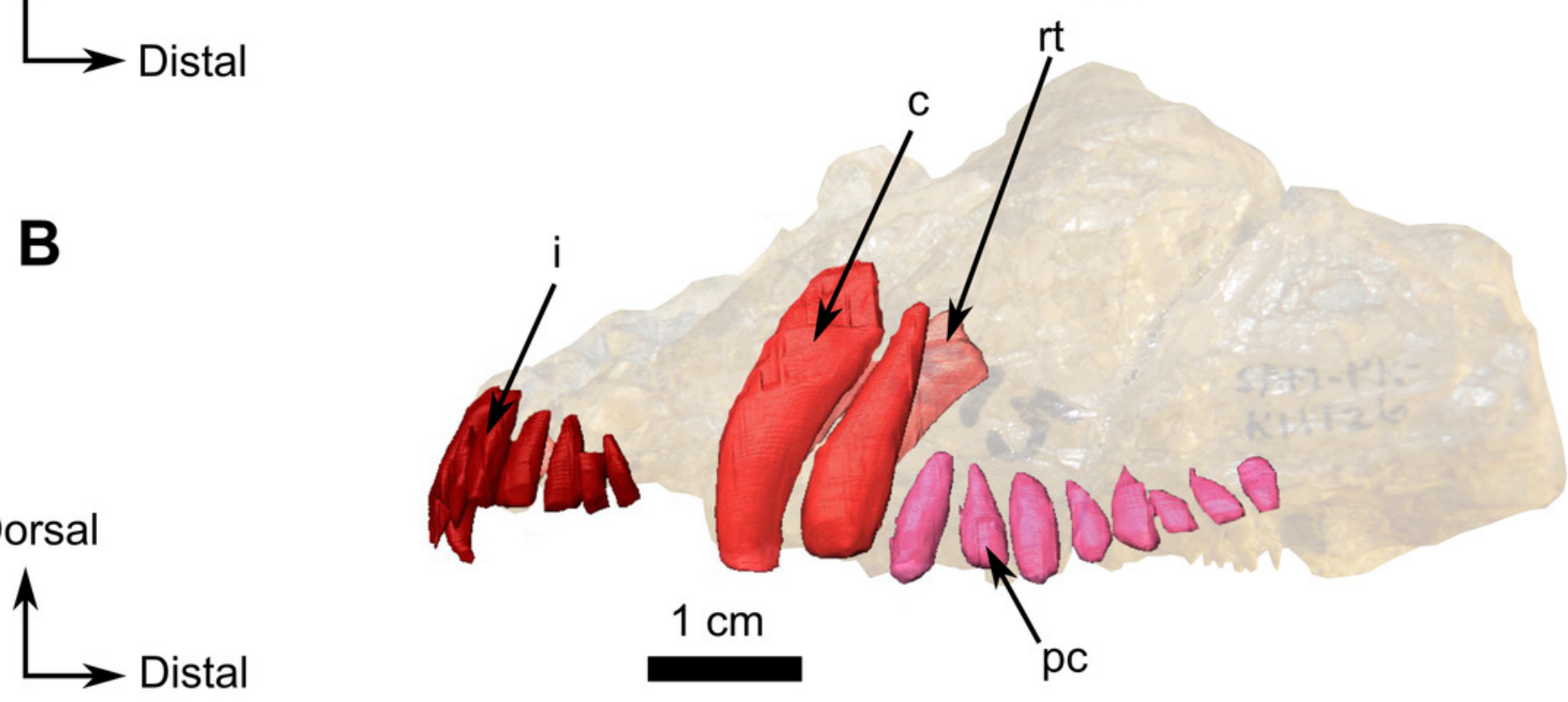


\section{Figure 15}

Holotype of Lemurosaurus pricei, skull, BP/1/816.

(A) CT image at the level of the supraorbital bosses and the braincase (B). Histology of supraorbital bosses, comprising thick and dense bone, and a well-ossified braincase, indicates that the specimen is an adult. (B) photograph of the right lateral view. Bright artefacts are caused by iron nodules. Pictures by A. Duhamel. Scan of the specimen was performed by Kudakwashe Jakata and belongs to the University of the Witwatersrand. Scale bar $=1 \mathrm{~cm}$.

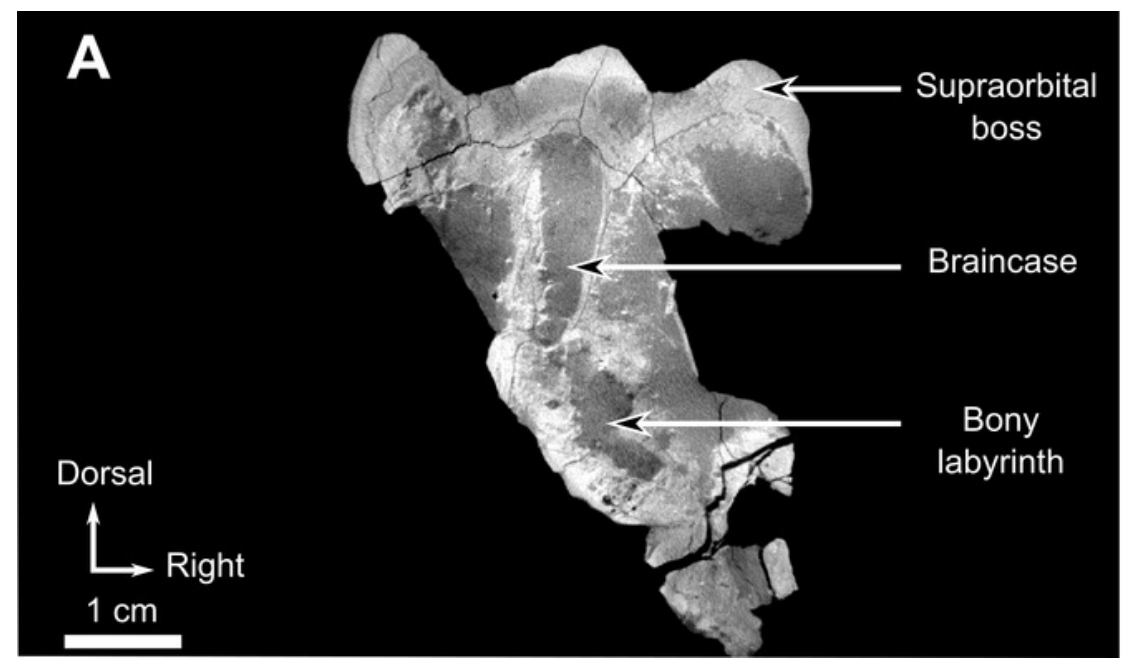

B

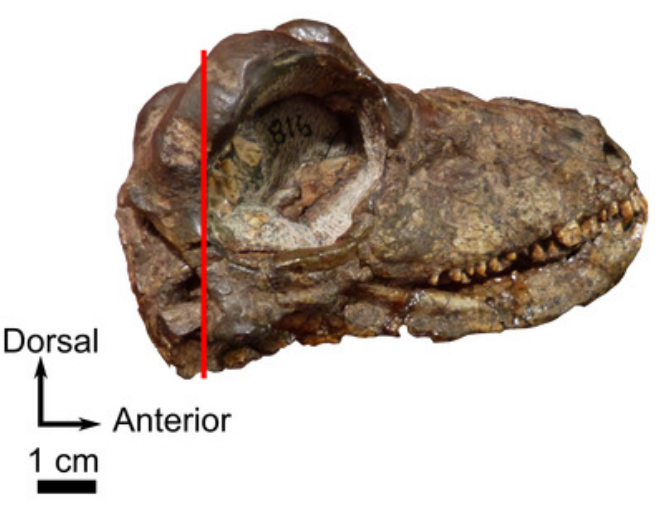




\section{Figure 16}

Anatomical comparison of BP/1/816 and NMQR 1702.

(A) holotype of Lemurosaurus pricei, skull, BP/1/816, from Dorsfontein farm, Graaff-Reinet

District, Eastern Cape Province, South Africa; Cistecephalus AZ, Beaufort Group, Karoo

Supergoup. Left: right lateral view; right: dorsal view. (B) NMQR 1702, from Petersburg

farm, Graaff-Reinet District, Eastern Cape Province, South Africa; Cistecephalus AZ, Beaufort

Group, Karoo Supergroup, South Africa. Left: right lateral view; right: dorsal view. Pictures

by A. Duhamel. Scale bar $=1 \mathrm{~cm}$. 


\section{$1 \mathrm{~cm}$}
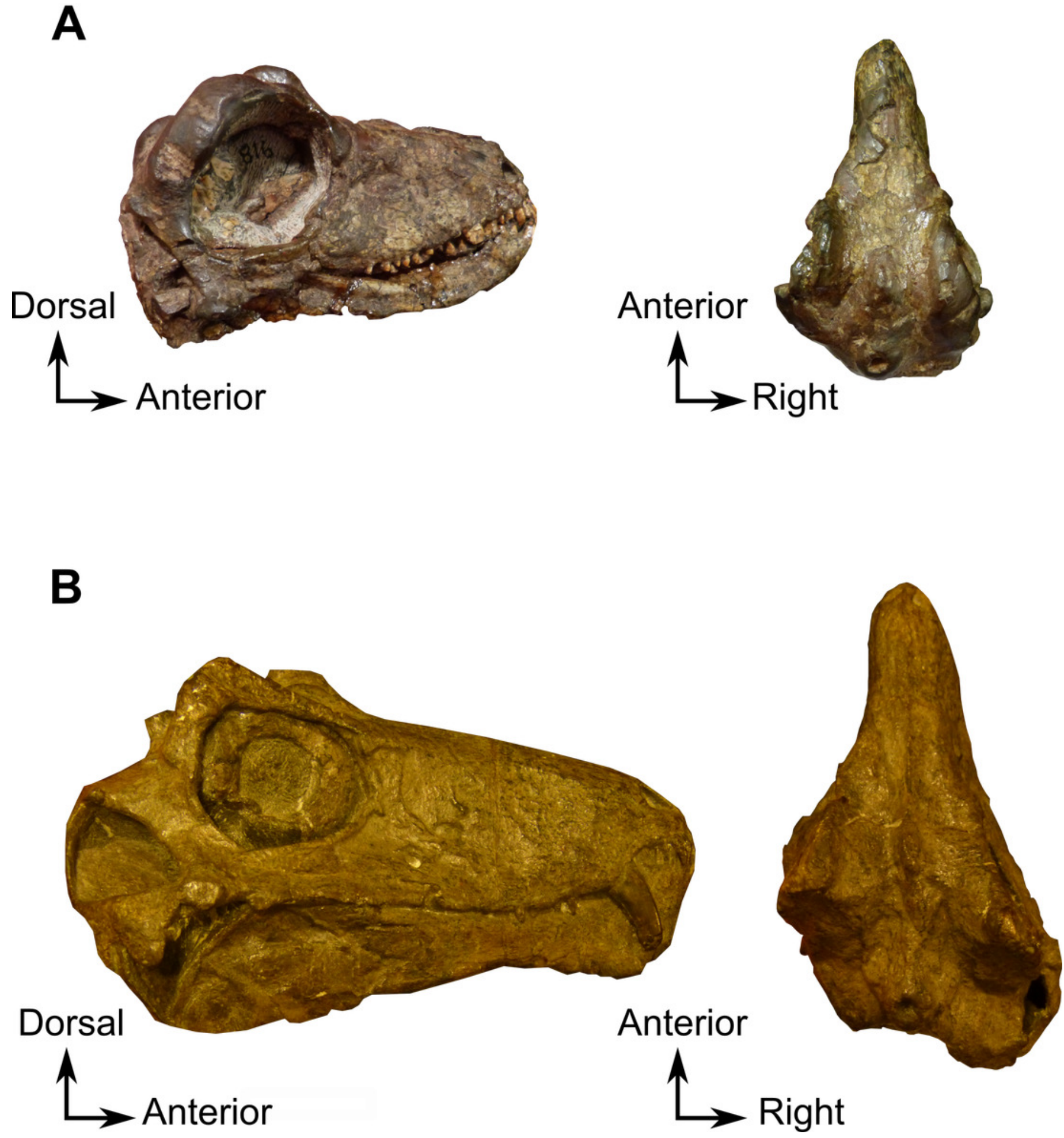


\section{Figure 17}

Lende Chiweta, skull, MAL 290.

CT-images (Left) and lateral view (Right); (A) at the level of the supraorbital bosses, (B)

braincase and $(\mathbf{C})$ foramen magnum. Bright points are artefacts resulting from the presence of iron nodules. Pictures by A. Duhamel. Scan of the specimen was performed by Kudakwashe Jakata and belongs to the University of the Witwatersrand. Scale bar $=1 \mathrm{~cm}$. 

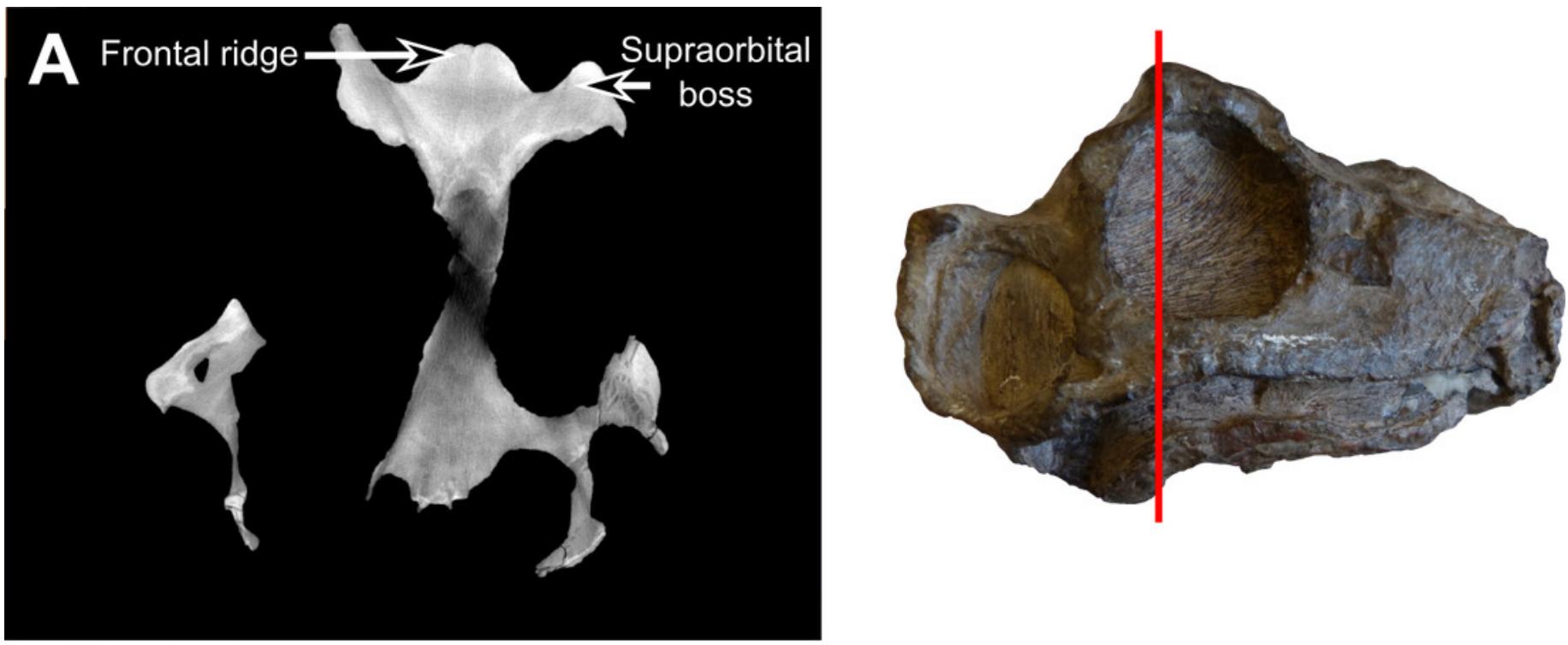

\section{B}
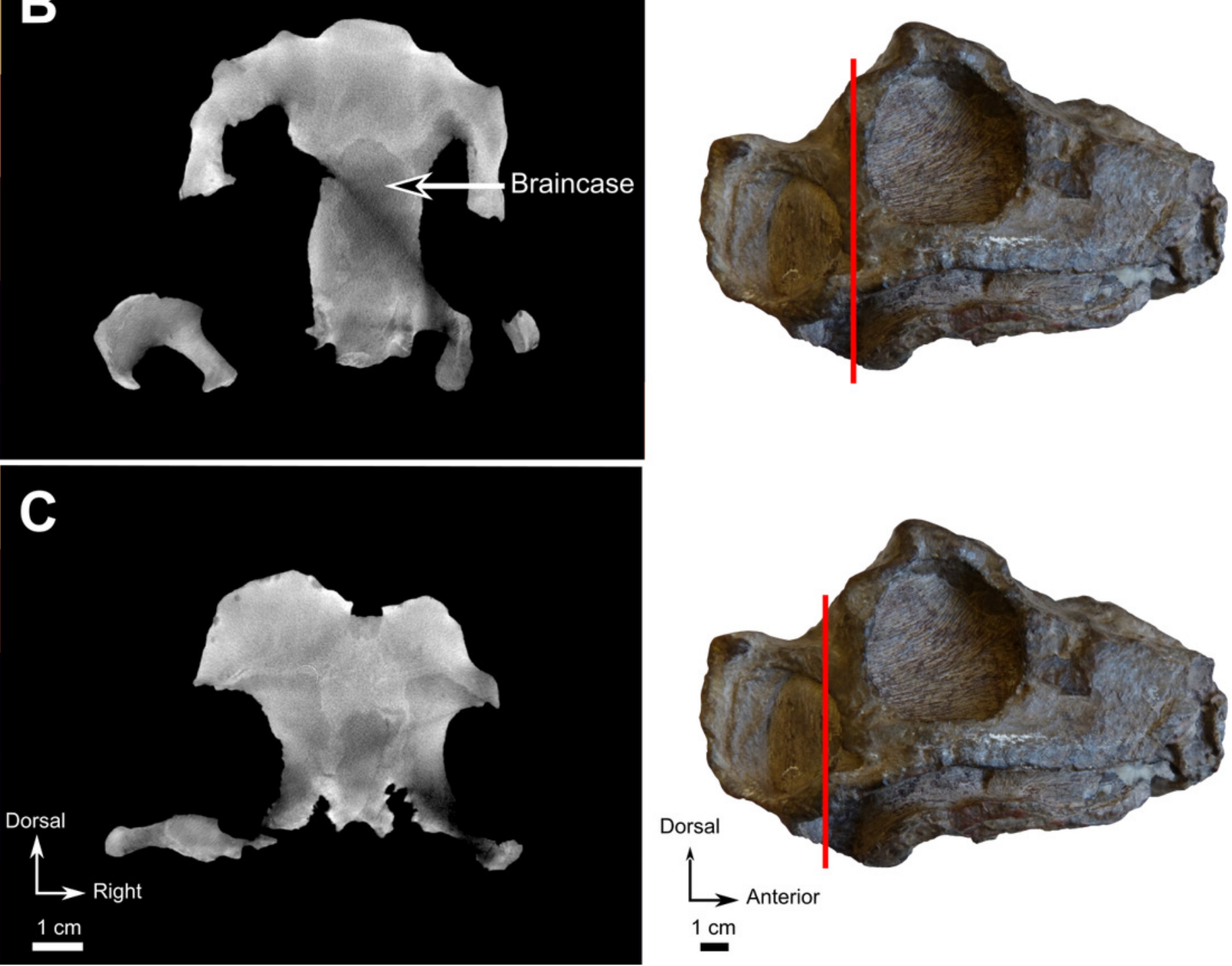


\section{Figure 18}

Lemurosaurus pricei, NMQR 1702.

CT image at the level of the supraorbital bosses and the braincase. Despite the quality of the scan, the thick supraorbital bosses, the well-ossified braincase, and absence of vasculature patterns in the supraorbital bosses, indicate that the specimen is an adult. Bright artefacts are caused by iron nodules. Scan of the specimen was performed by Vincent Fernandez and belong to the European Synchrotron Radiation Facility. Scale bar=1cm. 


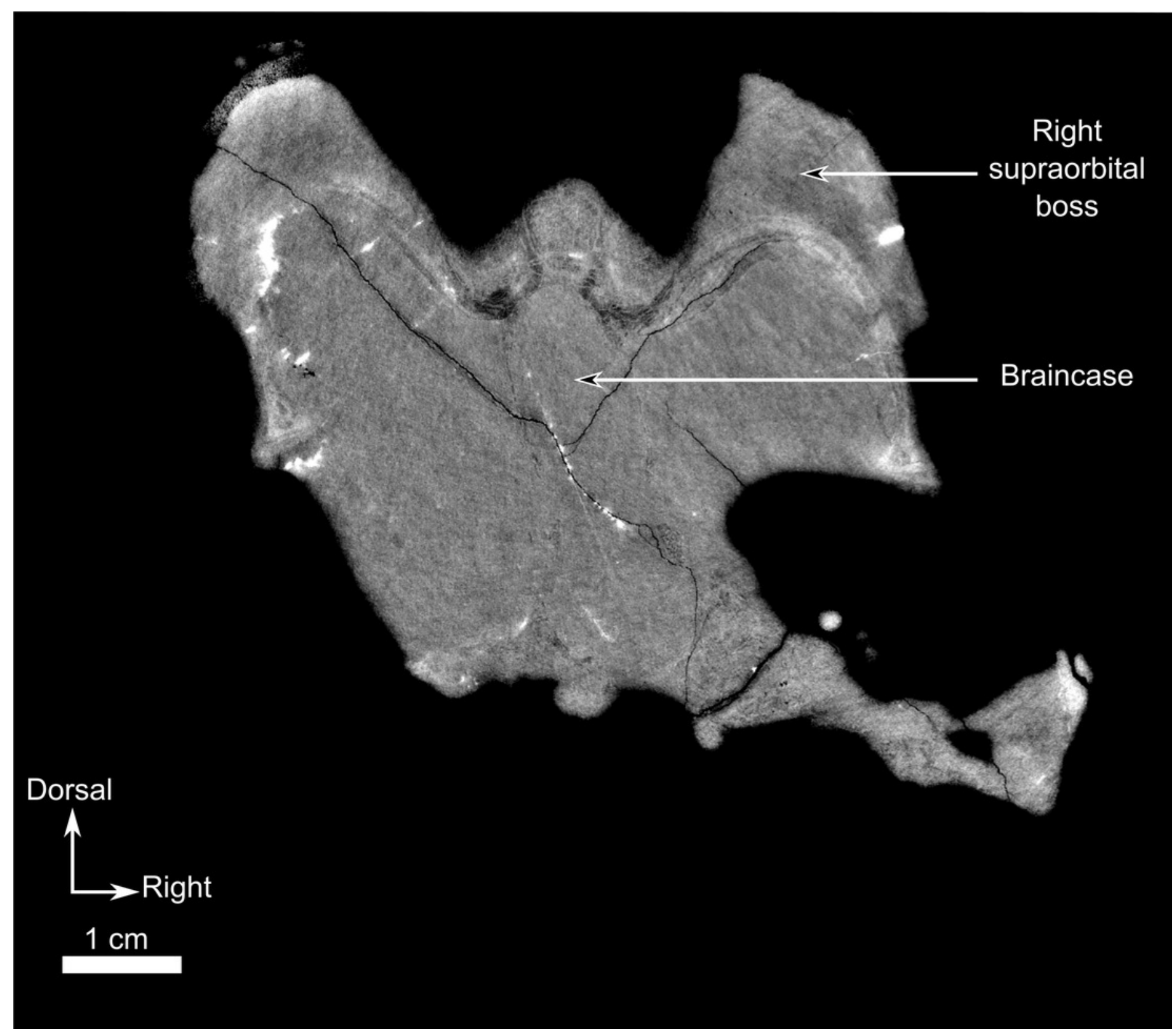




\section{Figure 19}

Burnetiamorpha indet., skull, CGS MJF 22.

(A) CT image at the level of the braincase (B). Bony labyrinth is fused to the braincase (which itself is not ossified) which suggests incomplete ossification and juvenility. (B) Photograph of the specimen in right lateral view. Bright artefacts are caused by iron nodules. Pictures by $A$. Duhamel. Scan of the specimen was performed by Kudakwashe Jakata and belongs to the University of the Witwatersrand. Scale bar $=1 \mathrm{~cm}$.

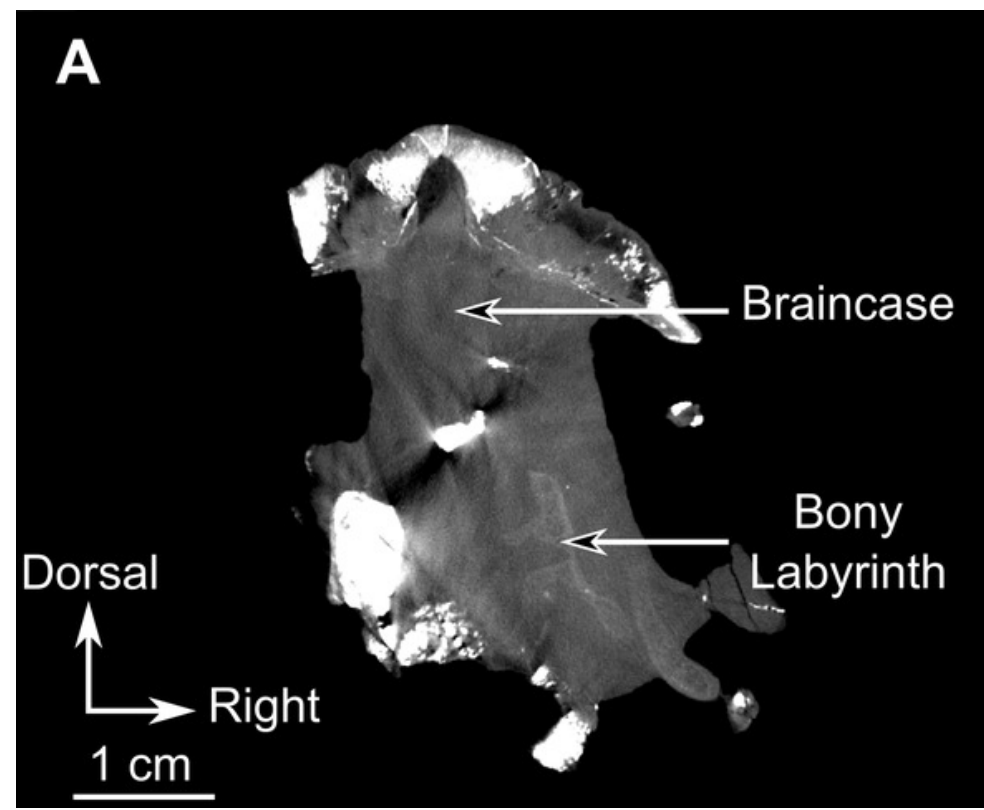

B

Dorsal

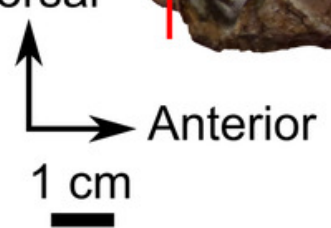




\section{Figure 20}

Burnetiamorpha indet., skull, CGS MJF 22.

(A) CT-image of a transverse section showing three symmetrical sutures, indicated by arrows, within the parietal. (B) Segmentation of the posterior part of the skull roof reveals the presence of extra-sutures in the preparietal and the parietal. The black circle represents the pineal foramen. Bright points are artefacts resulting from the presence of iron nodules. Scan of the specimen was performed by Kudakwashe Jakata and belongs to the University of the Witwatersrand. 3D reconstruction was made by $A$. Duhamel and belongs to the University of the Witwatersrand. Scale bar $=1 \mathrm{~cm}$.

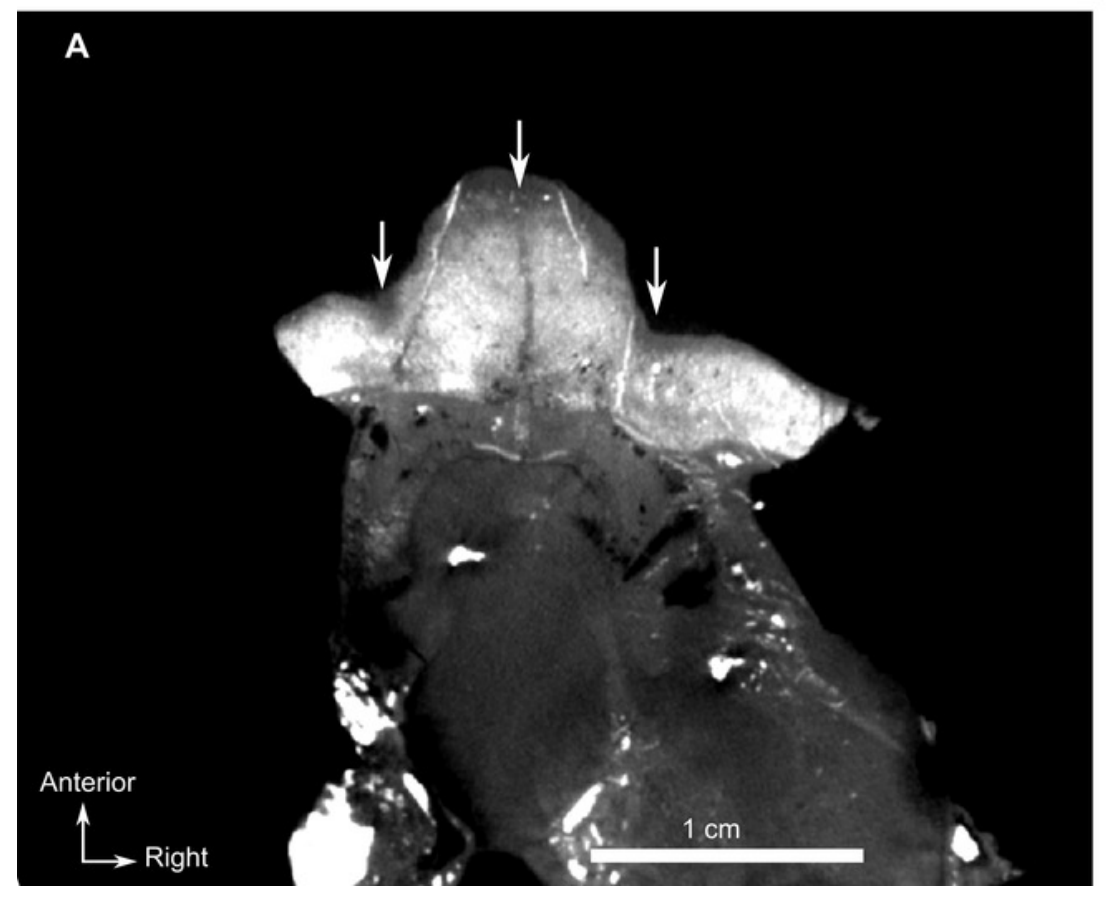

B

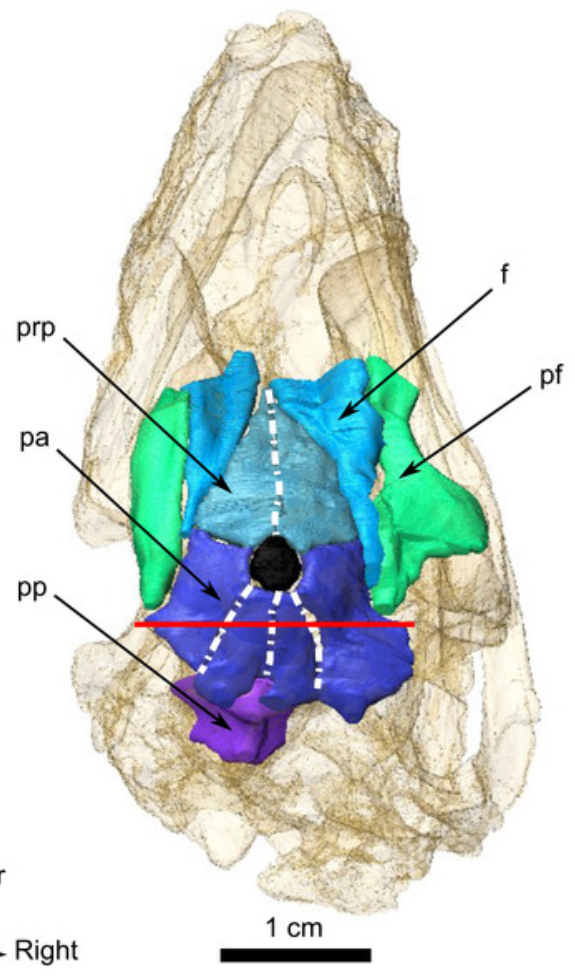




\section{Figure 21}

Burnetiamorph indet., dorsal piece, SAM-PK-K11126.

(A) CT-image of a transverse section showing three symmetrical sutures, indicated by arrows, within the parietal, at the level of the posterior border of the pineal foramen (B). (B) $3 D$ rendering of the dorsal piece in dorsal view reveals the presence of extra-sutures in the parietal. Bright points are artefacts resulting from the presence of iron nodules. Scan of the specimen was performed by Kudakwashe Jakata and belongs to the University of the Witwatersrand. 3D reconstruction was made by $A$. Duhamel and belongs to the University of the Witwatersrand. Scale bar $=1 \mathrm{~cm}$.
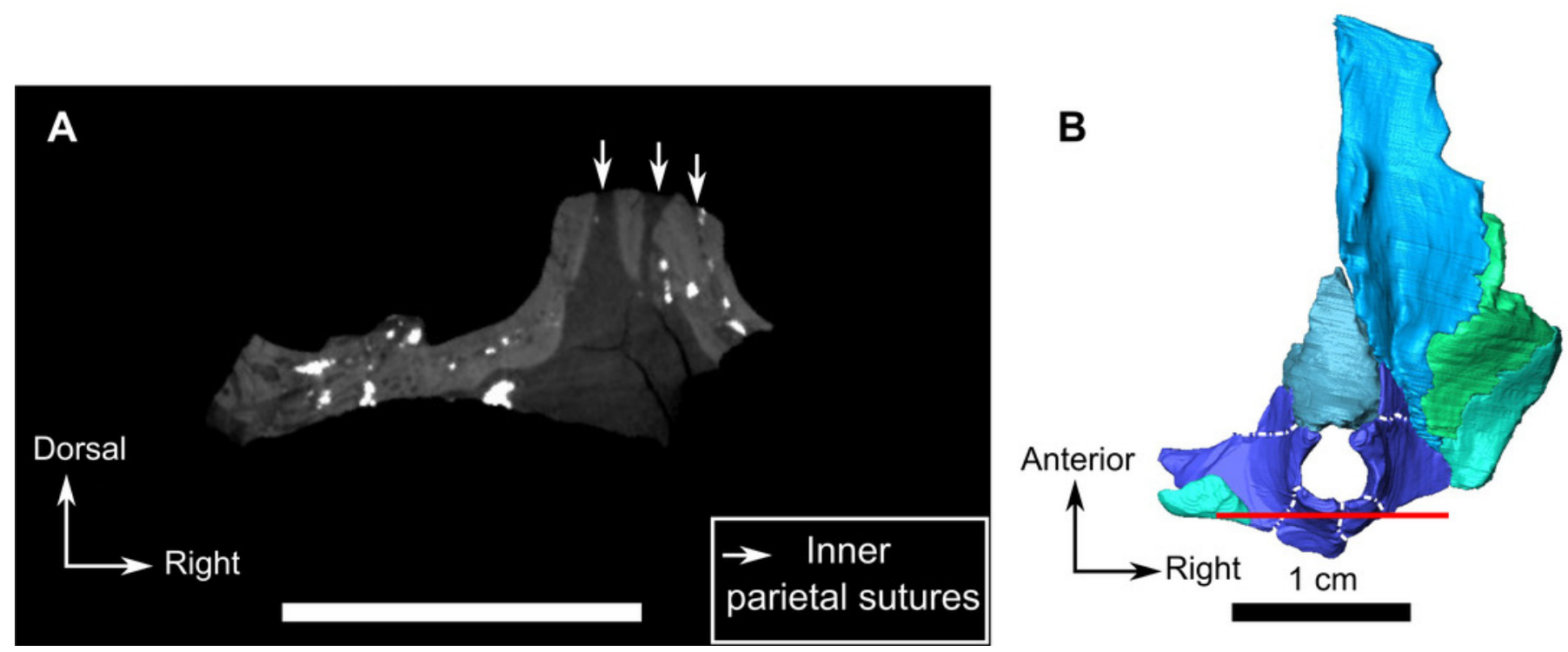
Figure 22

A hypothetical biarmosuchian ontogenetic series.

Characters present in only Burnetiamorpha are written and drawn in red. Characters present in all biarmosuchian taxa are written in green. Figure by A. Duhamel.

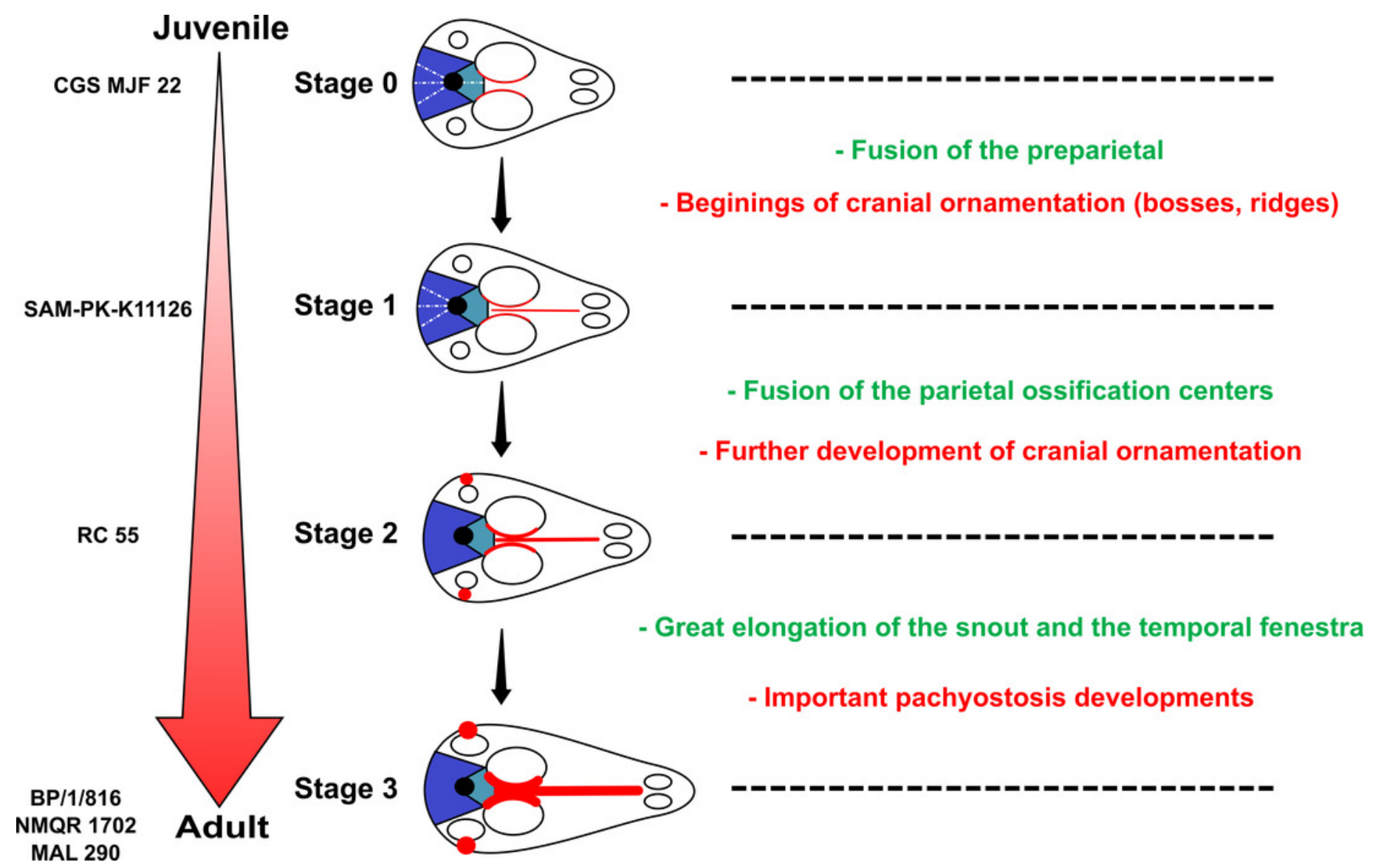

